\title{
EFFECT OF POST MANUFACTURE THERMAL DIP TREATMENT ON PROTEOLYSIS OF COMMERCIAL STRING CHEESE DURING STORAGE
}

\author{
A Thesis \\ presented to \\ the Faculty of California Polytechnic State University, \\ San Luis Obispo
}

In Partial Fulfillment

of the Requirements for the Degree

Master of Science in Agriculture, with Specialization in Dairy Products Technology

By

Melissa Karen Hsu

March 2013 
(C) 2013

Melissa Karen Hsu

ALL RIGHTS RESERVED 


\section{COMMITTEE MEMBERSHIP}

TITLE:

EFFECT OF POST MANUFACTURE THERMAL DIP

TREATMENT ON PROTEOLYSIS OF COMMERCIAL

STRING CHEESE DURING STORAGE

AUTHOR:

MELISSA KAREN HSU

DATE SUBMITTED: $\quad$ March 2013

COMMITTEE CHAIR: Phillip S. Tong, Ph.D., Professor

Dairy Science Department

California Polytechnic State University, San Luis Obispo

COMMITTEE MEMBER: Nana Y. Farkye, Ph. D., Professor

Dairy Science Department

California Polytechnic State University, San Luis Obispo

COMMITTEE MEMBER: Soma Roy, Ph. D., Assistant Professor

Statistics Department

California Polytechnic State University, San Luis Obispo 


\begin{abstract}
EFFECT OF POST MANUFACTURE THERMAL DIP TREATMENT ON

PROTEOLYSIS OF COMMERCIAL STRING CHEESE DURING STORAGE

Melissa Karen Hsu
\end{abstract}

String cheese, a Mozzarella cheese, has the unique ability to string in fibrous strands when pulled apart. Graders judge string cheese by its stringy texture; samples with copious amounts of string are awarded high ratings. But just as the texture of natural cheeses softens with time, the stringy texture of string cheese can diminish with age too.

Age related softening in cheese is due primarily to an important biochemical event known as proteolysis, which is attributed to inherent milk proteinases, residual coagulant activity, and enzymes from the lysis of starter culture microorganisms. It is hypothesized that a post manufacture heat treatment of string cheese could inactivate these proteolytic enzymes and slow or eliminate proteolysis during storage. Therefore, the main objective of this study was to determine the effects of a post manufacture thermal dip treatment on proteolytic activity in packaged, commercial string cheese. Proteolysis was examined qualitatively by Urea-PAGE electrophoresis, quantitatively by measuring percentage of water-soluble nitrogen (\%WSN), and by using a scoring method to analyze stringy texture during refrigerated storage.

Fresh, commercial string cheese was sourced on two separate occasions and treated six days after manufacture. Treatment consisted of dipping the packaged cheese sticks in water baths at $55^{\circ} \mathrm{C}, 75^{\circ} \mathrm{C}$, and $95^{\circ} \mathrm{C}$ for 30 and 60 seconds. String cheese that did not undergo treatment served as the control. Treated and control cheeses were stored 
at $4{ }^{\circ} \mathrm{C}$ until sampling for Urea-PAGE, WSN extraction, and texture analysis on days 1 , $11,22,29,49,91$, and 172 after treatment.

The degree of $\beta$-CN breakdown was not observed to be different between all treatment levels throughout the storage period. This was not expected since Mozzarella cheese exposed to a higher temperature should have more plasmin activity than that of cheese exposed to a lower temperature. There was a trend of slightly more intact $\alpha_{\mathrm{s} 1}-\mathrm{CN}$ in the most severely treated string cheese $\left(95^{\circ} \mathrm{C}\right.$ for $\left.60 \mathrm{~s}\right)$ when compared to the control at the final time point of the study. This suggests the possibility of successful inactivation of residual coagulant, intracellular enzymes, or other proteolytic enzymes in the string cheese at this treatment. However, only storage time had a significant effect on \%WSN $(\mathrm{p}<0.0001)$. A closer examination of the results may indicate that an extension of the storage time could show clearer impact of heat treatment on secondary proteolysis. From conducting texture analysis, it was also discovered that storage time was the only variable to have a significant effect on the stringy texture of string cheese $(\mathrm{p}<0.0001)$. Likewise, a closer examination of the results may suggest that an extension of the storage time may allow for clearer impact of heat treatment on texture.

The research completed in this study provides insight of the proteolytic effects from a thermal treatment process applied post string cheese manufacture. Though relationships between the treatments to the extent of secondary proteolysis and stringy texture were not significant, it was still found that there was more intact $\alpha_{\mathrm{s} 1}-\mathrm{CN}$ due to one of the treatments. These results suggest that it is possible that the use of other heat treatment parameters, longer storage period, or a combination of the two could show a significant relationship between thermal treatment and proteolysis. These results also 
suggest that further work to improve shelf life of string cheese or other cheese varieties through the concept of a post manufacture heat treatment may be promising.

Keywords: String Cheese, Mozzarella, Heat Treatment, Proteolysis, Proteolytic Activity, Texture 


\section{ACKNOWLEDGEMENTS}

I would like to thank Dr. Phillip Tong, Dr. Nana Farkye, and Dr. Soma Roy for their countless amount of guidance, encouragement, and support. This project would not have been possible without their expertise and counsel on the subject matter.

I would like to thank the supplier for providing string cheese samples to conduct this study. Thank you for readily answering any questions and providing much needed assistance throughout the research process.

I would also like to thank the DPTC staff and fellow graduate students for their aid in this project. I would like to acknowledge Matt Arnold and Gina Iliff for their tremendous help in the lab, Andrea Laubscher for always ordering general lab items, and Katy Lees, Sean Vink and Vandna Sikand for their enjoyable company. I am also grateful for the many moments of laughter with the graduate students: Hadi Eshpari, Lauren Collinsworth, Dan Zhao, Mariela Poveda, Emily Kong, Tracey Nguyen, Valerie Arechiga, Corbin Kembel, and Garrett Walsh.

I am appreciative of my Epic fellowship and community. Thank you for the friendships and love. Press on towards the goal.

Lastly, I would like to thank my parents for their support throughout my life. Thank you for your unconditional love. Enjoy the retirement! 


\section{TABLE OF CONTENTS}

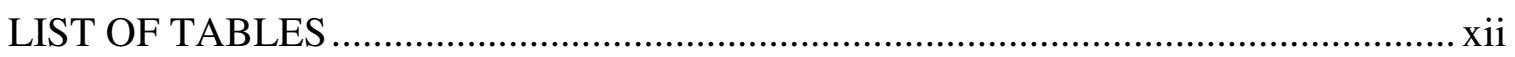

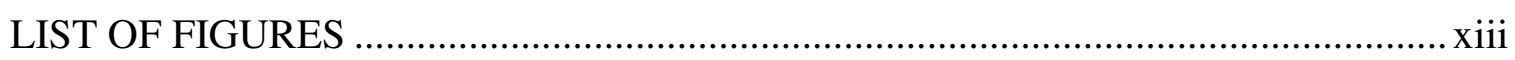

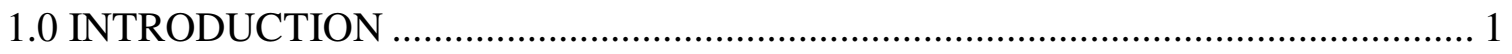

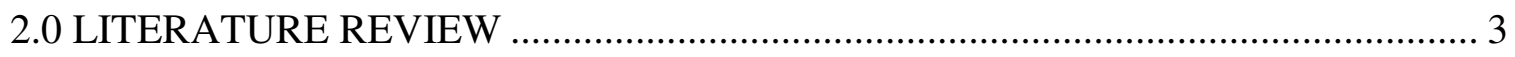

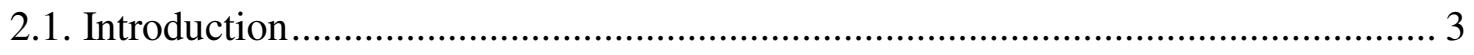

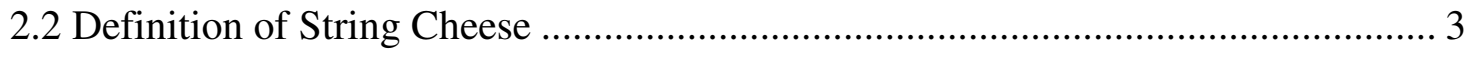

2.2.1. Historical Background Information of String Cheese ……............................. 3

2.2.2. Market Profile of String Cheese ………………............................................. 4

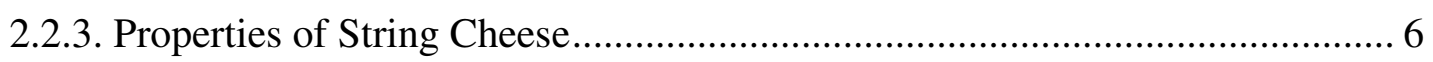

2.2.4. Standards of Identity of String Cheese ……………...................................... 7

2.2.5. Composition of String Cheese …………………...................................... 7

2.2.6. Cultures Used to Manufacture String Cheese .................................................. 8

2.2.7. Manufacturing Process of String Cheese ……................................................. 9

2.2.8. Expected Shelf Life of String Cheese ............................................................ 13

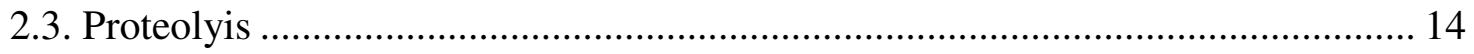

2.3.1. Definition of Proteolysis in String Cheese......................................................... 14

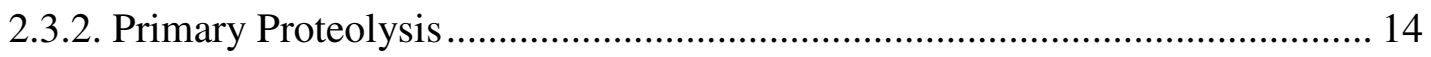

2.3.3. Secondary Proteolysis ............................................................................ 15

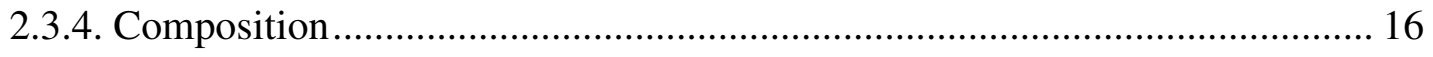

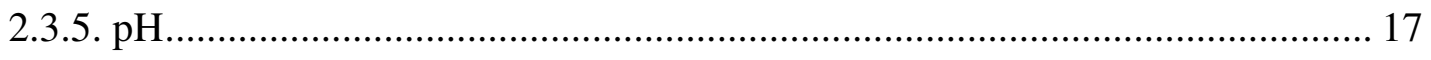

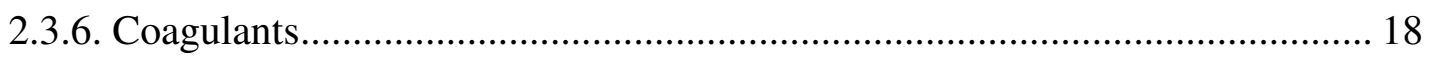

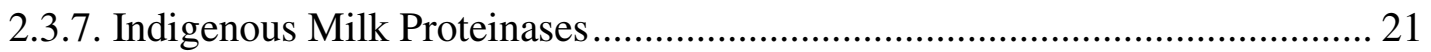


2.3.8. Enzymes from Starter Cultures ................................................................... 23

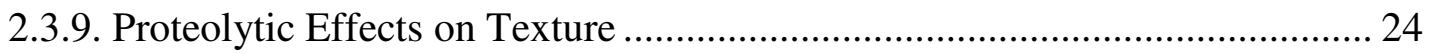

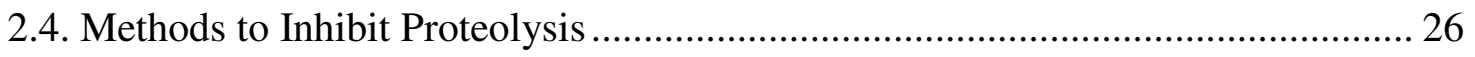

2.4.1. Maintain Clean Manufacturing Environment ................................................... 26

2.4.2. Use of Coagulant Type ………………………........................................ 27

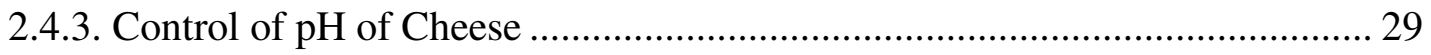

2.4.4. Control of Cooking and Stretching Temperature and Time ............................ 30

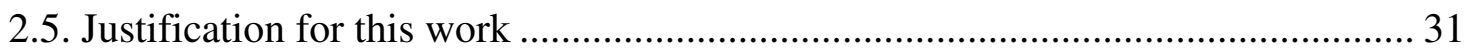

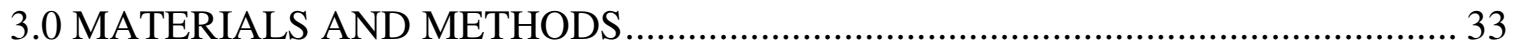

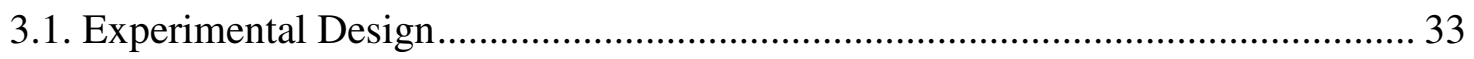

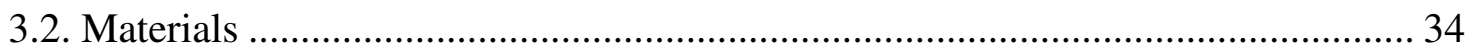

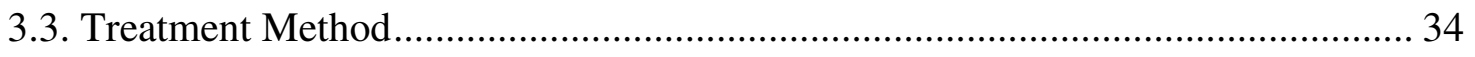

3.4. Chemical Composition Analysis of String Cheese ............................................... 37

3.4.1. Salt to Moisture ratio Analysis ....................................................................... 37

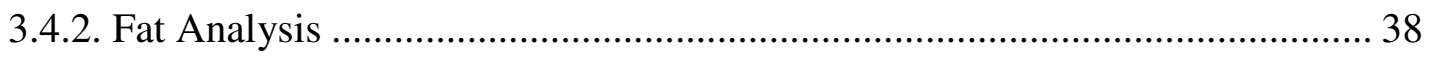

3.4.3. Total Nitrogen Analysis .............................................................................. 39

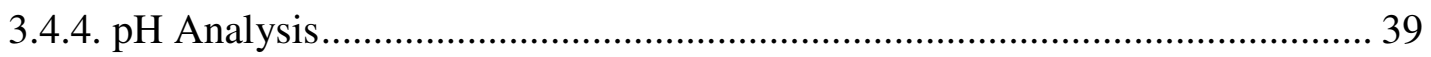

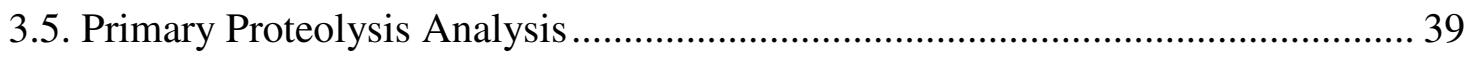

3.5.1. Urea-Polyacrylamide Gel Electrophoresis...................................................... 39

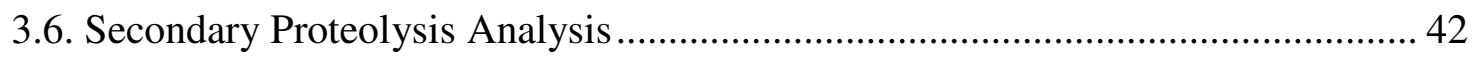

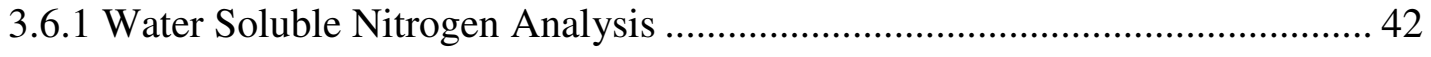

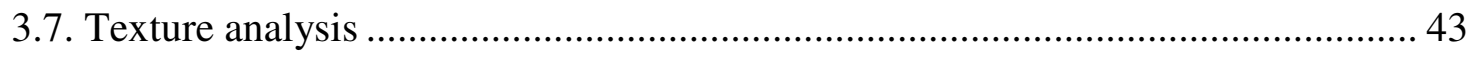

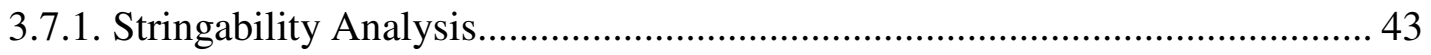




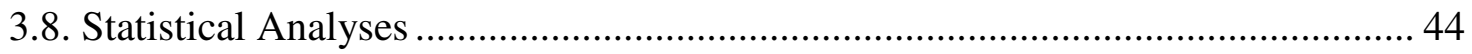

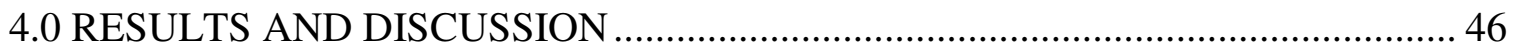

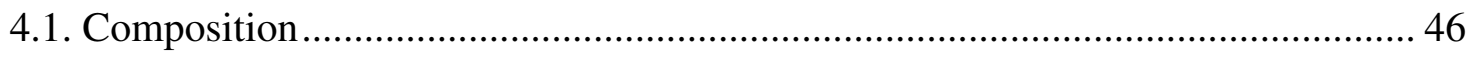

4.1.1. Salt to Moisture Ratio ..................................................................................... 46

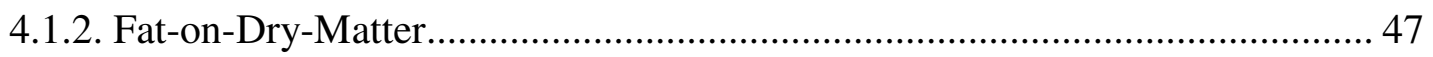

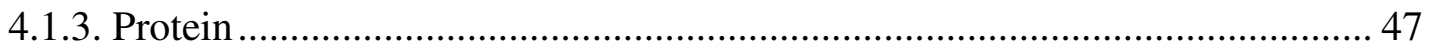

4.1.4. $\mathrm{pH}$

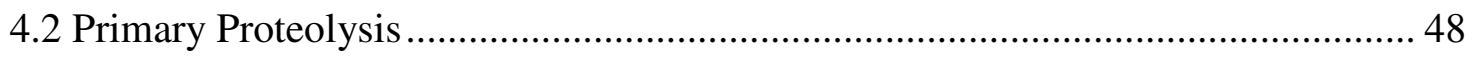

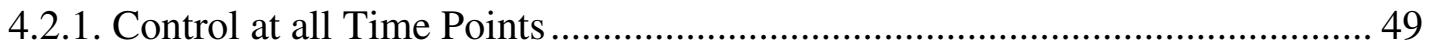

4.2.2. All Treatments at Final Time Point ........................................................... 52

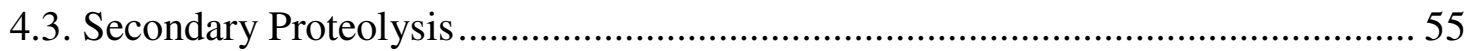

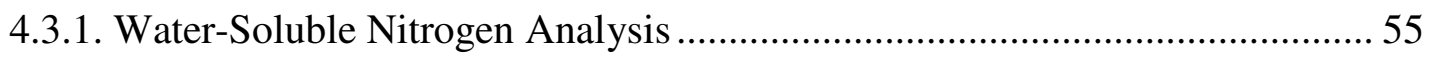

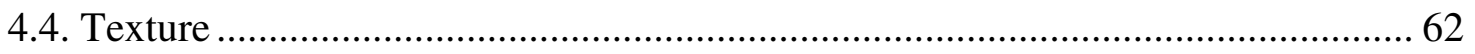

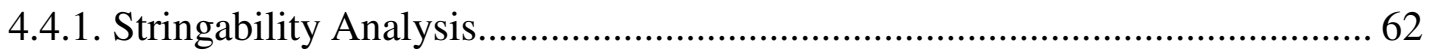

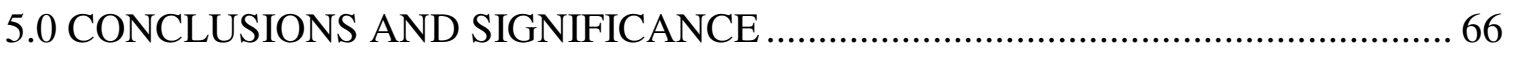

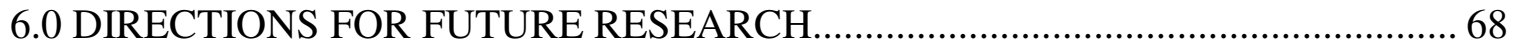

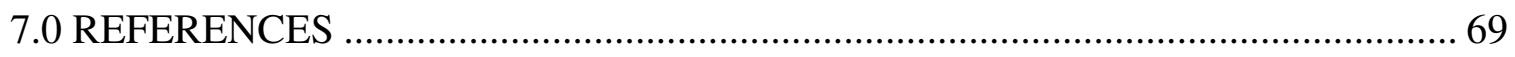

APPENDIX A: Data for Compositional Analysis of String Cheese ………………….... 77

APPENDIX B: Urea-PAGE Electrophoretograms of String Cheese ................................ 82

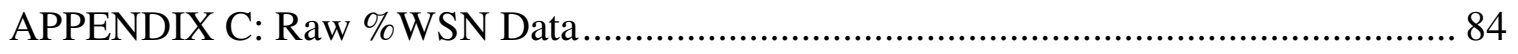

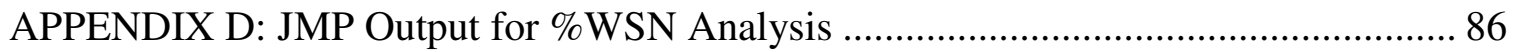

APPENDIX E: Alternative JMP Output for \%WSN Analysis (Factorial Design)........... 90

APPENDIX F: JMP Output for Stringability Analysis .................................................. 92 
APPENDIX G: Alternative JMP Output for Stringability Analysis (Factorial Design) .. 94 APPENDIX H: Minitab Output for Power Size and Maximum Detectable Differences

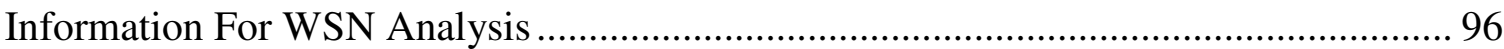
APPENDIX I: Minitab Output for Power Size and Maximum Detectable Differences

Information for Alternative WSN Analysis ................................................................. 97 


\section{LIST OF TABLES}

Table 1: Growing Flavors in String Cheese Segment (Anonymous, 2012) ..................... 5

Table 2: Compositional Standards for Mozzarella Cheese in the United States, adapted

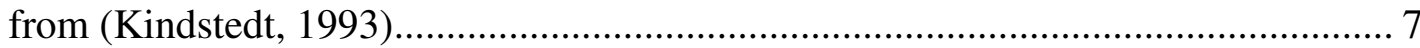

Table 3: Composition of Low-Moisture, Part Skim Mozzarella, adapted from (Cortes-Martinez et al., 2005; Jana and Mandal, 2011; Kindstedt, 1993; Kindstedt

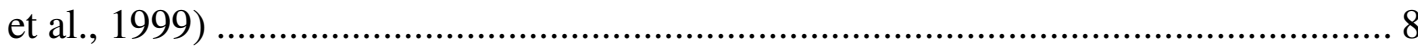

Table 4: Definition of Terms for Experimental Design ............................................ 33

Table 5: Composition Analysis of Commercial String Cheese .................................... 46

Table 6: Salt Concentration of Commercial String Cheese ......................................... 77

Table 7: Moisture Content of Commercial String Cheese .......................................... 78

Table 8: Fat-on-dry-matter Content of Commercial String Cheese ................................ 79

Table 9: Total Nitrogen Content of Commercial String Cheese .................................... 80

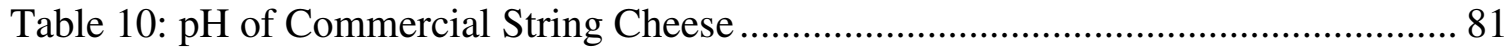

Table 11: Raw \%WSN data for the first replicate of the first batch .............................. 84

Table 12: Raw \%WSN data for the second replicate of the first batch .......................... 84

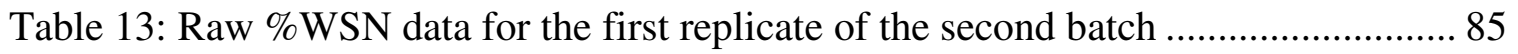

Table 14: Raw \%WSN data for the second replicate of the second batch...................... 85 


\section{LIST OF FIGURES}

Figure 1: Total Population Annual Eatings Per Capita of String Cheese

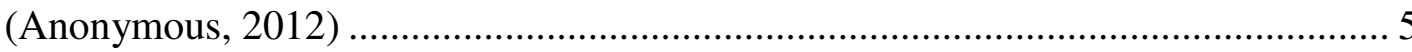

Figure 2: Depiction of string cheese with ample stringy texture .................................. 6

Figure 3: Flow chart for culture acidified Mozzarella string cheese manufacturing, adapted from (Cortes-Martinez et al., 2005; Kindstedt, 1993) .............................. 11

Figure 4: Flow chart for direct acidification Mozzarella string cheese manufacturing, adapted from (Cortes-Martinez et al., 2005; Kindstedt, 1993) .............................. 12

Figure 5: Schematic representation of the action of chymosin on $\kappa-\mathrm{CN}$ (Brooks, 2013)

Figure 6: Diagram showing the interrelationship between plasmin system in milk (Farkye, 1995) 22

Figure 7: Demonstration of Treatment Process 35

Figure 8: Demonstration of loosely wrapped cheesecloth around string cheese samples to ensure each sample received equal contact with hot water

Figure 9: Depiction of string cheese sampling for eletrophoretograms. The crosssection of the string cheese stick is shown and cheese was sampled from less than one millimeter from the surface (shaded area). Picture is not drawn to scale. . 42

Figure 10: Depiction of string cheese sampling for WSN extraction. The cross-section of the string cheese stick is shown and cheese was sampled from one and a half millimeters from the cheese surface (shaded area). Picture is not drawn to scale.... 43

Figure 11: Standards for Stringability Analysis 44 
Figure 12: Urea-PAGE electrophoretogram of control/untreated samples at all time points for the first replicate of the first batch (lane $1=1 \mathrm{~d}$ after treatment, lane $2=$ $11 \mathrm{~d}$ after treatment, lane $3=22 \mathrm{~d}$ after treatment, lane $4=29 \mathrm{~d}$ after treatment, lane $5=49 \mathrm{~d}$ after treatment lane $6=91 \mathrm{~d}$ after treatment, lane $7=172 \mathrm{~d}$ after treatment, lane $8=\mathrm{NaCN}$ standard)

Figure 13: Urea-PAGE electrophoretogram of control/untreated samples at all time points for the second replicate of the first batch (lane $1=1 \mathrm{~d}$ after treatment, lane $2=11 \mathrm{~d}$ after treatment, lane $3=22 \mathrm{~d}$ after treatment, lane $4=29 \mathrm{~d}$ after treatment, lane $5=49 \mathrm{~d}$ after treatment, lane $6=91 \mathrm{~d}$ after treatment, lane $7=172 \mathrm{~d}$ after treatment, lane $8=\mathrm{NaCN}$ standard)

Figure 14: Urea-PAGE electrophoretograms of control/untreated samples at all time points for the first replicate of the second batch (lane $1=1 \mathrm{~d}$ after treatment, lane $2=11 \mathrm{~d}$ after treatment, lane $3=22 \mathrm{~d}$ after treatment, lane $4=29 \mathrm{~d}$ after treatment, lane $5=49 \mathrm{~d}$ after treatment, lane $6=91 \mathrm{~d}$ after treatment, lane $7=172 \mathrm{~d}$ after treatment, lane $8=\mathrm{NaCN}$ standard)

Figure 15: Urea-PAGE electrophoretogram of control/untreated samples at all time points for the second replicate of the second batch (lane $1=1 \mathrm{~d}$ after treatment, lane $2=11 \mathrm{~d}$ after treatment, lane $3=22 \mathrm{~d}$ after treatment, lane $4=29 \mathrm{~d}$ after treatment, lane $5=49 \mathrm{~d}$ after treatment, lane $6=91 \mathrm{~d}$ after treatment, lane $7=172 \mathrm{~d}$ after treatment, lane $8=\mathrm{NaCN}$ standard)

Figure 16: Urea-PAGE electrophoretogram of all treated samples at 172 days after treatment day for the first replicate of the first batch (lane 1=control/untreated, 
lane $2=55^{\circ} \mathrm{C}$ for $30 \mathrm{~s}$, lane $3=55^{\circ} \mathrm{C}$ for $60 \mathrm{~s}$, lane $4=75^{\circ} \mathrm{C}$ for $30 \mathrm{~s}$, lane $5=75^{\circ} \mathrm{C}$ for $60 \mathrm{~s}$, lane $6=95^{\circ} \mathrm{C}$ for $30 \mathrm{~s}$, lane $7=95^{\circ} \mathrm{C}$ for $60 \mathrm{~s}$, lane $8=\mathrm{NaCN}$ standard) ................. 53

Figure 17: Urea-PAGE electrophoretogram of all treated samples at 172 days after treatment day for the second replicate of the first batch (lane 1=control/untreated, lane $2=55^{\circ} \mathrm{C}$ for $30 \mathrm{~s}$, lane $3=55^{\circ} \mathrm{C}$ for $60 \mathrm{~s}$, lane $4=75^{\circ} \mathrm{C}$ for $30 \mathrm{~s}$, lane $5=75^{\circ} \mathrm{C}$ for $60 \mathrm{~s}$, lane $6=95^{\circ} \mathrm{C}$ for $30 \mathrm{~s}$, lane $7=95^{\circ} \mathrm{C}$ for $60 \mathrm{~s}$, lane $8=\mathrm{NaCN}$ standard)

Figure 18: Urea-PAGE electrophoretogram of all treated samples at 172 days after treatment day for the first replicate of the second batch (lane 1=control/untreated, lane $2=55^{\circ} \mathrm{C}$ for $30 \mathrm{~s}$, lane $3=55^{\circ} \mathrm{C}$ for $60 \mathrm{~s}$, lane $4=75^{\circ} \mathrm{C}$ for $30 \mathrm{~s}$, lane $5=75^{\circ} \mathrm{C}$ for $60 \mathrm{~s}$, lane $6=95^{\circ} \mathrm{C}$ for $30 \mathrm{~s}$, lane $7=95^{\circ} \mathrm{C}$ for $60 \mathrm{~s}$, lane $8=\mathrm{NaCN}$ standard) 54

Figure 19: Urea-PAGE electrophoretogram of all treated samples at 172 days after treatment day for the second replicate of the second batch (lane $1=\mathrm{control} /$ untreated, lane $2=55^{\circ} \mathrm{C}$ for $30 \mathrm{~s}$, lane $3=55^{\circ} \mathrm{C}$ for $60 \mathrm{~s}$, lane $4=75^{\circ} \mathrm{C}$ for $30 \mathrm{~s}$, lane $5=75^{\circ} \mathrm{C}$ for $60 \mathrm{~s}$, lane $6=95^{\circ} \mathrm{C}$ for $30 \mathrm{~s}$, lane $7=95^{\circ} \mathrm{C}$ for $60 \mathrm{~s}$, lane $8=\mathrm{NaCN}$ standard) 54

Figure 20: Evolution of water-soluble nitrogen values per total nitrogen (\%WSN) during storage time after treatment at $4^{\circ} \mathrm{C}$ of all treated string cheese for the average of both batches. Error bars represent standard error for each sample. 58

Figure 21: Evolution of water-soluble nitrogen values per total nitrogen (\%WSN) during storage time after treatment at $4^{\circ} \mathrm{C}$ of control, $55^{\circ} \mathrm{C}$ for $60 \mathrm{~s}, 75^{\circ} \mathrm{C}$ for $30 \mathrm{~s}$, and $95^{\circ} \mathrm{C}$ for $60 \mathrm{~s}$ treated string cheese for the average both batches. Error bars represent standard error for each sample. 
Figure 22: Evolution of water-soluble nitrogen values per total nitrogen (\%WSN) during storage time after treatment at $4^{\circ} \mathrm{C}$ of control and $95^{\circ} \mathrm{C}$ for 60 s treated string cheese for the average of all replicates of both batches.

Figure 23: Effect of different levels of post manufacture heat treatment on stringability of string cheese during refrigerated storage at $4^{\circ} \mathrm{C}$ for the average of both batches. Error bars represent standard error for each sample. 64

Figure 24: Urea-PAGE electrophoretogram of all treated samples at 1 days after treatment day for the first replicate of the first batch (lane $1=$ control/untreated, lane $2=55^{\circ} \mathrm{C}$ for $30 \mathrm{~s}$, lane $3=55^{\circ} \mathrm{C}$ for $60 \mathrm{~s}$, lane $4=75^{\circ} \mathrm{C}$ for $30 \mathrm{~s}$, lane $5=75^{\circ} \mathrm{C}$ for $60 \mathrm{~s}$, lane $6=95^{\circ} \mathrm{C}$ for $30 \mathrm{~s}$, lane $7=95^{\circ} \mathrm{C}$ for $60 \mathrm{~s}$, lane $8=\mathrm{NaCN}$ standard) 82

Figure 25: Urea-PAGE electrophoretogram of all treated samples at 1 days after treatment day for the second replicate of the first batch (lane 1=control/ untreated, lane $2=55^{\circ} \mathrm{C}$ for $30 \mathrm{~s}$, lane $3=55^{\circ} \mathrm{C}$ for $60 \mathrm{~s}$, lane $4=75^{\circ} \mathrm{C}$ for $30 \mathrm{~s}$, lane $5=75^{\circ} \mathrm{C}$ for $60 \mathrm{~s}$, lane $6=95^{\circ} \mathrm{C}$ for $30 \mathrm{~s}$, lane $7=95^{\circ} \mathrm{C}$ for $60 \mathrm{~s}$, lane $8=\mathrm{NaCN}$ standard) 82

Figure 26: Urea-PAGE electrophoretogram of all treated samples at 1 days after treatment day for the first replicate of the second batch (lane $1=$ control/untreated, lane $2=55^{\circ} \mathrm{C}$ for $30 \mathrm{~s}$, lane $3=55^{\circ} \mathrm{C}$ for $60 \mathrm{~s}$, lane $4=75^{\circ} \mathrm{C}$ for $30 \mathrm{~s}$, lane $5=75^{\circ} \mathrm{C}$ for $60 \mathrm{~s}$, lane $6=95^{\circ} \mathrm{C}$ for $30 \mathrm{~s}$, lane $7=95^{\circ} \mathrm{C}$ for $60 \mathrm{~s}$, lane $8=\mathrm{NaCN}$ standard) 83 
Figure 27: Urea-PAGE electrophoretogram of all treated samples at 1 days after treatment day for the second replicate of the second batch (lane $1=$ control/untreated, lane $2=55^{\circ} \mathrm{C}$ for $30 \mathrm{~s}$, lane $3=55^{\circ} \mathrm{C}$ for $60 \mathrm{~s}$, lane $4=75^{\circ} \mathrm{C}$ for $30 \mathrm{~s}$, lane $5=75^{\circ} \mathrm{C}$ for $60 \mathrm{~s}$, lane $6=95^{\circ} \mathrm{C}$ for $30 \mathrm{~s}$,

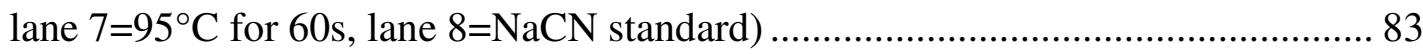

Figure 28: Actual by Predicted Plot for the Whole Model .......................................... 86

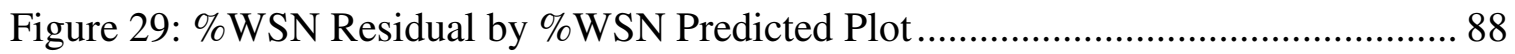

Figure 30: \%WSN Leverage Residuals by Treatment Leverage .................................. 88

Figure 31: \%WSN Leverage Residuals by Day after Treatment Leverage .................... 89

Figure 32: \%WSN Leverage Residuals by Treatment and Day After Treatment Interaction 89

Figure 33: Power Curve for One-Way ANOVA \%WSN Analysis. $\mathrm{x}$-axis is the maximum detectable difference in $\% \mathrm{WSN}$ 96

Figure 34: Power Curve for One-Way ANOVA \%WSN Alternative Analysis. X-axis is the maximum detectable difference in $\% \mathrm{WSN}$. 


\subsection{INTRODUCTION}

Pasteurized milk and dairy products typically have naturally short shelf life. Among the most perishable cheese products include Mozzarella cheese. One of the greatest innovations in natural cheeses is the creation of string cheese, a type of low-moisture, part skim Mozzarella cheese. String cheese is especially popular for children since parents believe it is a convenient and nutritious snack. Kids enjoy string cheese for its "play factor" of peeling fibrous strips of cheese apart before eating. This stringy texture is optimal within the first three weeks of ripening. Near the end of shelf life though, string cheese texture can become undesirably soft and lose some of its stringing properties from extensive protein breakdown due in part to proteolytic enzymes.

For many years, researchers have tried to improve the functional properties of cheeses through manipulating processing parameters, such as altering fat content, salt content, and coagulant type. Existing research specific to Mozzarella cheese has indicated possible relationships between the usages of different temperature parameters, such as during cooking and stretching processes on the degree of proteolysis. Although string cheese is essentially a form of Mozzarella, it has a unique size, surface area, manufacturing processes, and packaging specifications that make it considerably different. Therefore, it would not be appropriate to conclude that the same treatments applied to Mozzarella would have the same effect on string cheese.

To further explore the aforesaid links, the purpose of this thesis was to determine if the extent of proteolytic activity in string cheese could be inhibited through the implementation of a post manufacture thermal dip treatment. This study also explored the relationship that the thermal treatments had on the "stringability" of string cheese. Insight 
into these associations could prove beneficial to manufacturers and consumers alike since string cheese could potentially keep its distinctive properties for a longer time period. It is hoped that this study will contribute to the knowledge that a post manufacture heat treatment may have on string cheese's primary proteolysis, secondary proteolysis, and texture. 


\subsection{LITERATURE REVIEW}

\subsection{Introduction}

The purpose of this literature review is to lay a foundation of previous research and connect their relevance to string cheese. First, this literature review will give an overview of various aspects of string cheese: historical information, characteristics, manufacturing procedures, and shelf life. Next it will define proteolysis in string cheese and discuss what factors contribute to its progression and the textural transformation due to its action. It will also discuss possible manufacturing methods that could lessen proteolytic activity in string cheese and their limitations. In the final section of this chapter, the rationale for this thesis project will be presented.

\subsection{Definition of String Cheese}

\subsubsection{Historical Background Information of String Cheese}

String cheese, a form of Mozzarella cheese, is considered one of the greatest innovations in natural cheeses (Anonymous, 2010). Mozzarella is a pasta filata cheese, originating from Italy. Other similar types of pasta filata cheeses that existed prior to American string cheese are Oaxaca from Oaxaca, Mexico (Villanueva-Carvajal et al., 2012) and Karlacti from the Mediterranean area (Anonymous, 2013b). Oaxaca is a popular cheese incorporated in many Mexican dishes and is still mainly produced by handmade procedures (Villanueva-Carvajal et al., 2012). Karlacti is an Armenian cheese that has been around for thousands of years. It is seasoned with a Middle Eastern spice before being hand pulled into a long loop and twisted several times to create its stringy texture (Anonymous, 2013b). 
Pasta filata cheeses share a unique manufacturing step, which includes cooking and stretching of the curd in hot water. This process contributes to Mozzarella's fibrous structure, meltability, and stretching properties. While Mozzarella was invented in southern Italy, the United States has become the leading producer and consumer of Mozzarella. Italian immigrants brought Mozzarella manufacturing techniques to America, and soon after World War II, Mozzarella became ubiquitous by the popularity of pizza (Kindstedt, 1993).

String cheese manufacture in the United States emerged in the 1970s, facing many challenges. Little improvement in equipment and automated production made it difficult to keep up with the demand for string cheese. By the 1980s, there was much progress to develop extrusion and cutting equipment that created uniform and consistent product. At this time, string cheese became a popular component of children's lunchboxes, especially since it came in a single-serve package (Buragas, 2006). It had a simple and fun appeal to kids since they could peel strips away from the cheese stick as they ate it. This way of eating transformed the manner some consumers ate cheese, earning the product recognition as a great novelty item (Mayer, 2011).

\subsubsection{Market Profile of String Cheese}

String cheese has continually been a successful product since consumers have increased their snacking habits. The string cheese consumed per capita has continued to rise since 2009, as displayed in Figure 1 (Anonymous, 2012). It also was found that natural cheese use increased for forms perceived as convenient, such as string cheese (Anonymous, 2010). This growth for convenient cheese has triggered other cheese varieties to be packaged in similar ways. However, Mozzarella remained dominant and 
still possesses 91.2 percent of the market share among all string cheese types as shown in Table 1. The cheese market share that string cheese holds among the entire cheese market is relatively small, though, with just 6.1 percent (Anonymous, 2012).

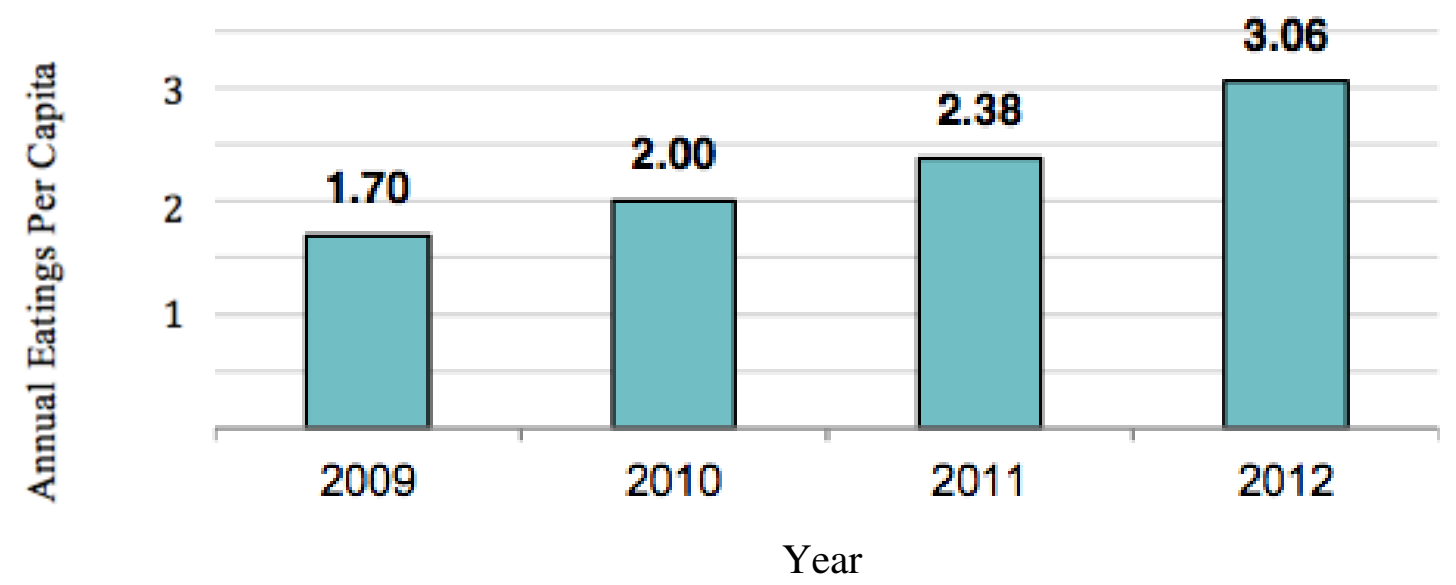

Figure 1: Total Population Annual Eatings Per Capita of String Cheese (Anonymous, 2012)

Table 1: Growing Flavors in String Cheese Segment (Anonymous, 2012)

\begin{tabular}{|l|c|c|c|c|c|c|c|}
\hline & & & & & & & \\
\hline
\end{tabular}

Consumer research reports that younger households favor string cheese while consumers above 65-years old do not purchase such an item. It was especially favored in large households with children since string cheese is a convenient and nutritious snack for lunchboxes (Anonymous, 2010; Anderson, 1996). In fact, children especially under the age of six consumed twice as much string cheese as adults (Anonymous, 2012). 


\subsubsection{Properties of String Cheese}

String cheese is typically a 15.24 centimeter long cylinder with less than 2.54 centimeter diameter (Anonymous, 2010). It has a mild flavor (Rankin et al., 2006) that tastes like lightly salted, fresh milk (Ganesan et al., 2012). Just as Swiss cheese is known universally for its holes, string cheese is known for its stringing properties, as shown in Figure 2. Others have described this texture to be like that of crabmeat or scallops (Taneya et al., 1992).

According to consumer research, string cheese is "consumed by peeling strips off from the whole piece" (Anonymous, 2010). This aspect provides children a fun factor for eating string cheese (Anderson, 1996). Coincidentally the ideal temperature to consume string cheese is at $25^{\circ} \mathrm{C}$ since it has been discovered to have optimal stringy texture (Taneya et al., 1992). This is also room temperature, which is about the same temperature that children eat string cheese by lunchtime at school.

Graders judge string cheese by its stringy texture. They tear each sample several times with their fingers, examining visually for the amount of fibrous material and thickness. String cheese with a lot of fibrous material on the torn surface receives a high rating (Taneya et al., 1992).

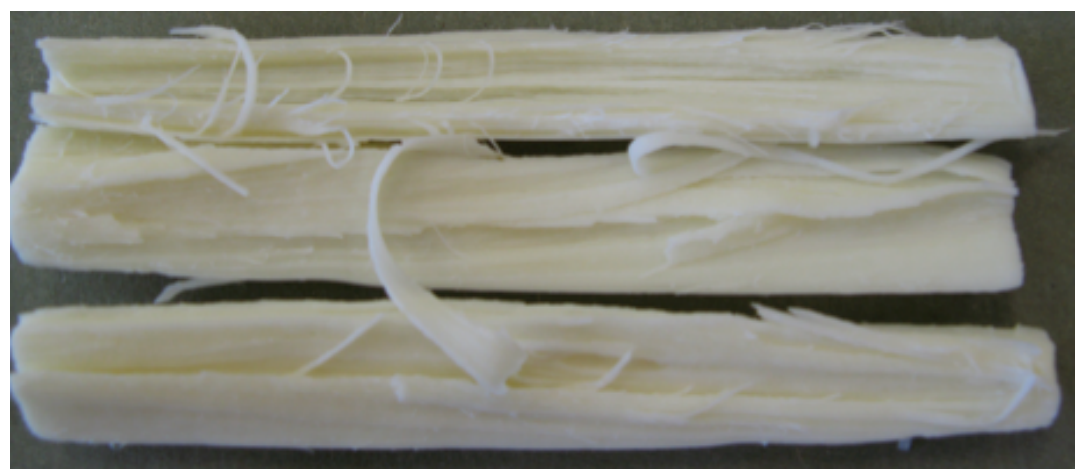

Figure 2: Depiction of string cheese with ample stringy texture 


\subsubsection{Standards of Identity of String Cheese}

Mozzarella cheese can be categorized into four different types by its standards of identity (Table 2). The basis for the differences is the moisture content and the fat-in-drymatter of the cheese. Mozzarella and part-skim Mozzarella have higher moisture and thus a softer body. They are typically consumed as fresh, table cheeses instead of used as pizza cheese since they have poor shredding ability and shorter shelf life. Low-moisture Mozzarella and low-moisture part-skim Mozzarella (LMPS) have lower moisture content and firmer body. These characteristics allow for good shredding ability and longer shelf life, which makes it more suitable as pizza cheese (Kindstedt, 1993). When examining the string cheese aisle in the grocery store, low-moisture, part skim Mozzarella is the standard type.

Table 2: Compositional Standards for Mozzarella Cheese in the United States, adapted from (Kindstedt, 1993)

\begin{tabular}{|l|l|l|}
\hline Type & Moisture (\%) & Fat-in-dry-matter (\%) \\
\hline Mozzarella & $>52$ but $\leq 60$ & $\geq 45$ \\
\hline Low-moisture & $>45$ but $\leq 52$ & $\geq 45$ \\
\hline Low-moisture, Part-skim & $>45$ but $\leq 52$ & $\geq 30$ but $<45$ \\
\hline Part-skim & $>52$ but $\leq 60$ & $\geq 30$ but $<45$ \\
\hline
\end{tabular}

\subsubsection{Composition of String Cheese}

As mentioned before, string cheese is a form of low-moisture, part skim

Mozzarella cheese. In addition to the moisture and fat-in-dry-matter contents that are part of its standard of identity, string cheese also has common values for salt content, protein content, and $\mathrm{pH}$. These are depicted in Table 3. 
Table 3: Composition of Low-Moisture, Part Skim Mozzarella, adapted from (CortesMartinez et al., 2005; Jana and Mandal, 2011; Kindstedt, 1993; Kindstedt et al., 1999)

\begin{tabular}{|l|c|}
\hline Salt (\%) & 1.60 \\
\hline Moisture (\%) & $>45$ but $\leq 52$ \\
\hline Fat-on-matter basis (\%) & $\geq 30$ but $<45$ \\
\hline Protein (\%) & $\sim 20$ \\
\hline $\mathrm{pH}$ & $5.2 *$ \\
\hline
\end{tabular}

$* \mathrm{pH}$ of 5.2 is for string cheese acidified by use of starter cultures, $\mathrm{pH}$ of 5.6 is typical for string cheese made using direct acidification (Kindstedt et al., 1999).

\subsubsection{Cultures Used to Manufacture String Cheese}

The literature does not define the exact cultures used to produce string cheese. However, the cultures used to make low-moisture Mozzarella cheese may include thermophilic cultures, such as Streptococcus thermophilus, Lactobacillus delbruekii ssp. bulgaricus, and Lactobacillus helveticus. Thermophilic cultures are capable of surviving in higher temperatures (Kindstedt, 1993). Typically, a loosely defined ratio of rods to cocci is used as the starter culture mixture (Kindstedt et al., 1999). The combination of rods and cocci has a synergistic relationship where acid production is much faster when the two are used together (Oberg and Broadbent, 1993). This occurs because $S$. thermophilus has an optimum growth range from $\mathrm{pH} 5.5$ to 6.0 and Lb. delbrueckii subsp. bulgaricus has an optimum growth range from pH 5.0 to 5.5 (Brothersen, 1986).

Manipulating the ratio of rods to cocci has implications on the rate of acidification and the population of the rods in the final cheese (Kindstedt et al., 1999). S. thermophilius produces acid faster than Lb. delbrueckii subsp. bulgaricus since it is most active in the $\mathrm{pH}$ range of cheesemaking (Brothersen, 1986; McCoy, 1997). However, the 
initial rod to coccus ratio affects the rate of acidification. Thus a higher rod to coccus ratio will cause a slower rate of acidification and consequently result in longer cheesemaking time (Yun et al., 1995). Since most cheesemakers prefer to reduce make time, if a higher rod to coccus ratio is used, a larger inoculum would also be implemented (Kindstedt et al, 1999). Increasing the inoculum may shorten the make time, but it also increases the concentration of rods in the final cheese (Yun et al., 1995). Lb. delbrueckii subsp. bulgaricus is more proteolytic than its counterpart, S. thermophilius (McCoy, 1997; Oberg and Broadbent, 1993). Therefore, increasing the rod to coccus ratio would influence the degree of proteolytic activity in the final cheese (Yun et al, 1995).

\subsubsection{Manufacturing Process of String Cheese}

String cheese can be manufactured by either the use of cultures or by direct acidification (Kindstedt, 1993). The advantages of direct acidification include quick, consistent manufacturing time, easy control of $\mathrm{pH}$, and lower cost and variability when compared to cheese acidified by cultures (Rehman and Farkye, 2006). However, the use of cultures can produce flavor compounds, improved texture, and possible increases in cheese yield that is not observed in cheeses produced by the direct acidification method (Mullan, 2005). Since texture is an important functional characteristic of string cheese, it is plausible that the culture acidification method would be best; however, string cheeses produced by both methods are on the market.

String cheese made by culture addition is shown in Figure 3. First, milk is standardized and pasteurized. The milk is acidified by the addition of cultures and coagulated by the addition of rennet (Cortes-Martinez et al., 2005). After the coagulum sets, it is cut and cooked in its whey at 42 to $45^{\circ} \mathrm{C}$. The primary function of cooking is to 
control both the moisture and calcium content of the curd at stretching and in the final product (Kindstedt et al., 1999). After cooking, the whey is drained at about pH 5.2 (Kindstedt, 1993). The remaining cheese curd is heated, kneaded, and stretched at about $80^{\circ} \mathrm{C}$ in a hot water mixer until a homogenous, fibrous mass is formed (Cortes-Martinez et al., 2005). In this process, shearing forces are applied to hot, plasticized curd so that the para-casein matrix lines up into fibers that are separated by free serum and fat globules (Taneya et al., 1992; McMahon et al., 1999; Guinee et al., 2002). This process is responsible for the stringy texture. The heated curd is fed through an extruder with 15 millimeter diameter nozzles to form a continuous rope shape and then cooled in a cold brine of about 18 percent salt concentration at $5^{\circ} \mathrm{C}$. After brining, the cheese is cut by knives activated by an optic sensor. Lastly the cheese sticks are brined again to continue the cooling process to $7^{\circ} \mathrm{C}$ and salted to 1.6 percent total salt before packaging. The final product is stored in refrigerated conditions (Cortes-Martinez et al., 2005). According to many studies, refrigerated storage is at $4^{\circ} \mathrm{C}$ (Cortez et al., 2008; Farkye et al., 1991b; Feeney et al., 2002; Tunick et al., 1995; Yun et al., 1993a).

For string cheese manufactured by the direct acidification method, cold standardized and pasteurized milk at $4^{\circ} \mathrm{C}$ is acidified to $\mathrm{pH} 5.6$ with a food-grade organic acid, such as citric or acetic acid. The acidified milk is warmed to $37^{\circ} \mathrm{C}$ and the following procedures are the same as the culture acidified method (Kindstedt, 1993). This process can be found in Figure 4. 


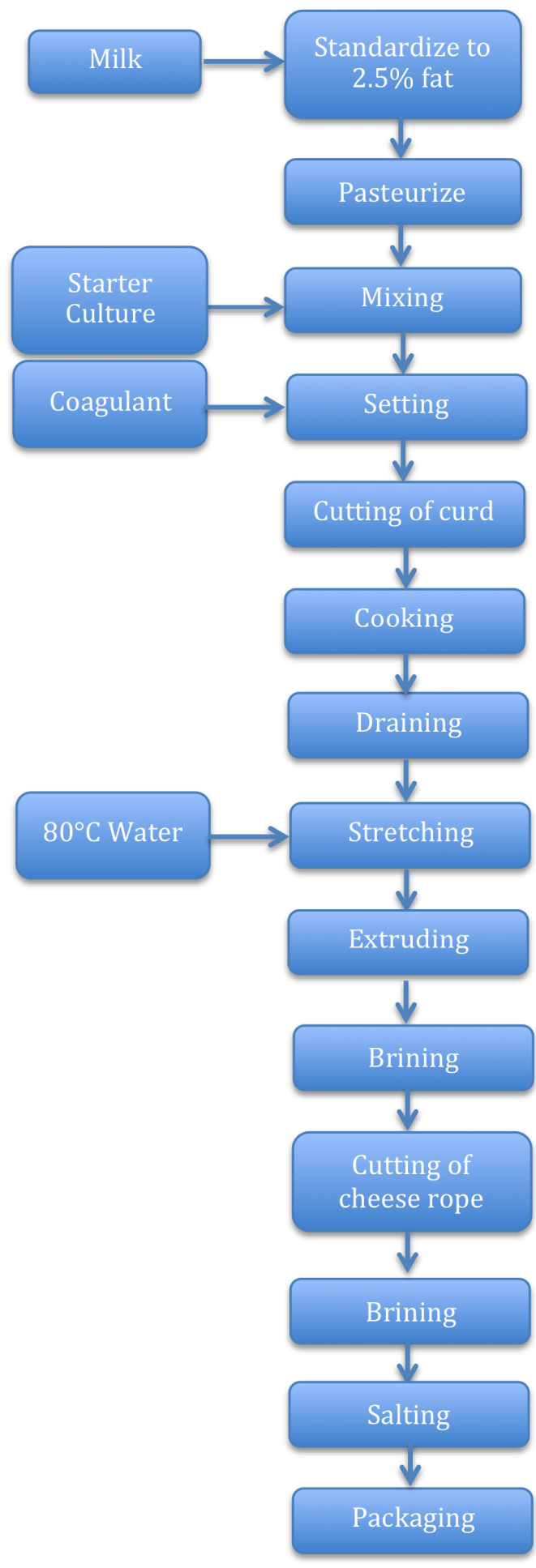

Figure 3: Flow chart for culture acidified Mozzarella string cheese manufacturing, adapted from (Cortes-Martinez et al., 2005; Kindstedt, 1993) 


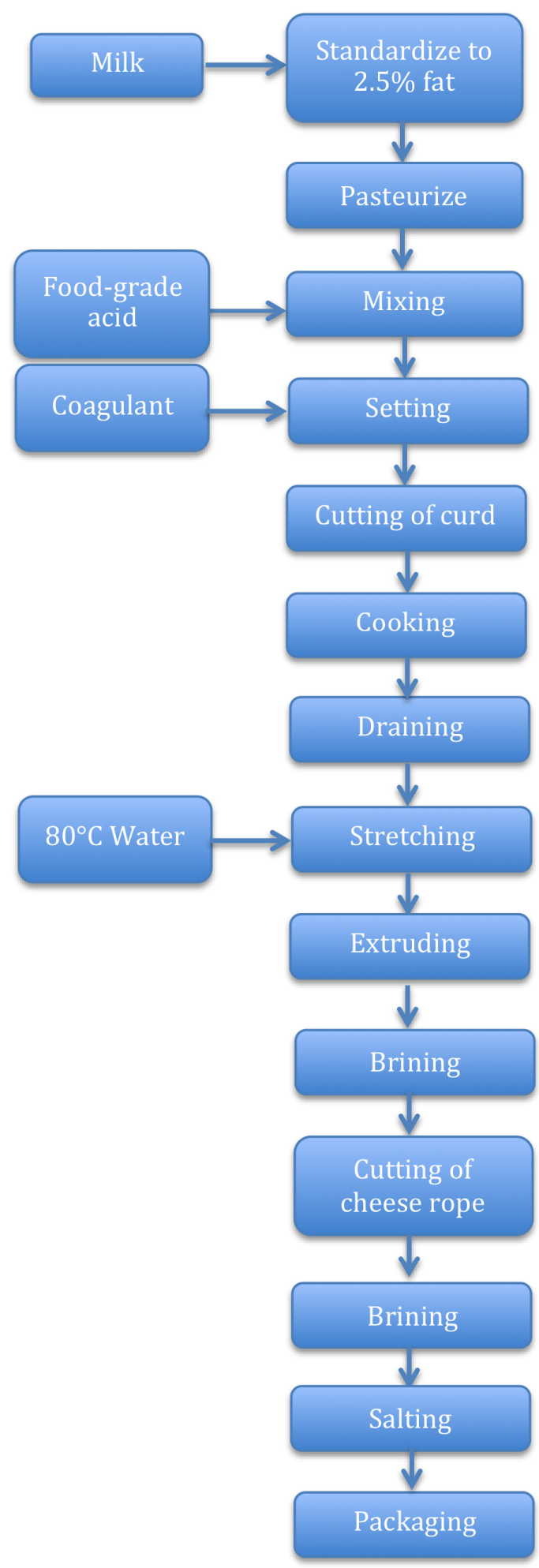

Figure 4: Flow chart for direct acidification Mozzarella string cheese manufacturing, adapted from (Cortes-Martinez et al., 2005; Kindstedt, 1993) 


\subsubsection{Expected Shelf Life of String Cheese}

The expected shelf life of string cheese is four months (Rankin et al., 2006). Shelf life of string cheese is important to consider since it can impact its marketability. Many physical, chemical, and microbiological changes occur in foods during processing and storage that can have negative implications on quality. At the end of a food product's shelf life, one or more quality attributes reaches an undesirable state, making the food unsuitable for sale (Man and Jones, 2000). For string cheese, the softening of the texture and lack of stringing properties at the end of its shelf life would make it unacceptable for sale.

Just like many foods, string cheese also exhibits microbial growth, enzymatic activity, and other biochemical changes during storage. Because string cheese has a high moisture content ( $>45$ but $\leq 52$ percent) and low salt content (1.6 percent), it has greater potential to spoil due to yeast, mold, and coliform growth (Guinee, 2004). Proper pasteurization, refrigeration and low $\mathrm{pH}$ of less than 5.4 are the only deterrents to the growth of unwanted microorganisms during storage (Ganesan et al., 2012).

Most of the enzymatic reactions are the result of coagulants, indigenous milk proteinases, and cultures, which will be discussed in more detail later in this chapter (Man and Jones, 2000). These enzymes may result in string cheese with a softer texture that wheys off more readily (Rankin et al., 2006). In addition, salt content, calcium content, and $\mathrm{pH}$ have a great effect on para-casein hydration, which affects the water binding capacity of the casein matrix. This also correlates with softer texture and tendency for syneresis (Guinee, 2004). Some other characteristics that would make string 
cheese unacceptable for consumption also include increase in free fatty acids, off-flavor development, and visual mold growth (Rankin et al., 2006).

\subsection{Proteolysis}

\subsubsection{Definition of Proteolysis in String Cheese}

Of the three primary events that occur during cheese ripening (glycolysis, lipolysis, and proteolysis), proteolysis is the most important and complex biochemical event that occurs during ripening (Fox, 1989; Fox and Law, 1991; Veloso et al., 2004). For most cheese varieties, there are five proteolytic agents in string cheese: residual milk-clotting enzyme, indigenous milk enzymes, proteases and peptidases from starter cultures, nonstarter bacteria, and secondary starter bacteria (Fox and Law, 1991). However, the main proteolytic agents are the coagulant and plasmin (Sheehan et al., 2007). And of course the length of ripening time determines the amount of proteolysis greatly (Fox, 1989; Park, 2001).

\subsubsection{Primary Proteolysis}

Proteolysis in cheese can be categorized into either primary proteolysis or secondary proteolysis. Primary proteolysis in cheese can be identified by changes in $\beta$-, $\alpha_{\mathrm{s}^{-}}, \gamma$-caseins, and other minor bands detected by polyacrylamide gel electrophoresis (Rank et al., 1985).

The first proteolytic reaction in cheese is the hydrolysis of $\alpha_{\mathrm{S} 1}-\mathrm{CN}$ to $\alpha_{\mathrm{s} 1}$-I-peptide by chymosin. This reaction causes the initial softening of cheese (Creamer and Olson, 1982; Sheehan et al., 2007; Feeney et al., 2002) that is desirable in most cheese varieties. Prior to this change, cheese texture is extremely rubbery and corky. According to Kaminogawa and Yamauchi (1972), the indigenous milk enzyme, cathepsin-D, also has a 
similar specificity towards $\alpha_{\mathrm{s} 1}-\mathrm{CN}$. However the activity and molecular properties of this milk acid protease need more investigation. Therefore, the initial softening of string cheese is attributed to the breakdown of $\alpha_{\mathrm{s} 1}-\mathrm{CN}$ to $\alpha_{\mathrm{s} 1}$-I-peptide by the action of chymosin.

The second major proteolytic breakdown of $\beta-\mathrm{CN}$ is owed to plasmin activity. The most notable and immediate by-products are $\gamma_{1}-\mathrm{CN}, \gamma_{2}-\mathrm{CN}$, and $\gamma_{3}-\mathrm{CN}$ (Farkye, 1995). Plasmin also hydrolyzes $\alpha_{\mathrm{s} 2}-\mathrm{CN}$, but its by-products have not been identified yet (Fox and Law, 1991). In string cheese, plasmin activity is inevitably the highest when compared to other cheeses and will be explained later in this chapter (Kindstedt, 1993).

\subsubsection{Secondary Proteolysis}

Secondary proteolysis is classified by the water-soluble by-products from primary proteolysis. These products consist of smaller protein fragments, peptides, and amino acids, which can be assessed by changes in concentration of extracted nitrogen (Rank et al., 1985). These changes are due to the action of chymosin and starter proteinases since plasmin contributes very little to water-soluble nitrogen; its by-products of $\gamma$-CNs from $\beta$ CN are not water-soluble (Farkye, 1995).

Cheese flavor is thought to be concentrated in water-soluble nitrogen fractions (Visser, 1993), though the flavor development is not entirely understood. It is generally believed that the water-soluble fraction contributes to background flavors and bitterness (Rank et al., 1985). As mentioned earlier in this chapter, string cheese flavor is mild and similar to the flavor of fresh milk. Therefore, extensive flavor development is not important like it would be for an aged cheese, such as sharp Cheddar cheese. 


\subsubsection{Composition}

Proteolysis depends very much on the composition of string cheese. The important compositional components to consider are salt to moisture ratio and calcium.

A study (Lawrence et al., 1987) showed that the salt to moisture ratio (S: M) had a linear relationship to percentages of intact $\alpha_{\mathrm{s} 1}-\mathrm{CN}$ and $\beta-\mathrm{CN}$. Cheddar cheese was produced with S: $\mathrm{M}$ at 4.0 percent, 6.0 percent, and 8.0 percent. After 28 days, only five percent of $\alpha_{\mathrm{s} 1}-\mathrm{CN}$ was intact but 50 percent of $\beta-\mathrm{CN}$ was intact in the cheese at 4.0 percent S: M. The 6.0 percent S:M cheese had 30 percent intact $\alpha_{\mathrm{s} 1}-\mathrm{CN}$ and 80 percent intact $\beta-\mathrm{CN}$. Lastly the 8.0 percent $\mathrm{S}$ : $\mathrm{M}$ cheese had 60 percent intact $\alpha_{\mathrm{s} 1}-\mathrm{CN}$ and 95 percent intact $\beta-\mathrm{CN}$. Therefore a higher $\mathrm{S}$ : $\mathrm{M}$ in string cheese should result in a cheese with more intact $\alpha_{\mathrm{s} 1}-\mathrm{CN}$ and $\beta-\mathrm{CN}$ and consequently less proteolysis.

Calcium in the serum phase and calcium bound to protein can both contribute to proteolysis, though the exact relationship has not been clearly defined (Lawrence et al., 1987). Some have reported that when the calcium in cheese slowly equilibrates, its bond with protein breaks, and the para-casein fibers weaken (O'Mahoney et al, 2005; Everett and Auty, 2008; Cortez et al., 2008). The smaller peptides resulting from this protein breakdown go into a serum phase, leaving only the intact caseins in the cheese matrix (Everett and Auty, 2008). In addition, Fox (1970) reported that caseins such as $\alpha_{\mathrm{s} 1}-\mathrm{CN}$ became more vulnerable to rennet-induced proteolysis at $\mathrm{pH} 6.6$ as the micellar calcium phosphate dissociated. These events due to calcium content would inevitably impact string cheese's texture since curd with low calcium to protein ratio requires a high $\mathrm{pH}$ (i.e., 5.6-5.7) for stretching. Likewise, curd with high calcium to protein ratio requires low pH (i.e., 5.1-5.2) for stretching (Kindstedt et al., 1999). 


\subsection{5. pH}

The independent role that $\mathrm{pH}$ plays in the level of proteolysis is not entirely understood because studies performed to examine effects of cheeses with different $\mathrm{pH}$ have shown confounding factors that influence proteolysis. These factors include concentrations of moisture, calcium, residual rennet, and degree of casein aggregation (Kimura et al, 1992; Kindstedt et al., 2001; Guinee et al., 2002; Sheehan and Guinee, 2004).

During ripening, the $\mathrm{pH}$ of cheese rises from the formation of alkaline nitrogen containing compounds and catabolism of lactic acid (Farkye and Fox, 1990b). The pH of cheese determines the degree of proteolysis and breakdown of $\alpha_{\mathrm{s} 1}-\mathrm{CN}$ to $\alpha_{\mathrm{s} 1}-\mathrm{CN}$ (f24199) by chymosin with the dependence of salt concentration (Mulvihill and Fox, 1980). At the normal dosage of rennet, which is about $2.2 \mathrm{CU} / \mathrm{milliliter}$, the hydrolysis of $\alpha_{\mathrm{s} 1}-\mathrm{CN}$ to $\alpha_{\mathrm{s} 1}-\mathrm{CN}$ (f24-199) and further hydrolysis of $\alpha_{\mathrm{s} 1}-\mathrm{CN}$ (f24-199) is hindered by 5 percent $\mathrm{wt} / \mathrm{vol} \mathrm{NaCl}$ for the $\mathrm{pH}$ of 5.8-7.0. At $\mathrm{pH} 5.2$ with the same salt concentration, the degree of hydrolysis by chymosin is about the same. However, additional breakdown of $\alpha_{\mathrm{s} 1}-\mathrm{CN}$ (f24-199) is greatly inhibited. As well, keeping the same salt concentration of 5 percent $\mathrm{wt} / \mathrm{vol} \mathrm{NaCl}$, the degree of hydrolysis of $\alpha_{\mathrm{s} 1}-\mathrm{CN}$ increases in the $\mathrm{pH}$ range of 5.2-6.4 (Feeney et al., 2002). It would be expected that as the $\mathrm{pH}$ increases in string cheese during ripening, the degree of $\alpha_{\mathrm{s} 1}-\mathrm{CN}$ breakdown would be less intense than if the $\mathrm{pH}$ remained low.

The $\mathrm{pH}$ of cheese also has an effect on plasmin activity. The association of plasmin and casein micelles is $\mathrm{pH}$ dependent (McMeekin et al., 1959; Richardson and Elston, 1984). Grufferty and Fox (1988b) report that plasmin dissociates from micelles very 
quickly at $\mathrm{pH} 4.6$, so there would be little to no plasmin activity in acid casein. The optimum $\mathrm{pH}$ for plasmin to be active is about 7.5 at $37^{\circ} \mathrm{C}$ and its activity increases as $\mathrm{pH}$ rises (Fox and Law, 1991; Grufferty and Fox, 1988a; Somers and Kelly, 2002). Similarly, another source says plasmin is optimally active at $\mathrm{pH} 7.0$ at $37^{\circ} \mathrm{C}$ (Kaminogawa et al., 1972). Therefore, it would be reasonable to say that if the curd were exposed to low $\mathrm{pH}$ (less than $\mathrm{pH}$ 7.0) during string cheese manufacture, then the plasmin activity would also remain low in the final product.

\subsubsection{Coagulants}

Chymosin is the principle enzyme responsible for milk coagulation (Hayes et al., 2002) and is essential for cheese ripening (Fox and Law, 1991). Rennet cleaves $\kappa-\mathrm{CN}$ at the $\mathrm{Phe}_{105}-\mathrm{Met}_{106}$ bond, resulting in a para- $\kappa-\mathrm{CN}$ and a hydrophilic glycomacropeptide (Visser, 1993; Hayes et al., 2002) as shown in Figure 5. As mentioned earlier, chymosin causes the initial softening of cheese where the breakdown of $\alpha_{s 1}-\mathrm{CN}$ to $\alpha_{\mathrm{s} 1}$-I-CN takes place (Creamer and Olson, 1982; Sheehan et al., 2007; Feeney et al., 2002). Chymosin can also act to hydrolyze $\beta-\mathrm{CN}$; though this action is reduced by 5 percent $\mathrm{NaCl}$ and complete inhibited by 10 percent $\mathrm{NaCl}$ concentration, presumably due to lower water activity (Fox and Law, 1991). Chymosin and other rennets have little impact on the hydrolysis of $\alpha_{\mathrm{s} 2}$-casein (Fox, 1989). 


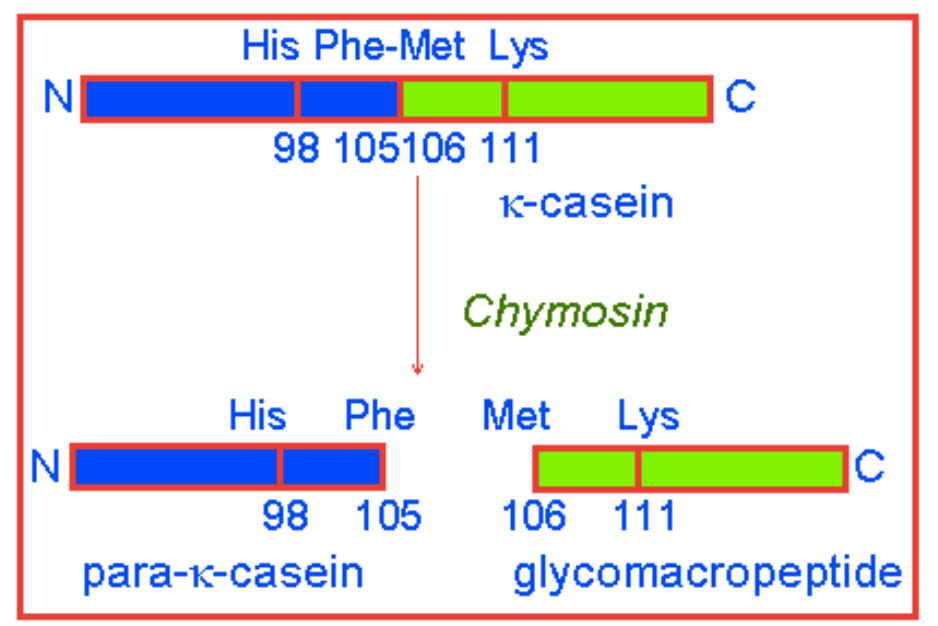

Figure 5: Schematic representation of the action of chymosin on $\kappa-\mathrm{CN}$ (Brooks, 2013)

The amount of chymosin activity that occurs in cheese depends on how much of it is retained in the cheese curd (Hayes et al., 2002). This quantity is related to the cooking and acidification steps during manufacturing (Holmes et al, 1977; Stadhouders and Hup, 1975). Chymosin activity is also dependent on the $\mathrm{pH}$, total solids, salt concentration, and water activity of the cheese (Garnot, 1985). Fox (1989) found chymosin to have optimal activity at $\mathrm{pH} 6.6$ and between the temperatures of 40 to $52^{\circ} \mathrm{C}$.

One study states that 90 percent of chymosin added to milk is lost to the whey (Winwood, 1989). Other studies say that only six percent of rennet is retained in cheese curd following pressing (Holmes et al., 1977; Fox and Law, 1991). The amount of remaining chymosin depends on the $\mathrm{pH}$ of the curd at the draining step. As the $\mathrm{pH}$ decreases, the amount of residual chymosin is higher (Holmes et al., 1977; Winwood, 1989; Fox and Law, 1991). Therefore, if the $\mathrm{pH}$ at draining is low during string cheese manufacture, then the amount of residual chymosin should be relatively high.

Rennet activity can be destroyed by heat treatment (Creamer, 1976). One study showed that increasing severity of milk heat treatment has little effect on chymosin activity. However, increasing cooking temperature during cheesemaking decreased 
chymosin activity as there was less $\alpha_{\mathrm{s} 1}-\mathrm{CN}$ to $\alpha_{\mathrm{s} 1}-\mathrm{I}-\mathrm{CN}$ reduction (Somers and Kelly, 2002). Sheehan et al. (2007) performed a study to see the effect of cooking temperature on residual chymosin activity. The temperatures they experimented with were $47^{\circ} \mathrm{C}$, $50^{\circ} \mathrm{C}$, and $53^{\circ} \mathrm{C}$. They found that increasing the cooking temperature significantly reduced but did not completely eliminate breakdown of $\alpha_{\mathrm{s} 1}-\mathrm{CN}$ to $\alpha_{\mathrm{s} 1}-\mathrm{I}-\mathrm{CN}$. Perhaps increasing the temperature of stretching water during string cheese manufacture would have similar effects on the breakdown of said peptides.

Many studies also reported that residual rennet is very low to nonexistent in Swiss cheese due to its high temperature cooking procedure (Fox and Law, 1999; Fox, 1988). In fact, a couple of studies relate the "rubbery" texture of Swiss cheese to the extensive inactivation of chymosin (Kosikowski and Mistry, 1997; McGoldrick and Fox, 1999). However, if the curd were cooked at a pH of less than 6.5, then results would be otherwise true (Garnot and Mollé, 1987). Also reported is that chymosin would be completely inactivated when cooked at $52^{\circ} \mathrm{C}$ for two hours (Matheson, 1981). Another study found that chymosin may be partially and reversibly denatured if the curd is cooked at $55^{\circ} \mathrm{C}$ (Hayes et al., 2002). While string cheese does have a similar rubbery texture (Rankin et al., 2006) to that of Swiss cheese and experiences high heat treatment during stretching, it is not conclusive to say if current manufacturing procedures would successfully inactivate all residual chymosin activity.

The amount of residual rennet also depends on the type of rennet used. For instance, porcine pepsin is easily denatured during cheese making (Fox and Law, 1991). Then there are microbial rennets, such as Mucor miehei and Mucor pusillus that behave 
independently of the $\mathrm{pH}$ for whey and curd distribution (Holmes et al., 1977). The subject of rennet type will be further explored in a later section of this chapter.

\subsubsection{Indigenous Milk Proteinases}

Natural proteolytic enzymes in milk are known to limit the shelf life of dairy products due to their contribution to protein breakdown (Rollema and Poll, 1986). Indigenous milk enzymes include plasmin, thrombin, cathepsin D, and aminopeptidases (Richardson, 1983).

Plasmin, also known as alkaline milk proteinase (Fox, 1989), is the principal indigenous milk proteinase that enters milk via mammary glands (Grufferty and Fox, 1988a; Richardson, 1983). It is acid and heat stabile (Richardson, 1983), capable of surviving pasteurization conditions (Kaminogawa et al., 1972). In fact, pasteurization of milk at $72^{\circ} \mathrm{C}$ for 15 seconds only decreased plasmin activity by 17 percent while activating other milk proteinases, such as plasminogen (Richardson, 1983). Plasmin is a trypsin-like serine proteinase that has a high specificity for peptide bonds that have lysyl and arginyl residues (Fox and Law, 1991; Farkye, 1995), of which $\beta-\mathrm{CN}$ and $\alpha_{\mathrm{s} 2}-\mathrm{CN}$ are most susceptible (Snoeren and van Riel, 1979; Andrews, 1983). Richardson (1983) has also supported that plasmin is connected with casein by lysine bonding sites since it was discovered that plasmin and plasminogen dissociated from casein in the presence of 6aminohexanoic acid or lysine.

Plasmin acts by primarily hydrolyzing $\beta$-casein to $\gamma_{1}-\mathrm{CN}$ [ $\beta-\mathrm{CN}$ (f29-209)], $\gamma_{2}-\mathrm{CN}$ $[\beta-\mathrm{CN}(\mathrm{f} 106-209)], \gamma_{3}-\mathrm{CN}[\beta-\mathrm{CN}(\mathrm{f} 108-209)]$ and proteose peptones, such as $5-[\beta-\mathrm{CN}$ (f1-105/107)] and 8-fast [ $\beta-C N$ (f1-28)] (Fox and Law, 1991; Eigel et al., 1984). Plasmin is also reported to hydrolyze $\alpha_{\mathrm{s} 2}$-casein and $\alpha_{\mathrm{s} 1}$-casein but information on the resulting 
products is limited. The products from $\alpha_{\mathrm{s} 2}$-casein are unknown while the products from $\alpha_{s 1}$-casein may be $\lambda$-casein. Plasmin has little effect on $\kappa$-casein, which is important for the stability of milk (Fox, 1989).

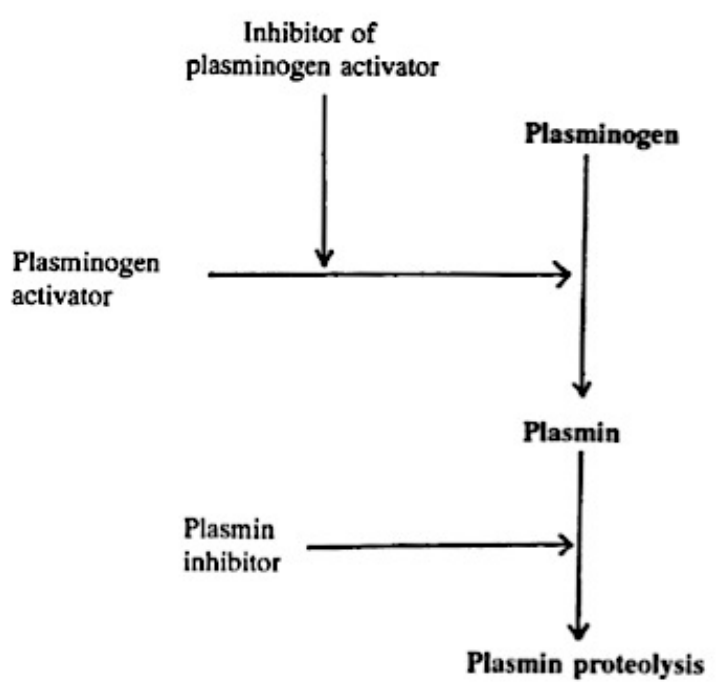

Figure 6: Diagram showing the interrelationship between plasmin system in milk (Farkye, 1995)

Milk contains a plasmin system that includes plasmin, plasminogen, plasmin inhibitors, plasminogen activators, and inhibitors of plasminogen activators (Fox and Law, 1991) and the concentrations of this system are dependent on the lactation stage and health of the cow (Barry and Donnelly, 1980). In milk, plasminogen is the precursor to plasmin and is activated during storage (De Rham and Andrews, 1982; Korycka-Dahl et al., 1983; Richardson, 1983). This notion can be seen in Figure 6 as it highlights how the plasmin system contributes to plasmin proteolysis.

Plasmin and plasminogen associate with casein micelles and are maintained in the curd with casein micelles (Farkye, 1995) while the rest of the components are soluble in the milk serum and are removed with the drained whey (Fox and Law, 1991). As said before, plasmin survives milk pasteurization; in fact, pasteurization is said to increase 
plasmin activity due to the inactivation of plasmin inhibitors and activation of plasminogen to plasmin (Lawrence et al., 1987; Grufferty and Fox, 1988b). It is also possible that this activity that occurs in milk also takes place in cheese. That is, plasminogen is converted to plasmin during high cooking temperatures since plasmin inhibitors and plasminogen inhibitors are lost in the drained whey (Fox and Law, 1991). When this idea is applied to string cheese manufacture, the high temperature of the stretching water should further inactivate plasmin inhibitors and activate plasminogen to plasmin. Thus, the plasmin activity would not be reduced from an increase in any heat treatment of the cheese.

\subsubsection{Enzymes from Starter Cultures}

As discussed before, string cheese cultures include thermophilic Lactobacillus species and Streptococcus salivarius subsp. thermophilus. These cultures all have the ability to survive the stretching process during string cheese manufacturing where curd temperatures can reach $55^{\circ} \mathrm{C}$ (Yun et al., 1995). The exact proteolytic systems of string cheese cultures are not entirely understood since they have not been studied greatly (Fox and Law, 1991; Law and Kolstad, 1983).

Though considered only weakly proteolytic (Fox, 1989), lactic acid bacteria need to maintain their growth and survival through nutritional requirements, which is accomplished by consuming amino acids (Thomas and Pritchard, 1987). Milk has readily available free amino acids, though quantities are not enough for optimal starter growth (Fox and Law, 1991). In fact, milk alone contains free amino acids and small peptides to support just 25 percent of the lactic acid bacteria growth population (Fox, 1989). 
Therefore, starter cultures acquire a proteolytic nature and are able to hydrolyze milk proteins to amino acids, essential for nutrition (Fox and Law, 1991).

In the final cheese product during the early ripening stage, lactic acid bacteria die and their cells lyse to release intracellular enzymes. These enzymes are capable of performing secondary proteolytic activity in the cheese matrix. When relating the proteolytic nature of starter cultures to string cheese, it would be difficult to reduce proteolysis due to the required usage of thermophilic cultures during culture-acidified manufacturing. However, starter cultures are only weakly proteolytic when compared to chymosin and plasmin, so their contribution to proteolysis is not as extensive (Law and Kolstad, 1983).

\subsubsection{Proteolytic Effects on Texture}

Texture is a subjective term that describes a sensory perception (Farkye and Fox, 1990a). It is a very important attribute since it is the first property that a consumer identifies and judges in a cheese sample (Lawrence et al., 1987). Texture is influenced by a variety of factors in cheese: casein to casein, casein to water, and casein to fat interactions, the state of water, whether it is bulk or bound to the casein matrix, $\mathrm{pH}$ and the state of calcium, whether it is ionic or bound to the casein matrix, temperature, salt concentration, and of course the extent of proteolysis (Everett et al., 2008).

The very first breakdown of $\alpha_{\mathrm{s} 1}-\mathrm{CN}$ to $\alpha_{\mathrm{s} 1}$-I-CN by chymosin is thought to cause the initial softening of cheese texture (Farkye and Fox, 1990a). During the first two weeks of refrigerated storage of Mozzarella cheese, para-casein fibers swell as they reabsorb free serum that was initially trapped between fibers formed during the shearing process of plasticized curd (Cortez et al., 2008). At the same time, calcium in Mozzarella 
slowly equilibrates, releasing its bond with protein, which gives way to a cheese with softer texture and more stretchable properties as the para-casein fibers weaken (O’Mahoney et al, 2005; Everett et al., 2008, Cortez et al., 2008).

Cooking temperature can also influence the texture of Mozzarella cheese. A study demonstrated that a reduction in cooking temperature from $45.9^{\circ} \mathrm{C}$ to $32.4^{\circ} \mathrm{C}$ resulted in an increase in breakdown of $\alpha_{\mathrm{s} 1}-\mathrm{CN}$ to $\alpha_{\mathrm{s} 1}-\mathrm{I}-\mathrm{CN}$. This breakdown, as suspected, resulted in a softer cheese with greater meltability (Tunick et al., 1995), presumably due to less chymosin inactivation.

A common defect in Mozzarella cheese is known as soft body defect. This flaw is characterized by a soft, pasty body with poor shredding properties (Kindstedt, 1993). Hull et al. (1983) discovered the cause to be from the proteolytic activity of a raw milk contaminant, Lactobacillus casei ssp. casei. This contaminant is resistant to pasteurization, salt-tolerant, and able to grow at $6^{\circ} \mathrm{C}$. Another study reported that $L b$. fermentum, Lb. lactis, and Lb. helveticus are also responsible for this soft body defect (Kindstedt, 1993). If the cheese milk used to produce string cheese were contaminated with such microorganisms, it would be difficult to avoid such defect.

Improper brining procedures have also led to Mozzarella with similar textural defect. Instead, the result is a cheese with soft, pasty, high moisture surface during ripening. When warm curd at $54^{\circ} \mathrm{C}$ is salted in cold brine at $4^{\circ}$, higher moisture is retained at the cheese surface during aging since moisture diffuses from the low-salt center to the high-salt surface (Kindstedt, 1993). A decrease in solute and increase in moisture also increases water activity (Rulikowska et al., 2013). Minor differences in water activity are known to significantly affect proteolytic activity (Choisy et al., 2000). 
Thus it is critical to ensure proper brining procedures to prevent any increase in water activity that would raise the level of proteolysis.

Proteolysis in Mozzarella cheese is not entirely negative since it is seen that the meltability and stretchability improve in the first one to three weeks of refrigerated storage (Fox et al. 2000; Kindstedt et al., 1999; Metzger et al., 2001; Guinee et al. 2002). However, a long aging time will result in Mozzarella that is too soft, which results in poor shredding properties (Fox et al. 2000). Similarly, a long aging time would result in a string cheese with poor stringiness, an important property for the product to appeal to children.

\subsection{Methods to Inhibit Proteolysis}

According to Yun et al. (1993b), control of cooking temperature, total cooking time, and $\mathrm{pH}$ of whey during cooking, as well as the choice of coagulant and starter culture are the most crucial factors that determine the composition and thus proteolysis of Mozzarella. The following will detail some feasible techniques to inhibit proteolysis in string cheese and their potential limitations for commercial usage.

\subsubsection{Maintain Clean Manufacturing Environment}

It is important to keep a clean manufacturing environment when producing cheese. Nonstarter bacteria, which consist of any organisms that can survive pasteurization of the cheese milk or gain access to the pasteurized milk or curd, could certainly contribute to proteolysis (Fox and Law, 1991). In order to prevent this from happening, it is crucial to ensure sanitary cheesemaking techniques at each step of the process. For example, it is essential to carefully select healthy cows and ensure proper pasteurization to have high quality milk. Also, the use of aseptic milking technique and 
aseptic vats can eliminate nonstarter bacteria (Fox, 1989). This can be challenging,

however, since it is difficult to completely eliminate microorganism from all surfaces in a manufacturing plant, workers, and air.

\subsubsection{Use of Coagulant Type}

There are six coagulant substitutes that have been discovered to be acceptable for cheese varieties: bovine, porcine, and chicken pepsins and the acid proteinases from Mucor miehei, M. pusillus, and Endothia parasitica. Chicken pepsin is not used in the United States; it is used mostly in Israel and less commonly in Czechoslovakia. Bovine pepsin performs the best regarding cheese yield and quality. Many commercial calf rennets contain about 50 percent bovine pepsin. Porcine pepsin is very sensitive to $\mathrm{pH}$ above 6.6 and is extensively denatured during cheesemaking, thus contributing very little to proteolysis. However, porcine pepsin has been withdrawn from most markets. The acceptability of fungal rennets has been pretty well received though they are very different from calf rennet (Fox, 1988).

Farkye (1995) studied the effects that these different coagulants would have on proteolysis. Though the study was done using Cheddar cheese, it would be reasonable to say that a similar outcome would have resulted if Mozzarella cheese were used instead. This is because Mozzarella manufacturing experiences higher heat processing when compared to the Cheddar process. The coagulants would presumably be completely inactivated or survive just like in Cheddar cheese making. This study was achieved by using chymosin, bovine pepsin, porcine pepsin, M. miehei and M. pusillus and examining electrophoretograms of these cheese types over time. It was learned that there was extensive proteolysis of $\alpha_{\mathrm{s} 1}-\mathrm{CN}$ in all cheeses except for the cheese made with porcine 
pepsin. After nine months of ripening, there was about 10 percent intact $\alpha_{s 1}-\mathrm{CN}$ in cheeses made with chymosin, bovine pepsin, M. miehei and M. pusillus. For the same amount of ripening time, there was about 40 percent intact $\alpha_{\mathrm{s} 1}-\mathrm{CN}$ for the cheese made with porcine pepsin. The breakdown of $\beta-\mathrm{CN}$ was most extensive in cheese made with $M$. miehei and M. pusillus. After nine months, only nine percent of intact $\beta$-CN remained in these cheeses.

From the study done on different coagulant types, it seems fair to say that porcine pepsin would be the optimal rennet to use. However, as Fox (1989) has stated, it is no longer available on the market. With that in mind, the remaining coagulant substitutes behave similarly in regards to proteolysis, contributing considerably to either $\alpha_{\mathrm{s} 1}-\mathrm{CN}$ or $\beta-\mathrm{CN}$ breakdown. These limitations make it problematic to reduce proteolysis in string cheese from a change in rennet type.

As well, inexpensive recombinant chymosins like Chy-Max, Maxiren, and Chymogen are most widely used in the cheesemaking industry today. These coagulants are highly purified with high specificity for the $\mathrm{Phe}_{105}-\mathrm{Met}_{106}$ cleavage site of $\kappa$-casein (Justesen et al., 2009). According to Fox et al. (2000), microbial chymosins have taken the market share from calf rennet and fungal rennet, representing 35 percent of the total market. The use of these coagulants has eliminated the need to extract chymosin from young calves, garnering large economic savings (Nip, 2004). These types of coagulants are already optimized for flavor, yield, cost, and other attributes specific to cheesemakers' needs (Anonymous, 2013a). To reiterate the conclusion from the aforementioned study, it would be difficult to reduce proteolysis in string cheese by 
changing the coagulant type since recombinant chymosins are already optimized for specific requirements.

\subsubsection{Control of $\mathrm{pH}$ of Cheese}

As discussed earlier, the $\mathrm{pH}$ of cheese has an effect on plasmin activity. While it is inconclusive whether the high temperature of the stretching waters would completely eliminate rennet from the curd, it is better to err on the cautious side and treat the cheese as if its rennet is still active. With this in mind, if curd is drained at a low $\mathrm{pH}$, more rennet is retained and thus there is greater hydrolysis of $\alpha_{\mathrm{s} 1}-\mathrm{CN}$ (Lawrence et al., 1987). Holmes et al. (1977) conducted a study to capture the effect of $\mathrm{pH}$ on whether the rennet would be in the curd or whey. Cheddar cheese was the vehicle for examination, so there was no effect of hot stretching water. It was reported that at $\mathrm{pH} 6.6,31$ percent of the rennet was in the curd and 72 percent of the rennet was in the whey. As the $\mathrm{pH}$ reduced to 5.2, 86 percent of the rennet was in the curd while 17 percent of the rennet was in the whey.

Since $\mathrm{pH}$ seems to have an opposite effect on the amount of plasmin activity and rennet activity in cheese, it is challenging to manipulate $\mathrm{pH}$ to inhibit proteolysis. Of course it is possible that the high temperature of the stretching water can completely eliminate rennet activity from string cheese. Then the ideal solution would be to lower the $\mathrm{pH}$ when draining the whey so that plasmin dissociates from the micelles (Lawrence et al., 1987). However, since there is inadequate information that suggests high cooking temperatures would completely eliminate rennet, it would be problematic to manipulate $\mathrm{pH}$ to reduce proteolysis in string cheese. 


\subsubsection{Control of Cooking and Stretching Temperature and Time}

The cooking temperature during Mozzarella cheese manufacturing has a relationship to the amount of moisture in the final product (Van Slyke and Price, 1952). Yun et al. (1993b) demonstrated this concept when they examined the effects of three cooking temperatures on the composition, proteolysis and functional properties of low moisture part-skim Mozzarella cheese. The three cooking temperatures studied were $38^{\circ} \mathrm{C}, 41^{\circ} \mathrm{C}$, and $44^{\circ} \mathrm{C}$. It was learned that the higher cooking temperature significantly lowered moisture content. The amount of moisture in Mozzarella can have an effect on its functionality, such as its shredability and meltability (Kindstedt et al., 1992). It was also learned that higher cooking temperature lessened the degree of proteolysis, as there was slower breakdown of $\alpha_{\mathrm{s}}$-caseins. Thus it is vital to control cooking temperature during cheese making since the final composition of the cheese can influence the extent of proteolysis. It was also learned that the impact that cooking temperature has on proteolysis is also dependent on the type of coagulant used, the $\mathrm{pH}$ during cooking, and the amount and activity of starter culture (Yun et al. 1993b).

Another study examined the stretching temperatures of hot Mozzarella curd to see its proteolytic effects. The examined temperatures were $74.6^{\circ} \mathrm{C}, 78^{\circ} \mathrm{C}, 83^{\circ} \mathrm{C}$, and $91.4^{\circ} \mathrm{C}$. From analyzing the soluble nitrogen percentages (SN\%) of the cheese samples over time, it was concluded that ripening time had a larger influence on proteolysis than stretching temperature. However, electrophoretograms showed that there was more intact $\alpha_{\mathrm{s} 1}$-CNs in the cheese that was stretched at the higher temperatures of $83^{\circ} \mathrm{C}$, and $91.4^{\circ} \mathrm{C}$. There were no differences in degree of hydrolysis of $\beta-\mathrm{CN}$ in the cheeses (Costabel et al., 2007). It seems reasonable to say that an increase in heat treatment temperatures of either 
cooking or stretching could retard the degree of proteolysis in string cheese. However, it is also probable that other factors and ripening time could also have effects on proteolytic activity.

\subsection{Justification for this work}

Proteolysis is a very complex biochemical event with many variables in play, such as moisture, salt concentration, calcium concentration, $\mathrm{pH}$, residual rennet, plasmin activity, cooking temperature, stretching temperature, and storage time. There have been many studies conducted to see the effects that different heating methods during manufacturing have on proteolysis in Mozzarella cheese. Such research has looked at various parameters in milk heating treatment, curd cooking temperatures, and stretching temperatures. Based on the literature, the majority of the studies showed that plasmin activity thrives with any increase in temperature during cheese processing due to the conversion of plasminogen to plasmin. The literature also lacks clarity about the exact temperature and time it takes for rennet in Mozzarella to be completely inactivated, with some studies reporting complete inactivation and other studies saying there is potential for rennet to reversibly denature at a specific temperature.

Despite there being evidence that increasing either cooking or stretching temperatures could reduce proteolysis in Mozzarella cheese, there is currently no study within literature that shows the same event occurring in string cheese. While string cheese is essentially a form of low-moisture, part skim Mozzarella, it has unique size, surface area, manufacturing processes, and packaging specifications that make it considerably different. Consequently, one cannot infer that a study performed on Mozzarella would translate directly in string cheese. 
Also, there exists no literature examining the effect of an additional heat treatment on amount of proteolysis in Mozzarella cheese. The concept of thermal processing after packaging has been employed since the beginning of canning. The canning process consists of food manufacturing, can filling, air exhaustion, sealing, and a thermal process of heating and cooling. The purpose of canning is to preserve food by eliminating and inhibiting microbial growth (Guerrero-Legarreta and Hui, 2010). Similarly, this thesis aims to inhibit proteolysis by applying a thermal process after string cheese manufacturing and vacuum packaging. In particular, the objective of this study is to apply a post manufacture thermal dip treatment to finished commercial string cheese so that proteolytic activity would halt after optimal ripening conditions have been attained. The hypothesis is that these treatments would extend the product's stringy texture while maintaining its mild, milk flavor beyond current shelf-life standards. 


\subsection{MATERIALS AND METHODS}

\subsection{Experimental Design}

Table 4: Definition of Terms for Experimental Design

\begin{tabular}{|c|c|}
\hline $\boldsymbol{i}$ & Treatment Levels \\
\hline 1 & Control \\
\hline 2 & $55^{\circ} \mathrm{C}$ for 30 seconds \\
\hline 3 & $55^{\circ} \mathrm{C}$ for 60 seconds \\
\hline 4 & $75^{\circ} \mathrm{C}$ for 30 seconds \\
\hline 5 & $75^{\circ} \mathrm{C}$ for 60 seconds \\
\hline 6 & $95^{\circ} \mathrm{C}$ for 30 seconds \\
\hline 7 & $95^{\circ} \mathrm{C}$ for 60 seconds \\
\hline & \\
\hline $\boldsymbol{j}$ & Days after Treatment \\
\hline 1 & 1 \\
\hline 2 & 11 \\
\hline 3 & 22 \\
\hline 4 & 29 \\
\hline 5 & 49 \\
\hline 6 & 91 \\
\hline 7 & 172 \\
\hline $\boldsymbol{k}$ & Batch \\
\hline 1 & manufactured June 12,2012 \\
\hline 2 & manufactured July 17,2012 \\
\hline
\end{tabular}

The design of the experiment was a generalized randomized complete block design (GRCBD). GRCBD allows replications of treatments within blocks. The model used to analyze the data on \%WSN, as described in Section 3.6, is shown below:

$$
y_{i j k}=\mu+\tau_{i}+\beta x_{j}+\gamma_{k}+(\tau \beta x)_{i j}+\varepsilon_{i j k}
$$

The model used to analyze the data on stringability, which is described in Section 3.7, is an ordinal logistic regression model. This model allows for the response variable to be categorical. The model is shown below:

$$
\ln \left(\frac{\text { prob(rating })}{1-\operatorname{prob}(\text { rating })}\right)=\mu+\tau_{i}+\beta x_{j}+\gamma_{k}+(\tau \beta x)_{i j}+\varepsilon_{i j k}
$$


The definitions of the terms are as follows and are further detailed in Table 4: $\mathrm{y}_{\mathrm{ijk}}=$ the response variable for the first model, which is expressed as \%WSN (quantitative)

$\ln [$ prob(rating $) /(1-$ prob(rating $))]=$ the response variable for the second model, which is expressed as the natural log of the odds of Stringability Rating where Stringability Rating is a categorical variable $\tau_{\mathrm{i}}=$ main effect of the ith temperature and time treatment level $\beta=$ change in response attributable to a unit change in refrigerated storage time $x$ $\gamma_{\mathrm{k}}=$ main effect of the kth block $(\tau \beta x)_{i j}=$ interaction effect of the ith temperature and time treatment level and $\mathrm{jth}$ refrigerated storage time $\mathrm{x}$ $\varepsilon_{\mathrm{ijk}}=$ random error term, and we assume $\varepsilon_{\mathrm{ijk}} \sim \mathrm{N}\left(0, \sigma^{2}\right)$

\subsection{Materials}

String cheese was received on two separate occasions from a single supplier. The first batch was manufactured on June 12, 2012 and the second batch was manufactured on July 17, 2012. The two groups of cheeses had expiration dates of November 9, 2012 and December 14, 2012, respectively. Treatment was applied to the string cheese on June 18, 2012 for the first batch and July 23, 2012 for the second batch. Sample preparation for primary proteolysis, secondary proteolysis, and texture analysis were completed on the following days after treatment for both batches: 1, 11, 22, 29, 49, 91, and 172 .

\subsection{Treatment Method}

String cheese was stored in a $4^{\circ} \mathrm{C}$ refrigerator upon arrival at California Polytechnic State University's Dairy Products Technology Center on June 15, 2012 for 
the first batch and July 20, 2012 for the second batch. On treatment days, 50 string cheese sticks were randomly assigned to one of the seven experimental groups. Treatment was applied by using cheesecloth to wrap string cheese sticks within original wrapper and lowering into a water bath (ISOTEMP 210, Fisher Scientific) at specified temperatures of $55^{\circ} \mathrm{C}, 75^{\circ} \mathrm{C}$, or $95^{\circ} \mathrm{C}$ for 30 or 60 seconds as depicted in Figure 7 . After being completely submerged in hot water, the sticks were cooled in an ice bath to quickly stop the heat treatment. Treatment levels were replicated twice per batch. A third replication of batch would have been better for statistical analysis. However, there was not enough time to conduct treatment, sampling, and testing on an additional set of string cheese samples.

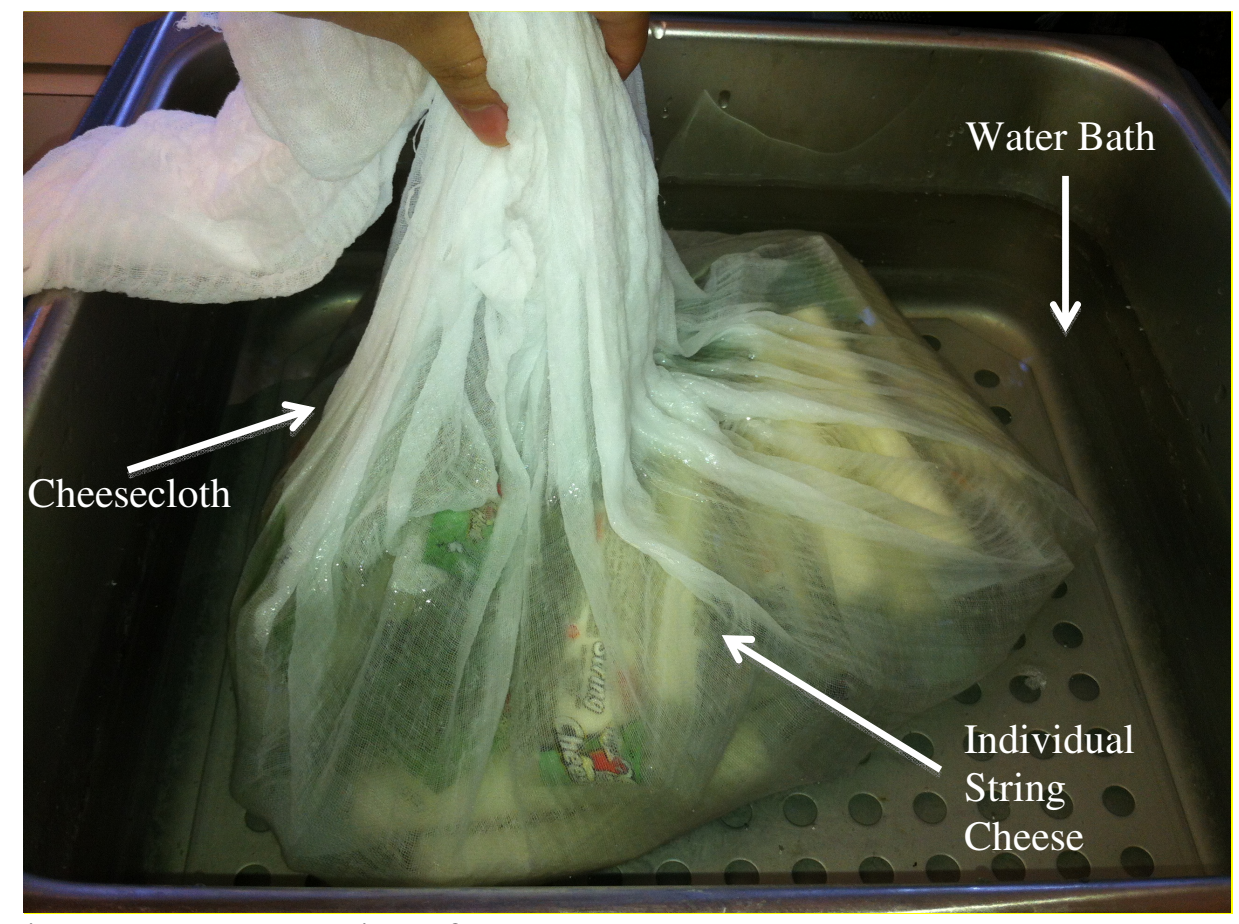

Figure 7: Demonstration of Treatment Process

The temperatures of $55^{\circ} \mathrm{C}, 75^{\circ} \mathrm{C}$, and $95^{\circ} \mathrm{C}$ were chosen to study possible effects on proteolysis based on current heat processing parameters within Mozzarella manufacturing. $55^{\circ} \mathrm{C}$ is approximately the temperature of the cheese curd after stretching 
procedures (Cortez et al., 2008; Creamer, 1976; Viotto Chaves and Grosso, 1999; Yun et al., 1993a) and is also the temperature that chymosin is thought to be partially and reversibly denatured (Hayes, et al., 2002; Sheehan et al., 2007). $75^{\circ} \mathrm{C}$ approximates the temperature of pasteurization (Farkye and Landkammer, 1992; Feeney et al., 2002;

Richardson, 1983; Somers and Kelly, 2002) and was also found to be the temperature of milk treatment that resulted in a 17 percent deduction in plasmin activity (Richardson, 1983). Lastly $95^{\circ} \mathrm{C}$ was selected to be an extreme temperature for examination.

The times of 30 and 60 seconds were chosen since a preliminary pilot study revealed that very long treatment times had adverse effects on the string cheese's color and texture. As well, treatment time was to target the outer layer of the string cheese due to its higher susceptibility to proteolysis from the brining procedure, which was explained in Section 2.3.9. Hence, only a short treatment time would be necessary to achieve the targeted temperatures at the cheese's surface.

The use of cheesecloth was to ensure easy removal so that each stick received the same amount of time in the hot water bath. It was important that the cheesecloth was not tightly wrapped around the sticks so that the hot water had access to each cheese sample as displayed in Figure 8. After treatment, sticks of cheese were randomly grouped into different sampling dates and stored in a $4^{\circ} \mathrm{C}$ refrigerator. 


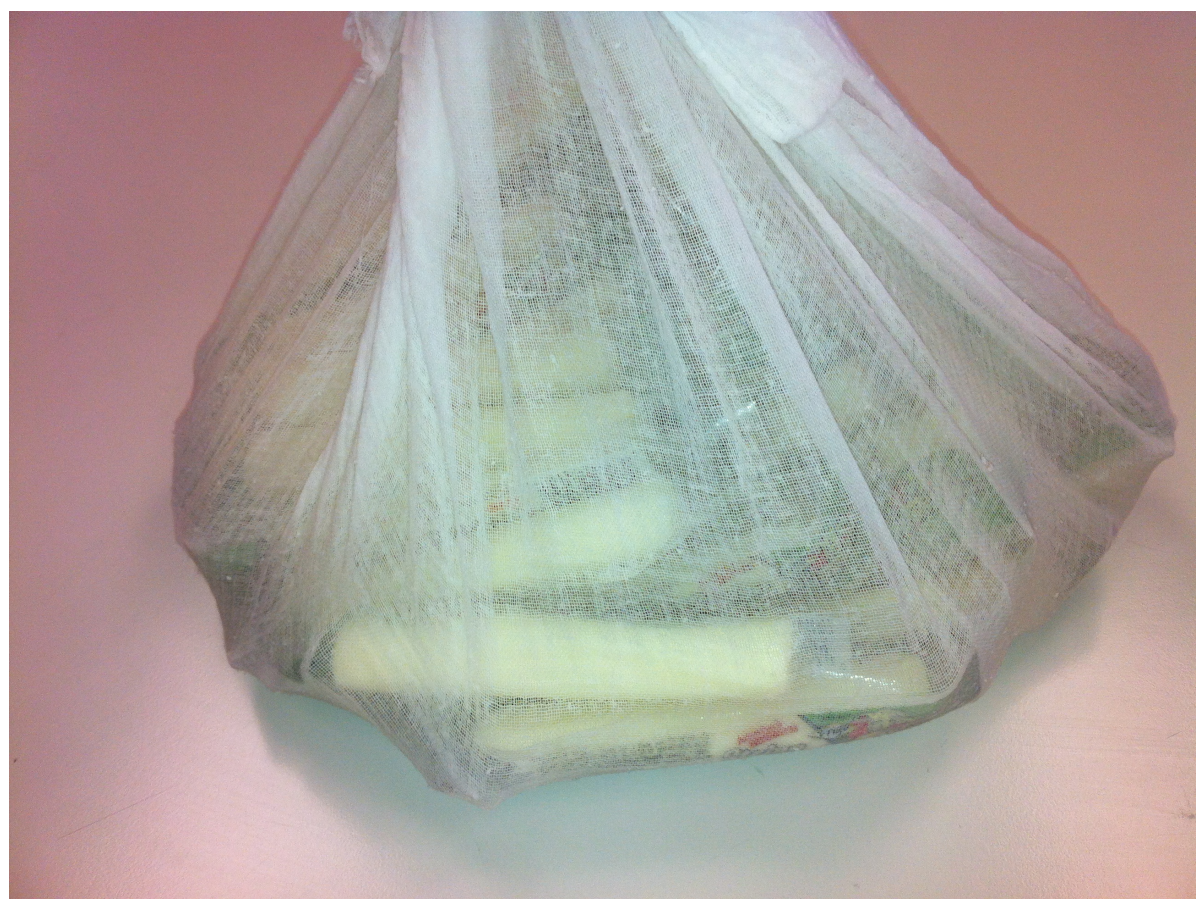

Figure 8: Demonstration of loosely wrapped cheesecloth around string cheese samples to ensure each sample received equal contact with hot water

\subsection{Chemical Composition Analysis of String Cheese}

All composition analyses were conducted on the same 10 random sticks of string cheese from each batch.

\subsubsection{Salt to Moisture ratio Analysis}

First, the moisture was determined in duplicate by measuring the water weight loss after two to three grams of grated string cheese was dried in a vacuum oven (Isotemp Vacuum Oven Model 281A, Fisher Scientific) at $100^{\circ} \mathrm{C}$ and at least $-86 \mathrm{kPa}$ for 5 hours, according to the modified AOAC method (AOAC 926.08).

$\mathrm{Next}$, the $\mathrm{NaCl}$ content was measured in duplicate by chloride analysis using the Corning 926 Analyzer Salt Analyzer (Corning Medical and Scientific Glass Works). Five grams of cheese sample from the same cheese sticks were grated and an appropriate amount of deionized water was added to a Whirlpak bag. The amount of water used was 
calculated by [100-(cheese sample weight in grams) x (\%moisture in sample)]. The cheese and water mixture were homogenized using a stomacher for three minutes. After a milky substance resulted, the mixture was filtered through a Whatman ${ }^{\mathrm{TM}}$ No. 41 paper. The Chloride Analyzer was calibrated by adding 250 microliters Chloride Meter Standard (200 mg/L Cl, Sherwood) to the Combined Acid Buffer (cat\# 131-3751, Nelson James, Inc.) and getting a reading between 97 and 103 three consecutive times. After calibration, 250 microliters of filtrate was added to the Combined Acid Buffer to get a reading. That number was converted to milligrams per liter on the Analyzer and multiplied by 0.04 to get the percentage of salt in the sample.

The average percentage of salt was divided by the average percentage of moisture for each batch to get the salt-to-moisture ratio, which was multiplied by 100 to get a percentage.

\subsubsection{Fat Analysis}

The fat content was determined by the Babcock method according to modified methods of Hooi et al. (2004) and AOAC 920.111. Instead of the respective 15 and 17.5 milliliters of sulfuric acid, 18 milliliters of sulfuric acid (cat\# SA174-4, Fisher Scientific) were added to the cheese sample. Also, glymol was not added to the Babcock bottle prior to reading results, as its only purpose is to aid with reading results. This analysis was done once because there was not enough cheese sample per stick to perform it in duplicate. Fat determination was essentially done to ensure that the received string cheese was within the standard range; its contribution to proteolysis was not a main concern in this study. 


\subsubsection{Total Nitrogen Analysis}

The total nitrogen (TN) was determined by measuring total nitrogen content by macro-Kjeldahl according to a modified AOAC method (2001.14). Instead of using a copper catalyst solution and potassium sulfate, three Kjeldahl tablets (cat\# K310-1000, Fisher Scientific) were used to serve the same purpose. Boiling chips were eliminated. Kjelsorb (cat\# SK15-20, Fisher Scientific) also replaced both the methyl red/bromocresol green indicator solution and boric acid as specified by the official method. In addition to the method, approximately one gram of sucrose (S5-3, Fisher Scientific) was added to samples to aid in the consumption of sulfuric acid (Persson, 2008). Samples were digested in a block digestor (Tecator ${ }^{\mathrm{TM}}$ Digestor, Foss) at $230^{\circ} \mathrm{C}$ for 30 minutes and then $430^{\circ} \mathrm{C}$ for 2 hours. Digests were then distilled in an automatic distillation unit (Kjeltec ${ }^{\mathrm{TM}}$ 2200, Foss). Measurements were performed in duplicate.

\subsection{4. pH Analysis}

The string cheese samples were measured directly with a pH meter (model 410 A+, ORION) with glass electrode (9157BN, ORION) at ambient temperature as described by Delgado et al. (2011). This measurement was carried out in duplicate.

\subsection{Primary Proteolysis Analysis}

\subsubsection{Urea-Polyacrylamide Gel Electrophoresis}

Urea gel electrophoresis was done using Mini-PROTEAN II Slab electrophoresis unit (Bio-Rad) according to a method similar to that of Andrews (1983). Resolving gels were prepared by mixing 6.0 milliliters of 40 percent acrylamide solution (cat\# 161-0148, Bio-Rad), 0.100 grams of N, N' methylene bisacrylamide (cat\# M7256-100G, Sigma Aldrich), and 14.0 milliliters of separating gel buffer. The separating gel buffer was 
prepared by mixing 32.15 grams of tris(hydroxymethyl)methylamine (cat\# 42457-5000, ACROS), 192.85 grams Urea (BP169-212, Fisher Scientific), and 2.86 milliliters of concentrated $\mathrm{HCl}$ (cat\# SA49, Fisher Scientific), dissolving to 500 milliliters with deionized water and adjusting the $\mathrm{pH}$ to 8.9. After filtering the resolving gel mixture through a Whatman ${ }^{\mathrm{TM}}$ No. 41 paper, polymerization was catalyzed with 10 microliters of N,N,N',N'-tetramethylethylenediamine or TEMED (cat\# 161-800, Bio-Rad) and 75.2 microliters of 10 percent (wt./vol.) ammonium persulfate (cat\# A7460-500G, SigmaAldrich).

The stacking gel was prepared by dissolving 1.0 milliliter of 40 percent acrylamide solution, 0.020 grams of $\mathrm{N}, \mathrm{N}$ ' methylene bisacrylamide, and 9.0 milliliters of stacking gel buffer. The stacking gel buffer was prepared by mixing 4.15 grams of tris(hydroxymethyl)methylamine, 150 grams of Urea, and 2.2 milliliters of $\mathrm{HCl}$, dissolving to 500 milliliters with deionized water and adjusting the $\mathrm{pH}$ to 7.6. After filtering the stacking gel mixture through a Whatman ${ }^{\mathrm{TM}}$ No. 41 paper, polymerization was catalyzed with 5 microliters of TEMED and 60 microliters of 10 percent (wt./vol.) ammonium persulfate.

The electrode buffer consisted of 3.0 grams tris(hydroxymethyl)methylamine and 14.6 grams glycine (cat\# G8898-1KG, Sigma Aldrich), dissolved to one liter with deionized water and adjusted to a $\mathrm{pH}$ of 8.4.

Gels were pre-equilibrated at $120 \mathrm{~V}$ for 10 minutes. Then the gels were loaded with 4 microliters of sample. The sample consisted of a random 0.01 grams of cheese from less than 1 millimeter of the outer layer of the string cheese stick (depicted in Figure 9) and 1 milliliter of sample buffer. Only the outer layer of cheese was used for analysis 
since the short time of the treatment was thought to only affect this area. For a better cheese sampling method, the entire outer layer $(<1$ millimeter) should have been homogenized prior to adding 0.01 grams of cheese to the gel sample. This would have ensured a better representation of the string cheese.

The sample buffer consisted of 0.75 grams tris(hydroxymethyl)methylamine, 49 grams Urea, 0.4 milliliters of concentrate $\mathrm{HCl}, 0.7$ milliliters of beta mercapto ethanol (cat\# BP176-100, Fisher Scientific), 0.15 grams of Bromophenol Blue (cat\# BP115-25, Fisher Scientific) dissolved to 100 milliliters with deionized water. The gels were run at $150 \mathrm{~V}$ until Bromophenol blue tracking dye was seen at the bottom of the slab, which took approximately 120 minutes.

The gels were stained directly by the method of Blakesley and Boezi (1977). Gel stain was made by first creating a Coomassie solution by mixing 0.5 grams Coomassie Brilliant G250 (cat\# BP100-25, Fisher Scientific) with 250 milliliters of deionized water. Then 250 milliliters of $1 \mathrm{M} \mathrm{H}_{2} \mathrm{SO}_{4}$ was created by mixing $13.9 \mathrm{~mL}$ concentrated $\mathrm{H}_{2} \mathrm{SO}_{4}$ (cat\# A300SI-212, Fisher Scientific) with 236.1 milliliters of deionized water. These two mixtures were combined and held overnight. The next day the mixture was filtered through Whatman ${ }^{\mathrm{TM}}$ No. 541 paper. Then 55.5 milliliters of $10 \mathrm{M} \mathrm{KOH}$ was prepared by mixing 31.14 grams $\mathrm{KOH}$ pellets (cat\# P250-500, Fisher Scientific) to 24.4 milliliters of deionized water. This $10 \mathrm{M} \mathrm{KOH}$ solution was added to the filtrate. Lastly 66.66 grams trichloroacetic acid powder (cat\# A322-500, Fisher Scientific) was added. Gels were stained overnight and de-stained with deionized water the next day. The Gel-Doc (BioRad) and Quantity One ${ }^{\circledR}$ software v.4.6.3 (Bio-Rad) were used to capture gel images. 


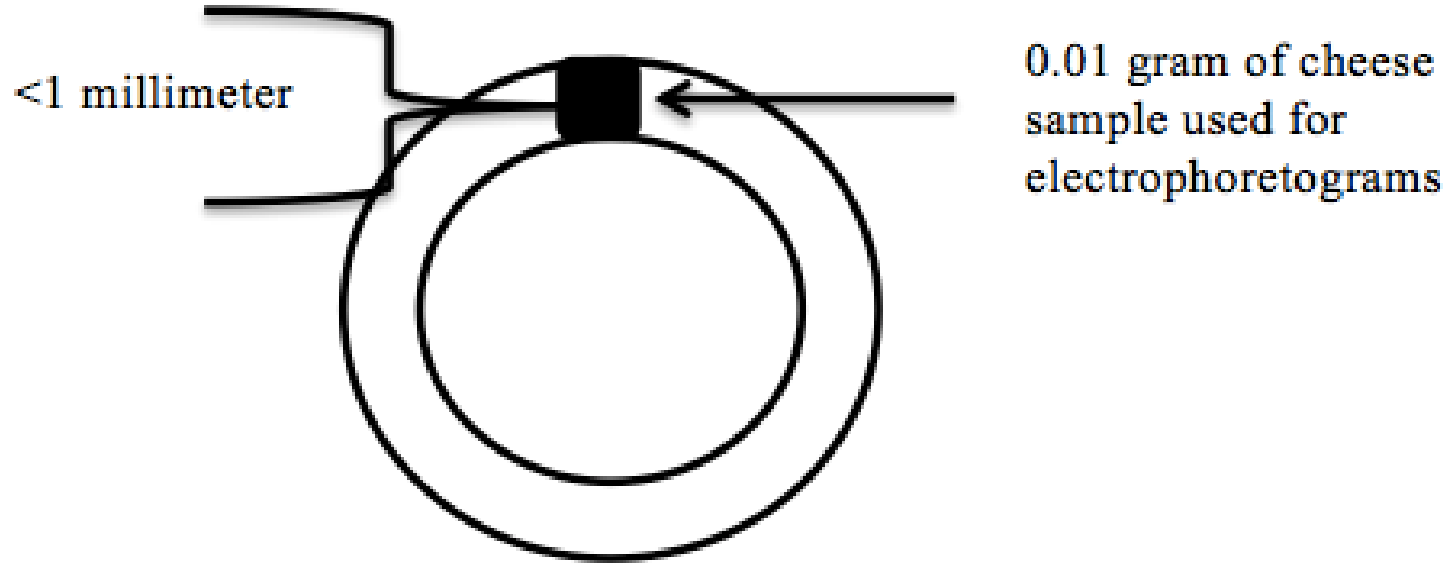

Figure 9: Depiction of string cheese sampling for electrophoretograms. The cross-section of the string cheese stick is shown and cheese was sampled from less than one millimeter from the surface (shaded area). Picture is not drawn to scale.

\subsection{Secondary Proteolysis Analysis}

\subsubsection{Water Soluble Nitrogen Analysis}

Water Soluble Nitrogen (WSN) was extracted according to a modified method by Kuchroo and Fox (1982) by using 15 grams of cheese from the outer layer. This was accomplished by using a knife to slice $1.5 \mathrm{~mm}$ of cheese from the perimeter as depicted in Figure 10. The cheese sample accounted for approximately 54 percent of the total cheese weight. Thirty milliliters of water was added to the cheese in a Whirlpak bag and homogenized in a stomacher for 90 seconds until a milky substance resulted. The homogenized samples were warmed in $40^{\circ} \mathrm{C}$ water bath for one hour. After warming, the cheese mixture was transferred to $50 \mathrm{~mL}$ Falcon tubes and centrifuged at $4000 \mathrm{rpm}$ for 30 minutes at $4{ }^{\circ} \mathrm{C}$. After centrifugation, the top fat layer was discarded and the supernatant was filtered through Whatman ${ }^{\mathrm{TM}}$ No. 41 paper into a new $50 \mathrm{ml}$ Falcon tube. Samples were kept frozen until nitrogen content analysis by the Kjeldahl method. 
The Kjeldahl procedure followed the same as described when determining total nitrogen of string cheese samples (Section 3.4.3). One gram of WSN extract was used as a sample. The titrant used was $0.01 \mathrm{~N} \mathrm{HCl}$ (cat\# SA54-20, Fisher Scientific) since the nitrogen content is much lower than the total nitrogen content of cheese.

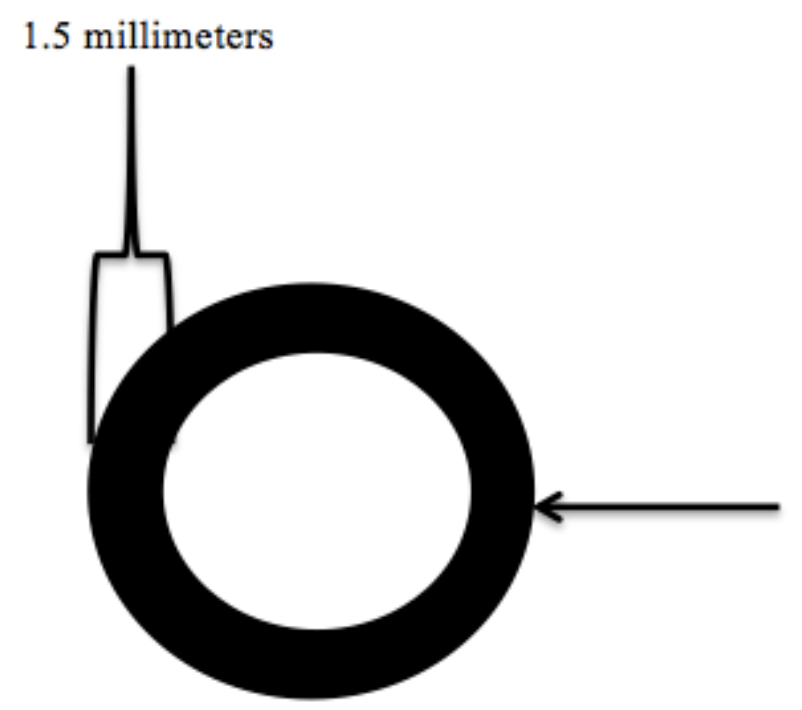

15 grams of cheese sample used for WSN extraction

Figure 10: Depiction of string cheese sampling for WSN extraction. The cross-section of the string cheese stick is shown and cheese was sampled from one and a half millimeters from the cheese surface (shaded area). Picture is not drawn to scale.

\subsection{Texture analysis}

\subsubsection{Stringability Analysis}

A method to evaluate the unique property of stringiness of the string cheese over time post treatment was developed. To imitate a string cheese manufacturing plant's technique to examine its stringiness quality like mentioned in Section 2.2.3, a randomly selected cheese stick was pulled apart in thirds length-wise. Four standards were developed and captured by photograph with specific descriptions to eliminate any potential bias ratings, as shown in Figure 11. A score of one through four was given to each sample based on its comparison to the standards. To account for variability of the string cheese due to temperature, all samples were at room temperature prior to 
conducting this test. Also, only one person (me) conducted this entire test to eliminate variability between different people's scoring judgment.
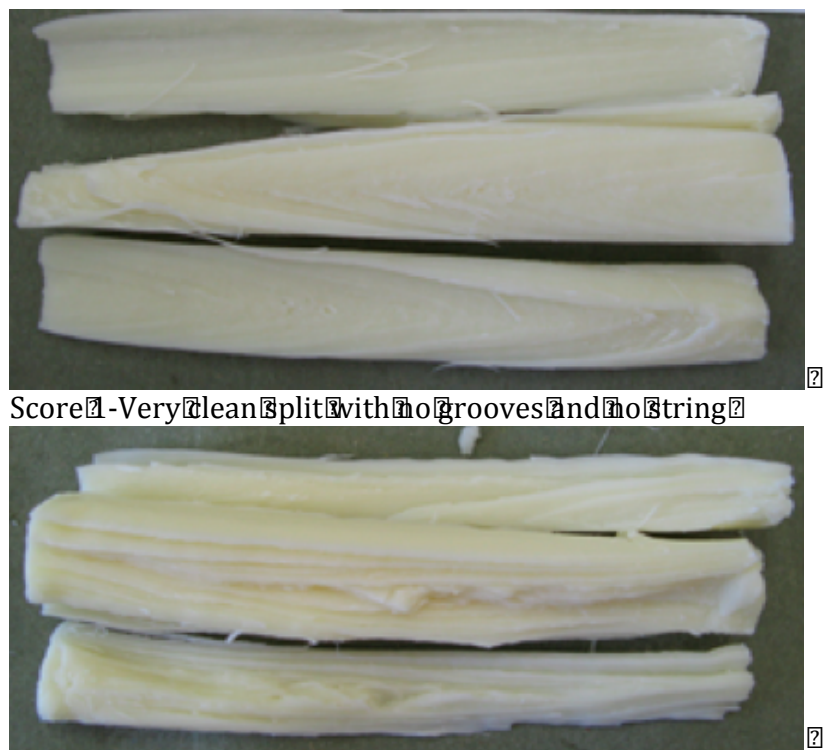

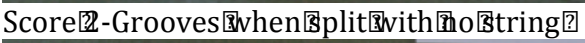

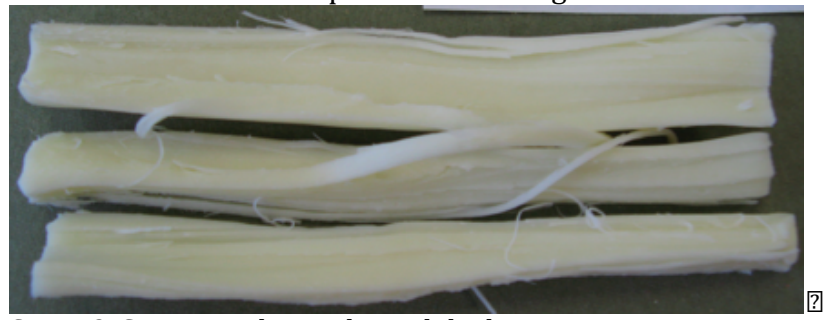

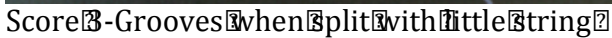
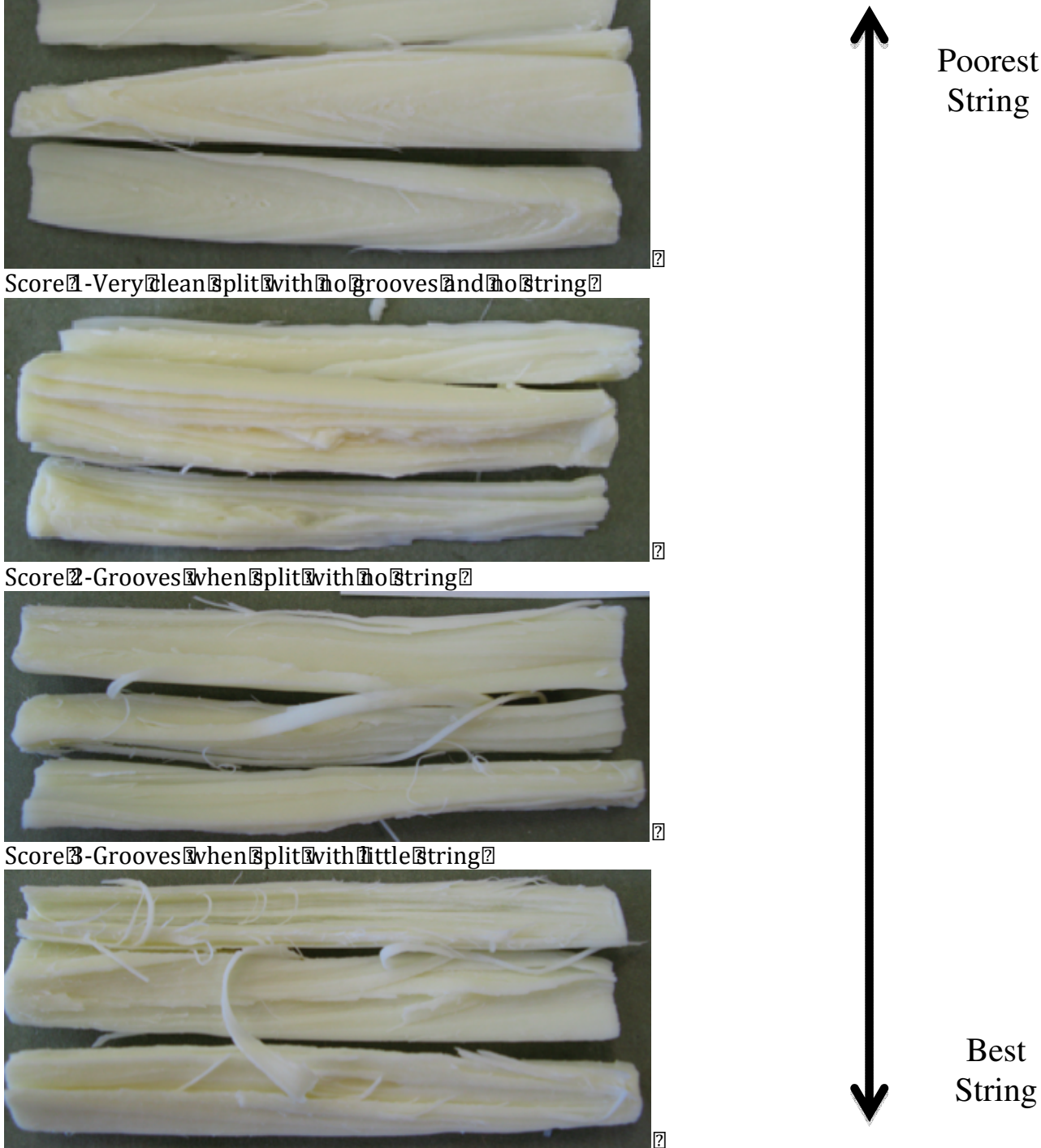

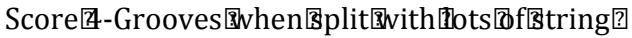

Figure 11: Standards for Stringability Analysis

\subsection{Statistical Analyses}

The statistical analysis of secondary proteolysis was conducted using the "Fit Model" command in JMP Pro 10. This command is capable of performing a General Linear Model, which was used in this experiment. Batch or the block was a random effect. Treatment, refrigerated storage time, and the interaction between the two were 
treated as fixed effects. The overall significance level was at $\alpha=0.05$, and so the test for the effect of treatment, the effect of refrigerated storage time, and the interaction of treatment and refrigerated storage time were each at 0.0167 level of significance. This was computed by dividing 0.05 by 3 , which is known as a Bonferroni adjustment. This was done to adjust for testing of three factors (heat treatment, storage time, and the interaction of heat treatment and storage time).

The statistical analysis of the Stringability test was conducted using the "Fit Ordinal Logistic" command in JMP Pro 10. This command is capable of analyzing data with ordinal data as the response variable. Treatment, refrigerated storage time, the interaction between treatment and refrigerated storage time, and batch were fixed effects. Logistic models do not support random effects and this was okay because the treatment of batch as a fixed effect did not affect the analysis. The overall significance level was at $\alpha=0.05$ and so the test for the effect of treatment, the effect of refrigerated storage time, and the interaction of treatment and refrigerated storage time were each at 0.0167 level of significance. Again, this was computed by dividing 0.05 by 3 . 


\subsection{RESULTS AND DISCUSSION}

\subsection{Composition}

The expected standard composition for string cheese can be found in Table 3 of Section 2.2.5. The composition for the two batches of commercial string cheese used in this research is presented in Table 5 .

Table 5: Composition Analysis of Commercial String Cheese

\begin{tabular}{|c|c|c|c|c|c|c|}
\hline Batch & $\begin{array}{c}\text { Salt } \\
(\boldsymbol{\%})\end{array}$ & $\begin{array}{c}\text { Moisture } \\
(\mathbf{\%})\end{array}$ & $\begin{array}{c}\text { S: M } \\
(\boldsymbol{\%})\end{array}$ & $\begin{array}{c}\text { Fat-on-dry- } \\
\mathbf{m a t t e r} \\
(\mathbf{\%})\end{array}$ & $\begin{array}{c}\text { Protein } \\
(\boldsymbol{\%})\end{array}$ & $\mathbf{p H}$ \\
\hline 1 & 1.40 & 49.79 & 2.81 & 31.36 & 22.01 & 5.30 \\
\hline 2 & 1.66 & 50.23 & 3.31 & 31.67 & 22.20 & 5.08 \\
\hline
\end{tabular}

\subsubsection{Salt to Moisture Ratio}

String cheese is typically brine salted until the total salt content is 1.6 percent (Cortes-Martinez et al., 2005). In the batches that were received, the first batch had an average salt content of 1.40 percent while the second batch had an average salt content of 1.66 percent. It was observed that several but not all of the cheese sticks in the second batch tasted abnormally saltier than expected. The same samples that were extremely salty were also a lot firmer and brittle in texture. This is presumably due to water expulsion from the higher salt content. These unusual samples were discarded and not used in the study.

The moisture content of string cheese should be greater than 45 percent but less than or equal to 52 percent (Kindstedt, 1993). The first batch had an average moisture content of 49.79 percent while the second batch had an average moisture content of 50.23 
percent. Both of these values are within range for the standards of identity of lowmoisture, part skim Mozzarella cheese.

The salt to moisture ratio (S: M) of the two batches is computed by dividing the salt concentration by the moisture content and multiplying by 100 . The first batch had an S: M of 2.81 percent while the second batch had an S: M of 3.31 percent. The higher S: $\mathrm{M}$ of the second batch is due to the higher salt content since both batches had similar moisture contents. As mentioned in Section 2.3.4, a higher S: M in string cheese should result in a cheese with more intact $\alpha_{\mathrm{s} 1}-\mathrm{CN}$ and $\beta-\mathrm{CN}$ and consequently less proteolysis.

\subsubsection{Fat-on-Dry-Matter}

The fat-on-dry-matter of string cheese was expected to be greater than or equal to 30 percent but less than 45 percent (Kindstedt, 1993). The fat contents of the received string cheese from both batches fell within range of the standards of identity of lowmoisture, part skim Mozzarella cheese. The first batch had an average fat-on-dry-basis of 31.36 percent and the second batch had an average fat-on-dry-basis of 31.67 percent. The fat contents of both batches were similar to each other.

\subsubsection{Protein}

The protein content of low-moisture, part skim Mozzarella was expected to be 20 percent (Jana and Mandal, 2011). The received cheese had total nitrogen contents of 3.45 percent and 3.48 percent for the first and second batch, respectively. With a conversion factor of 6.38, the protein contents would be 22.01 percent for the first batch and 22.20 percent for the second batch. Though the protein content is slightly higher than expected, it is still at a reasonable level. 


\subsection{4. $\mathrm{pH}$}

The $\mathrm{pH}$ of a culture acidified string cheese is expected to be 5.2 (Kindstedt et al., 1999). The $\mathrm{pH}$ of the first batch of cheese was 5.30 while the $\mathrm{pH}$ of the second batch was a lot lower at 5.08. As discussed in Section 2.4.3, $\mathrm{pH}$ has an effect on the extent of proteolytic activity in cheese. At a lower draining $\mathrm{pH}$ such as 5.2, there is higher amount of residual rennet in the curd (Holmes et al., 1977). Therefore, there could be residual rennet activity in the string cheese if the cooking and stretching heating parameters applied during manufacturing did not completely inactivate the coagulant. The $\mathrm{pH}$ that plasmin dissociates from casein micelles very quickly is at $\mathrm{pH} 4.6$ (Grufferty and Fox, 1988b). The $\mathrm{pH}$ of the string cheese in our study was higher than 4.6, alluding to the fact that plasmin activity would remain active for cheeses from both batches.

\subsection{Primary Proteolysis}

Primary proteolysis of the treated string cheese was qualitatively examined through Urea-PAGE electrophoretograms. Intensity of $\beta-\mathrm{CN}$ and $\alpha_{\mathrm{s} 1}-\mathrm{CN}$ and their breakdown products were observed to relate the effect of the treatments to the degree of proteolysis.

Additional electrophoretograms in Appendix B section were done to examine the effect that the treatment would have on string cheese on the first day post treatment. This was done to ensure there were no immediate, negative implications from the treatment. The conclusion was that there were no immediate, negative effects on the string cheese since all casein bands appeared to be normal and similar to the control. 


\subsubsection{Control at all Time Points}

The following electrophoretograms (Figures 12, 13, 14, and 15) depict the extent of primary proteolysis of untreated, control string cheese at all sampling time points of

the study. Overall, it was seen that $\beta$-CN breakdown continued with storage time as the $\beta$ $\mathrm{CN}$ band became less intense and the breakdown products' bands became more intense. This was expected since Mozzarella cheese is known to have high plasmin activity when compared to other cheeses outside of the pasta filata family. The high cooking and stretching temperatures inactivate plasmin inhibitors while activating the conversion of plasminogen to plasmin (Fox and Law, 1991).

At 91 days after treatment, the $\gamma_{2}$-CN band disappeared but reappeared later at 172 days for both replicates in the first batch of string cheese. Also noticed was the disappearance of $\gamma_{2}-\mathrm{CN}$ at 22 and 49 days after treatment for both replicates in the second batch of string cheese. The $\gamma_{2}-\mathrm{CN}$ bands did reappear at day 29 after treatment and all the time points after 49 days after treatment. There exists no literature explaining the disappearance and reappearance of bands in electrophoretograms, so the cause for these results are unclear.

The electrophoretograms also show that the breakdown of $\alpha_{\mathrm{s} 1}$-CN increased during storage time. This was evident by the increase in breakdown products seen below the $\alpha_{\mathrm{s} 1}-\mathrm{CN}$ band in the later sampling dates, such as 49,91 , and 172 days after treatment. This was expected since both potential residual rennet activity and intracellular enzymes released from starter culture lysis are capable of hydrolyzing $\alpha_{\mathrm{s} 1}-\mathrm{CN}$. 


$\begin{array}{llllllll}1 & 2 & 3 & 4 & 5 & 6 & 7 & 8\end{array}$

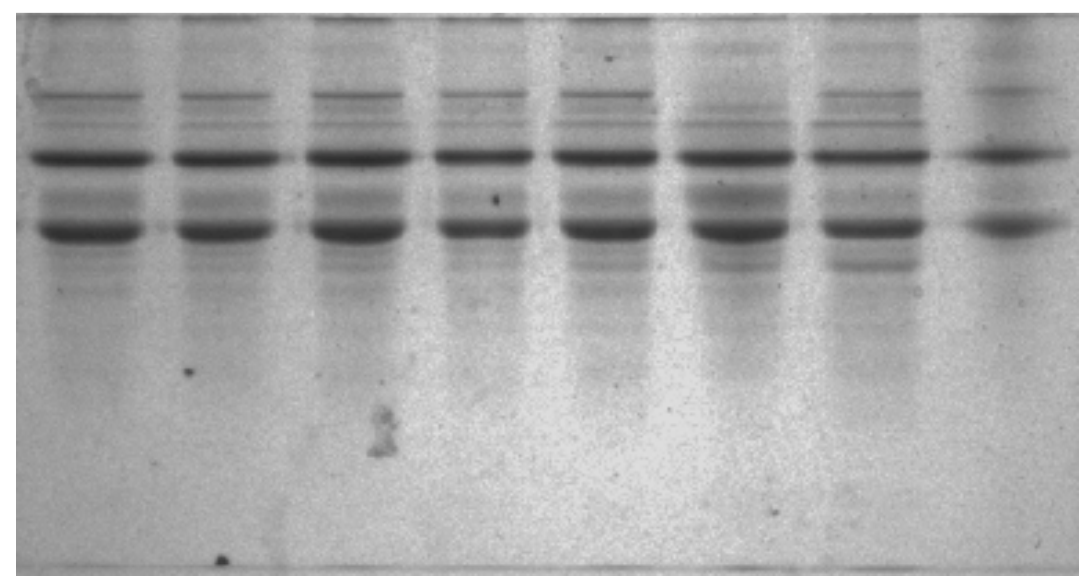

Figure 12: Urea-PAGE electrophoretogram of control/untreated samples at all time points for the first replicate of the first batch (lane $1=1 \mathrm{~d}$ after treatment, lane $2=11 \mathrm{~d}$ after treatment, lane $3=22 \mathrm{~d}$ after treatment, lane $4=29 \mathrm{~d}$ after treatment, lane $5=49 \mathrm{~d}$ after treatment lane $6=91 \mathrm{~d}$ after treatment, lane $7=172 \mathrm{~d}$ after treatment, lane $8=\mathrm{NaCN}$ standard)

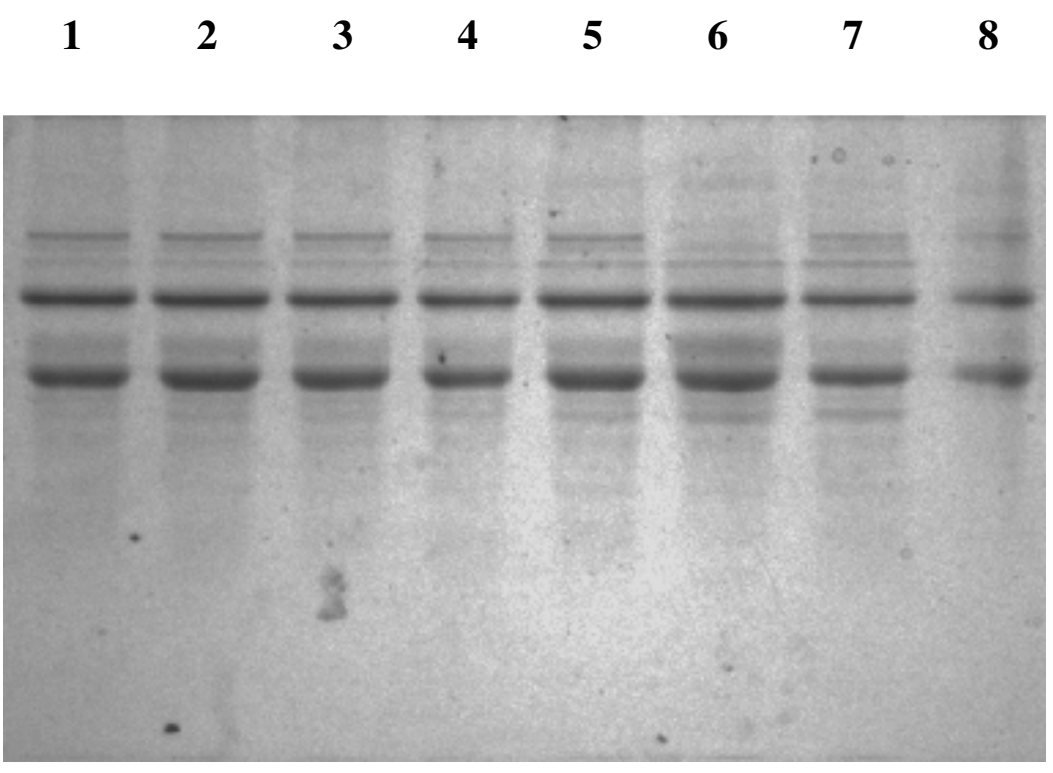

Figure 13: Urea-PAGE electrophoretogram of control/untreated samples at all time points for the second replicate of the first batch (lane $1=1 \mathrm{~d}$ after treatment, lane $2=11 \mathrm{~d}$ after treatment, lane $3=22 \mathrm{~d}$ after treatment, lane $4=29 \mathrm{~d}$ after treatment, lane $5=49 \mathrm{~d}$ after treatment, lane $6=91 \mathrm{~d}$ after treatment, lane $7=172 \mathrm{~d}$ after treatment, lane $8=\mathrm{NaCN}$ standard) 


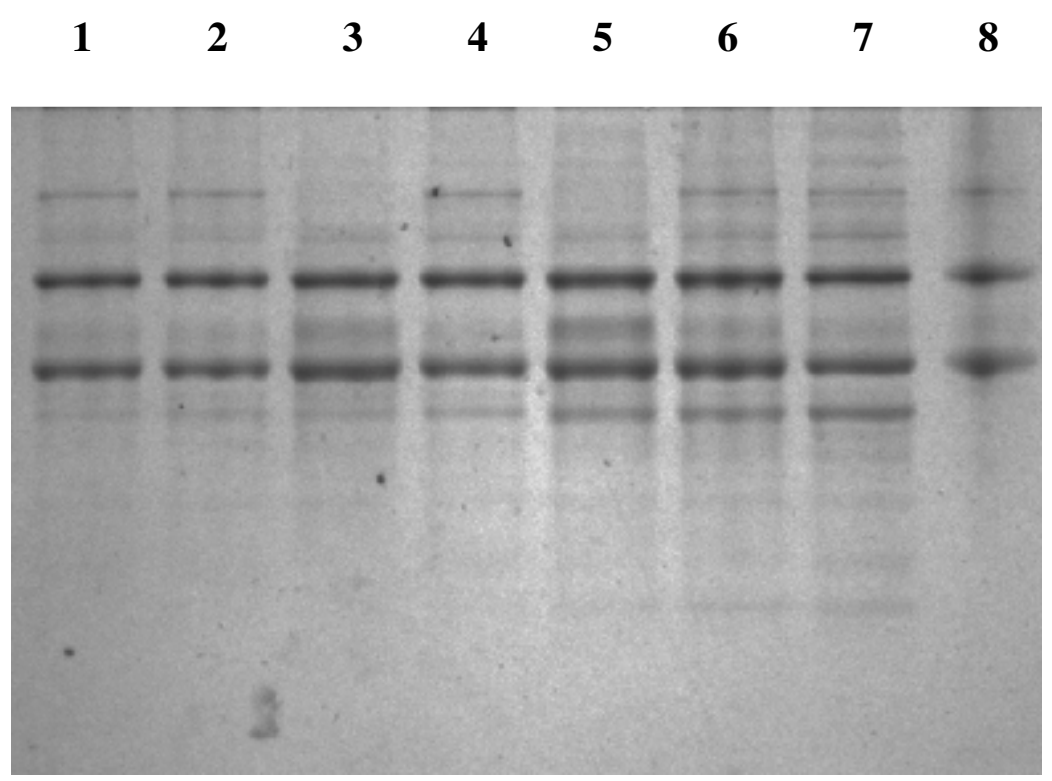

Figure 14: Urea-PAGE electrophoretograms of control/untreated samples at all time points for the first replicate of the second batch (lane $1=1 \mathrm{~d}$ after treatment, lane $2=11 \mathrm{~d}$ after treatment, lane $3=22 \mathrm{~d}$ after treatment, lane $4=29 \mathrm{~d}$ after treatment, lane $5=49 \mathrm{~d}$ after treatment, lane $6=91 \mathrm{~d}$ after treatment, lane $7=172 \mathrm{~d}$ after treatment, lane $8=\mathrm{NaCN}$ standard)

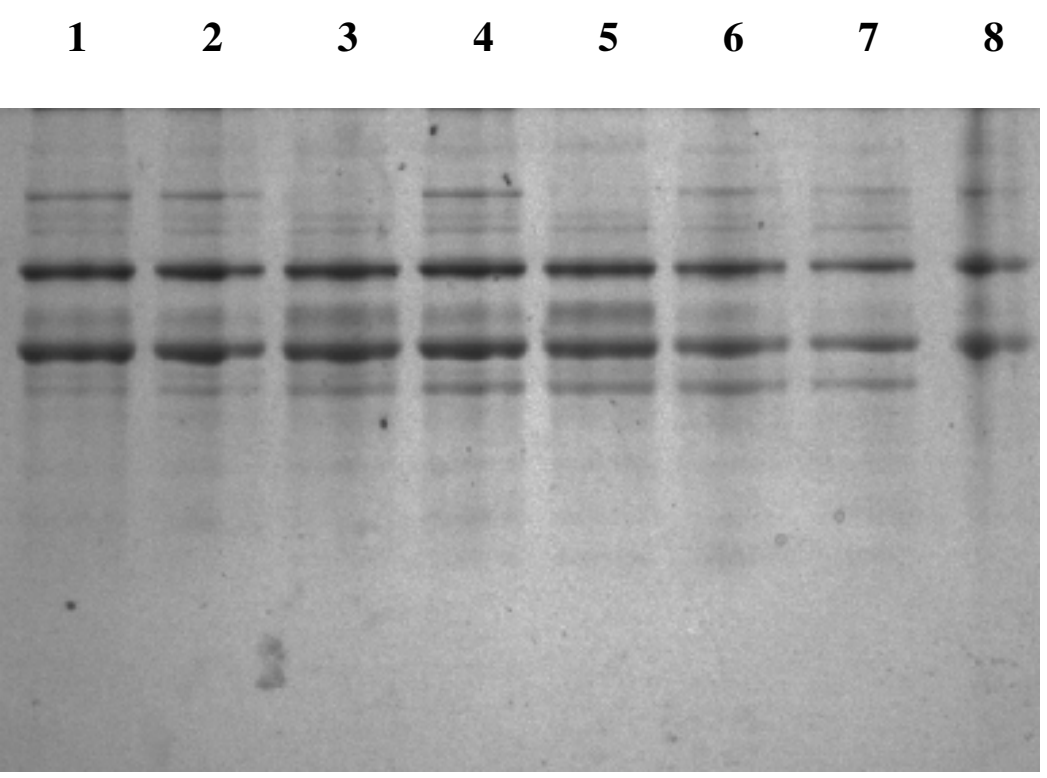

Figure 15: Urea-PAGE electrophoretogram of control/untreated samples at all time points for the second replicate of the second batch (lane $1=1 \mathrm{~d}$ after treatment, lane $2=11 \mathrm{~d}$ after treatment, lane $3=22 \mathrm{~d}$ after treatment, lane $4=29 \mathrm{~d}$ after treatment, lane $5=49 \mathrm{~d}$ after treatment, lane $6=91 \mathrm{~d}$ after treatment, lane $7=172 \mathrm{~d}$ after treatment, lane $8=\mathrm{NaCN}$ standard) 


\subsubsection{All Treatments at Final Time Point}

The following electrophoretograms (Figures 16, 17, 18, and 19) depict the extent of primary proteolysis of string cheese at the final sampling time point of 172 days post treatment for all treatments. Overall, it was seen that the extent of $\beta-\mathrm{CN}$ breakdown was the same among the control and all treated cheeses. This was not expected since Mozzarella cheese exposed to a higher temperature should have more plasmin activity than that of cheese exposed to a lower temperature. The increase in plasmin activity is a result of the inactivation of plasmin inhibitors and conversion of plasminogen to plasmin when Mozzarella undergoes any thermal process.

The electrophoretograms also show that there was discrepancy between and within batches when examining the breakdown of $\alpha_{\mathrm{s} 1}-\mathrm{CN}$. The electrophoretogram in Figure 16 shows similar degree of $\alpha_{\mathrm{s} 1}-\mathrm{CN}$ breakdown for all treatments while the electrophoretogram in Figure 17 shows less pronounced $\alpha_{\mathrm{s} 1}-1-\mathrm{CN}$ breakdown product in the most severe heat treatment of $95^{\circ} \mathrm{C}$ for 60 seconds. The electrophoretogram in Figure 18 shows more intense $\alpha_{\mathrm{s} 1}-\mathrm{CN}$ bands for the string cheeses treated at $95^{\circ} \mathrm{C}$ for 30 seconds and $95^{\circ} \mathrm{C}$ for 60 seconds than the other treated and untreated string cheeses. And lastly the electrophoretogram in Figure 19 show that there was more intense $\alpha_{\mathrm{s} 1}-\mathrm{CN}$ bands and less pronounced $\alpha_{\mathrm{s} 1}-1-\mathrm{CN}$ breakdown product for the string cheeses treated at $95^{\circ} \mathrm{C}$ for 60 seconds than the other treated and untreated string cheeses. The last three electrophoretograms (Figure 17, Figure 18, and Figure 19) suggest that there was less breakdown of $\alpha_{\mathrm{s} 1}-\mathrm{CN}$ when the string cheese was treated at a higher temperature of $95^{\circ} \mathrm{C}$ for 60 seconds and occasionally for the treatment at $95^{\circ} \mathrm{C}$ for 30 seconds. 


$\begin{array}{llllllll}1 & 2 & 3 & 4 & 5 & 6 & 7 & 8\end{array}$

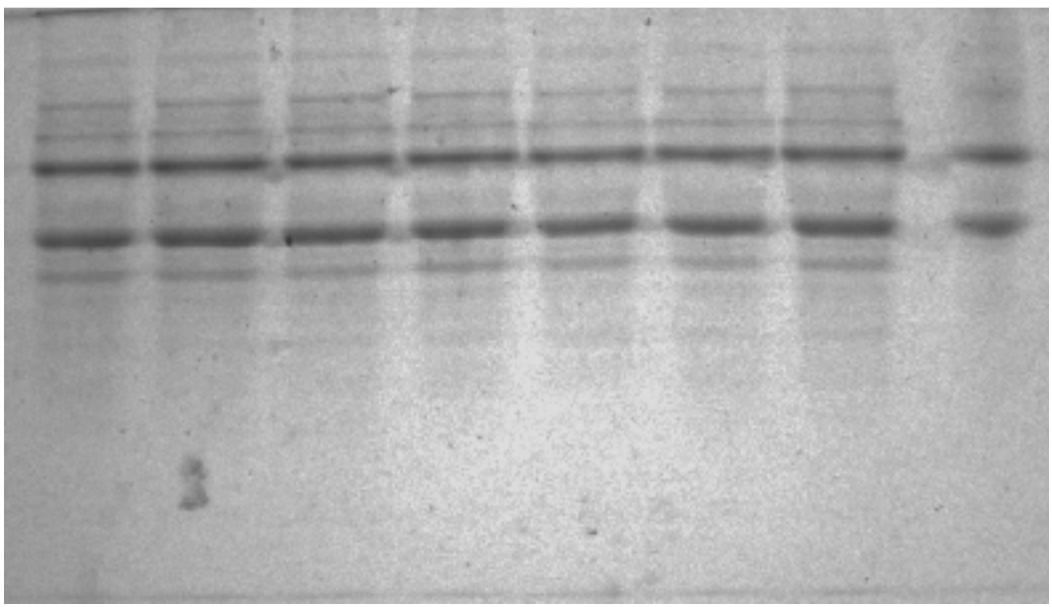

Figure 16: Urea-PAGE electrophoretogram of all treated samples at 172 days after treatment day for the first replicate of the first batch (lane $1=$ control/untreated, lane $2=55^{\circ} \mathrm{C}$ for $30 \mathrm{~s}$, lane $3=55^{\circ} \mathrm{C}$ for $60 \mathrm{~s}$, lane $4=75^{\circ} \mathrm{C}$ for $30 \mathrm{~s}$, lane $5=75^{\circ} \mathrm{C}$ for $60 \mathrm{~s}$, lane $6=95^{\circ} \mathrm{C}$ for $30 \mathrm{~s}$, lane $7=95^{\circ} \mathrm{C}$ for $60 \mathrm{~s}$, lane $8=\mathrm{NaCN}$ standard)

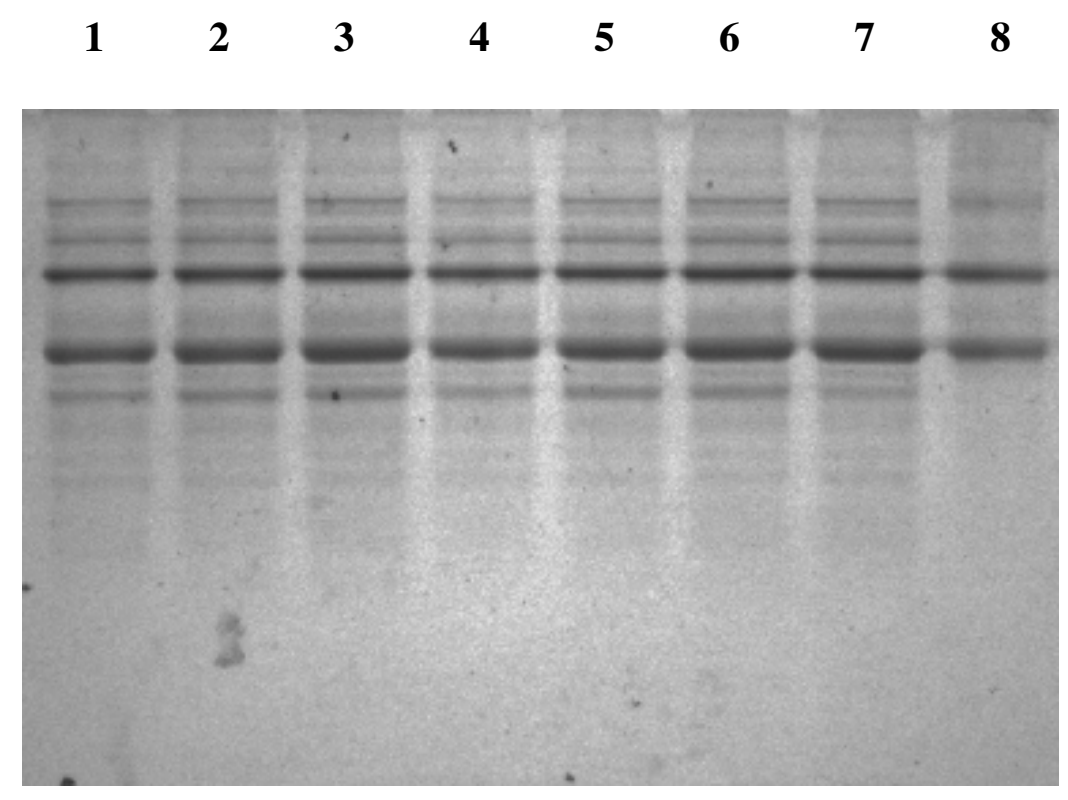

Figure 17: Urea-PAGE electrophoretogram of all treated samples at 172 days after treatment day for the second replicate of the first batch (lane $1=$ control/untreated, lane $2=55^{\circ} \mathrm{C}$ for $30 \mathrm{~s}$, lane $3=55^{\circ} \mathrm{C}$ for $60 \mathrm{~s}$, lane $4=75^{\circ} \mathrm{C}$ for $30 \mathrm{~s}$, lane $5=75^{\circ} \mathrm{C}$ for $60 \mathrm{~s}$, lane $6=95^{\circ} \mathrm{C}$ for $30 \mathrm{~s}$, lane $7=95^{\circ} \mathrm{C}$ for $60 \mathrm{~s}$, lane $8=\mathrm{NaCN}$ standard) 


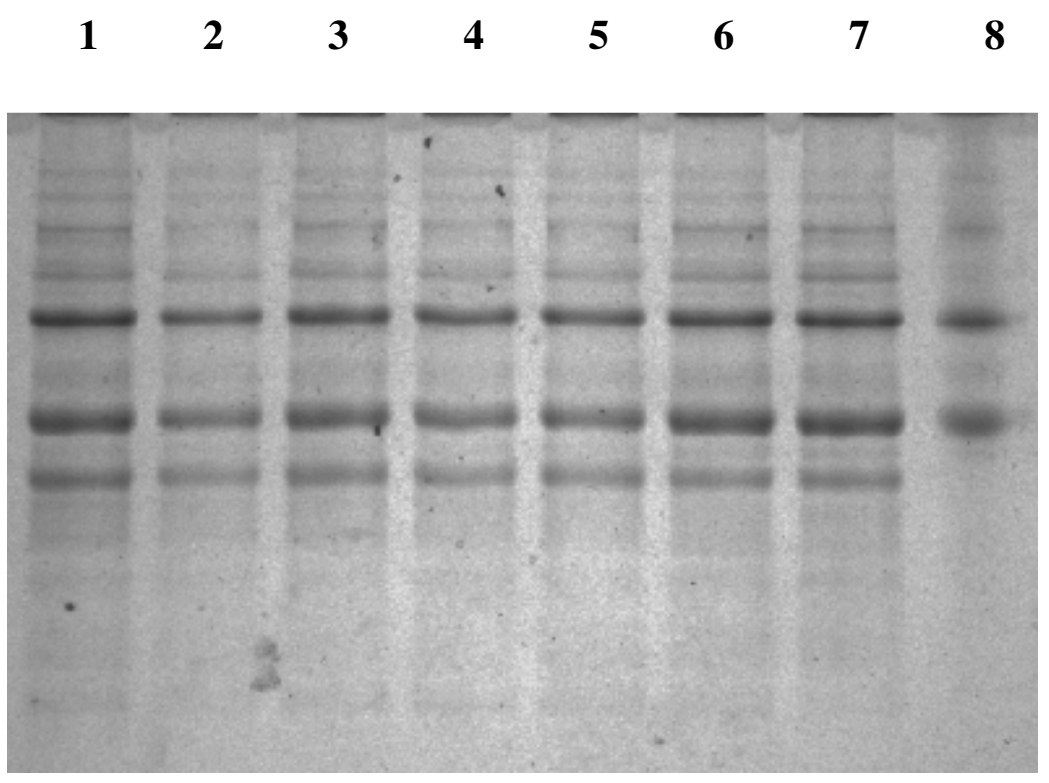

Figure 18: Urea-PAGE electrophoretogram of all treated samples at 172 days after treatment day for the first replicate of the second batch (lane $1=$ control/untreated, lane $2=55^{\circ} \mathrm{C}$ for $30 \mathrm{~s}$, lane $3=55^{\circ} \mathrm{C}$ for $60 \mathrm{~s}$, lane $4=75^{\circ} \mathrm{C}$ for $30 \mathrm{~s}$, lane $5=75^{\circ} \mathrm{C}$ for $60 \mathrm{~s}$, lane $6=95^{\circ} \mathrm{C}$ for $30 \mathrm{~s}$, lane $7=95^{\circ} \mathrm{C}$ for $60 \mathrm{~s}$, lane $8=\mathrm{NaCN}$ standard)

$\begin{array}{llllllll}1 & 2 & 3 & 4 & 5 & 6 & 7 & 8\end{array}$

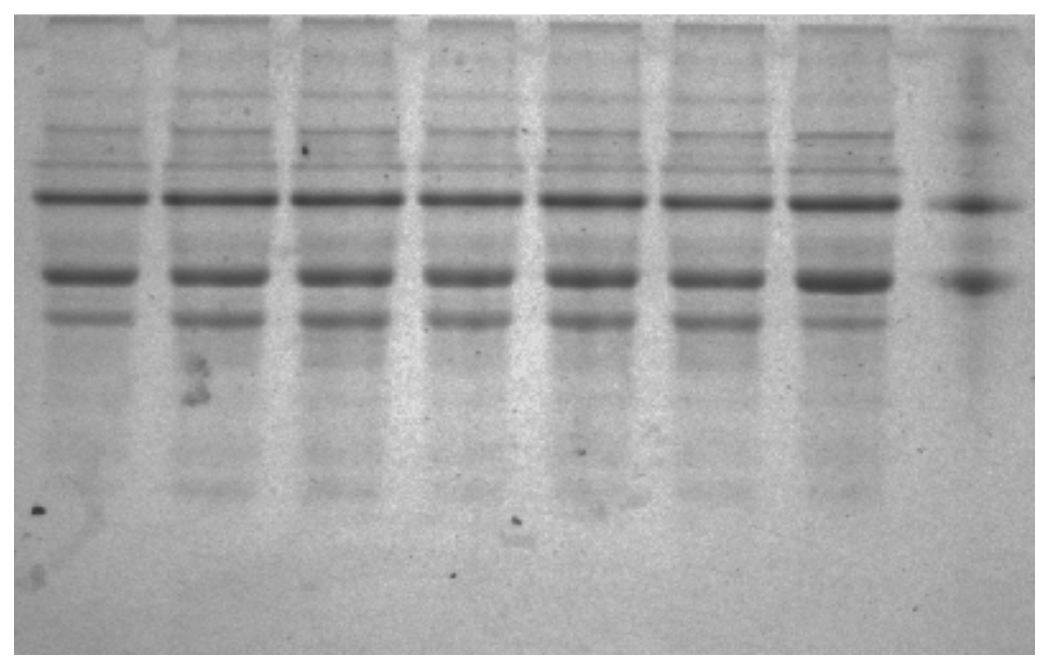

Figure 19: Urea-PAGE electrophoretogram of all treated samples at 172 days after treatment day for the second replicate of the second batch (lane $1=$ control/untreated, lane $2=55^{\circ} \mathrm{C}$ for $30 \mathrm{~s}$, lane $3=55^{\circ} \mathrm{C}$ for $60 \mathrm{~s}$, lane $4=75^{\circ} \mathrm{C}$ for $30 \mathrm{~s}$, lane $5=75^{\circ} \mathrm{C}$ for $60 \mathrm{~s}$, lane $6=95^{\circ} \mathrm{C}$ for $30 \mathrm{~s}$, lane $7=95^{\circ} \mathrm{C}$ for $60 \mathrm{~s}$, lane $8=\mathrm{NaCN}$ standard) 
Despite there being slight decrease in the degradation of $\alpha_{\mathrm{s} 1}-\mathrm{CN}$ at the last time point identified in the majority of the electrophoretograms, the heat treatments did not show very clear effects on the extent of primary proteolysis. It is possible that differences in manufacturing procedures of string cheese could impact the heat treatment effects on primary proteolysis. Some cheese manufacturers may make their string cheese with very low amounts of proteolytic enzymes. Other cheese manufacturers may make their string cheese with high amounts of proteolytic enzymes. If string cheese were sourced from a different supplier who used a high concentration of proteolytic enzymes, then perhaps the heat treatments would have shown more distinct differences in $\alpha_{\mathrm{s} 1}-\mathrm{CN}$ breakdown. As well, the use of more severe heat treatments may be able to show greater effects on primary proteolysis. If both or either the temperature and time that the string cheese was submerged in hot water were increased, then it would also be plausible that the heat treatments would have shown clearer effects on the amount of $\alpha_{\mathrm{s} 1}-\mathrm{CN}$ breakdown.

\subsection{Secondary Proteolysis}

Secondary proteolysis of the treated string cheese was quantitatively examined by the nitrogen determination of water-soluble nitrogen (WSN) extract of the outer layer of the treated string cheese samples. The WSN value was divided by the average total nitrogen value of each batch to get \%WSN. This data was statistically analyzed using the "Fit Model" command in JMP Pro 10 (Appendix D).

\subsubsection{Water-Soluble Nitrogen Analysis}

At an overall $\alpha=0.05$, there was no evidence that the post manufacture heat treatments had a significant relationship to the amount of \%WSN during storage time (p $=0.4987)$. There was also no significant interaction between treatment and storage time 
$(p=0.1095)$. Only refrigerated storage time had a significant effect on the degree of $\%$ WSN $(\mathrm{p}<0.0001)$. An additional analysis was performed where the control data was eliminated, which allowed for a factorial design. Similarly, these results did not show any evidence for differences between heat treatments; only storage time had a significant effect on the degree of \%WSN $(\mathrm{p}<0.0001)$ (Appendix E).

The statistical power of this study was calculated using Minitab 16.1.1 and was found to be 99.13 percent. The high statistical power is attributed mainly to the large total sample size. The power indicates that the experiment was sure to detect a 1.56 percent maximum difference in \%WSN (Appendix H). For the additional analysis mentioned above, the statistical power was 99.96 percent. The experiment was sure to detect a 1.81 percent maximum difference in \%WSN (Appendix I). Therefore, it is concluded that the differences in \%WSN cannot be attributed to the treatments; only storage time had a significant effect on the extent of secondary proteolysis. It is also important to mention that the data did not violate any ANOVA assumptions as indicated in Figure 29 (Appendix D).

Though there has not been literature examining the effects of additional heat treatments like the one imposed in this study, current literature has looked at the effects of altering cooking and stretching temperatures. As mentioned in Section 2.4.4, it was learned through these studies that while increasing the temperatures of both processes retarded $\alpha_{\mathrm{s} 1}-\mathrm{CN}$ breakdown, refrigerated storage time had a greater influence on proteolytic activity in Mozzarella cheese. Thus, the results in this study are similar to that of previous research. 
The following bar graph (Figure 20) depicts the evolution of water-soluble nitrogen values per total nitrogen during refrigerated storage time for all string cheese samples in this study. There were no significant differences between the treatments levels since treatment did not have a significant effect on the \%WSN. However, trends of treatment levels can still be observed and will be discussed further.

Overall, the \%WSN for control string cheese increased during refrigerated storage time. At the final time point of 172 days after treatment, the control cheese had its highest \%WSN value. 172 days after treatment is equivalent to one month after the string cheeses' expiration date. Thus it was expected that the \%WSN would reflect a high value after the cheeses' marked shelf life due to extensive proteolysis.

When examining the $\% \mathrm{WSN}$ for the lower heat treatments of $55^{\circ} \mathrm{C}$ for 30 seconds, $55^{\circ} \mathrm{C}$ for 60 seconds, and $75^{\circ} \mathrm{C}$ for 30 seconds, it was generally noticed that the $\%$ WSN values were similar to or even higher than that of the control samples until the last time point of 172 days after treatment. It is possible that the treatments of string cheese samples with comparable results to the control were insufficient in inactivating residual coagulant and/or intracellular enzymes in the string cheese during the earlier sampling dates. At the final time point of 172 days after treatment, all treated samples had lower \%WSN values than the control. This demonstrates the possibility that the treatments were most effective during a longer storage period.

Also noticed was that the string cheese treated at higher heat treatments, such as $75^{\circ} \mathrm{C}$ for 60 seconds, $95^{\circ} \mathrm{C}$ for 30 seconds, and $95^{\circ} \mathrm{C}$ for 60 seconds may have experienced more complete inactivation of the coagulant or intracellular enzyme than that of the control and less severe treatments, explaining the lower \%WSN throughout storage 
time. Of course, there were several occasions that showed the \%WSN values for these treated string cheeses were higher than the control. This again could be attributed to human error when preparing the WSN extract, human error during Kjeldahl analysis, or inherent variation in the string cheese samples. It is also possible that the treatments take a longer amount of time to become effective. When looking at days 49, 91, and 172 after treatment, the same higher treated samples had lower \%WSN values when compared to the control.

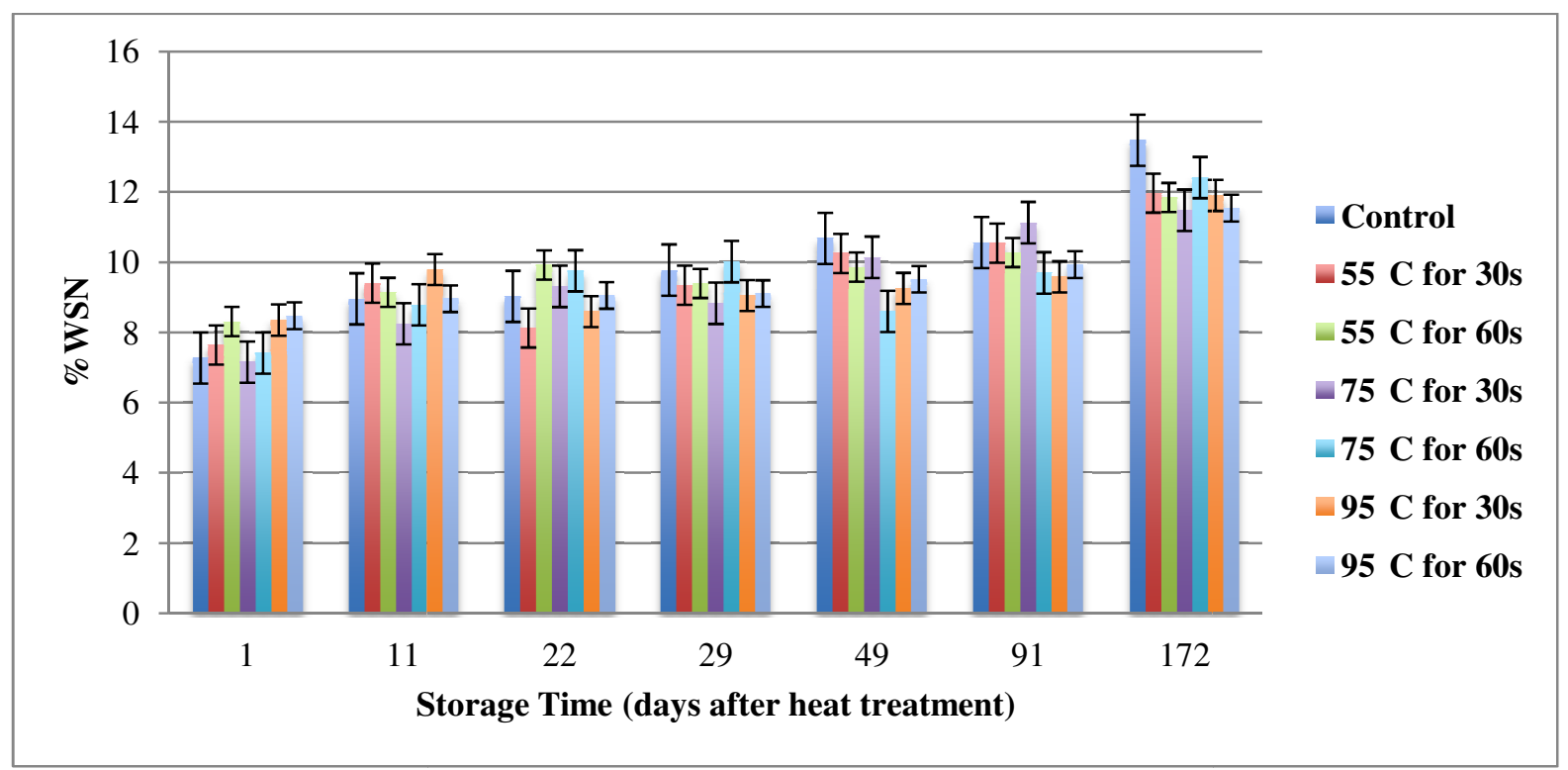

Figure 20: Evolution of water-soluble nitrogen values per total nitrogen (\%WSN) during storage time after treatment at $4^{\circ} \mathrm{C}$ of all treated string cheese for the average of both batches. Error bars represent standard error for each sample.

Closer examination of \%WSN results is depicted in Figure 21. With the elimination of a few data points, it is easier to determine the threshold for when treatment appears effective.

As explained earlier, generally the string cheese treated at $55^{\circ} \mathrm{C}$ for 60 seconds seemed to have similar or higher \%WSN values when compared to the control, as evident in Figure 20. The string cheese treated at $55^{\circ} \mathrm{C}$ for 60 seconds had slightly higher $\%$ WSN when compared to the control from days 1 to 22 after heat treatment. From days 29 to 
172 after heat treatment, the string cheese had slightly lower \%WSN when compared to that of the control.

At the treatment level of $75^{\circ} \mathrm{C}$ for 30 seconds, the $\%$ WSN levels of the string cheeses were generally lower than that of the control with a few exceptions. In Figure 21, the \%WSN of string cheese treated at this level was similar or lower than that of the control from days 1 to day 49 after treatment. At day 91 after heat treatment, the \%WSN value was higher than that of the control. At the final time point of 172 days after treatment, the \%WSN value was much lower than that of the control. Any unusual discrepancies could be owed to human error when preparing the WSN extract, human error during Kjeldahl analysis, and/or inherent variation in the string cheese samples. Although the trend for this treatment level was not very clear, the \%WSN values were lower than the control for most of the time points. More importantly, the \%WSN levels were lower than that of the control at the final time point. This hints at a decrease in secondary proteolysis from a prolonged shelf life due to this treatment level.

The last treatment level to examine is the most severe treatment of $95^{\circ} \mathrm{C}$ for 60 seconds. Out of all of the treatment levels, this one seemed to be the most effective in lowering the degree of secondary proteolysis. Figure 21 shows that the level of \%WSN was only slightly higher than that of the control for day 1 post heat treatment. At days 11 and 22 after heat treatment, the $\%$ WSN value was similar to that of the control. At all remaining days after heat treatment, the \%WSN values were lower than that of the control. Again, this hints at a decrease in secondary proteolysis from a prolonged shelf life due to this treatment level. It is important to mention that any unusual results could 
be due to human error when preparing the WSN extract, human error during Kjeldahl analysis, and/or inherent variation in the string cheese samples.

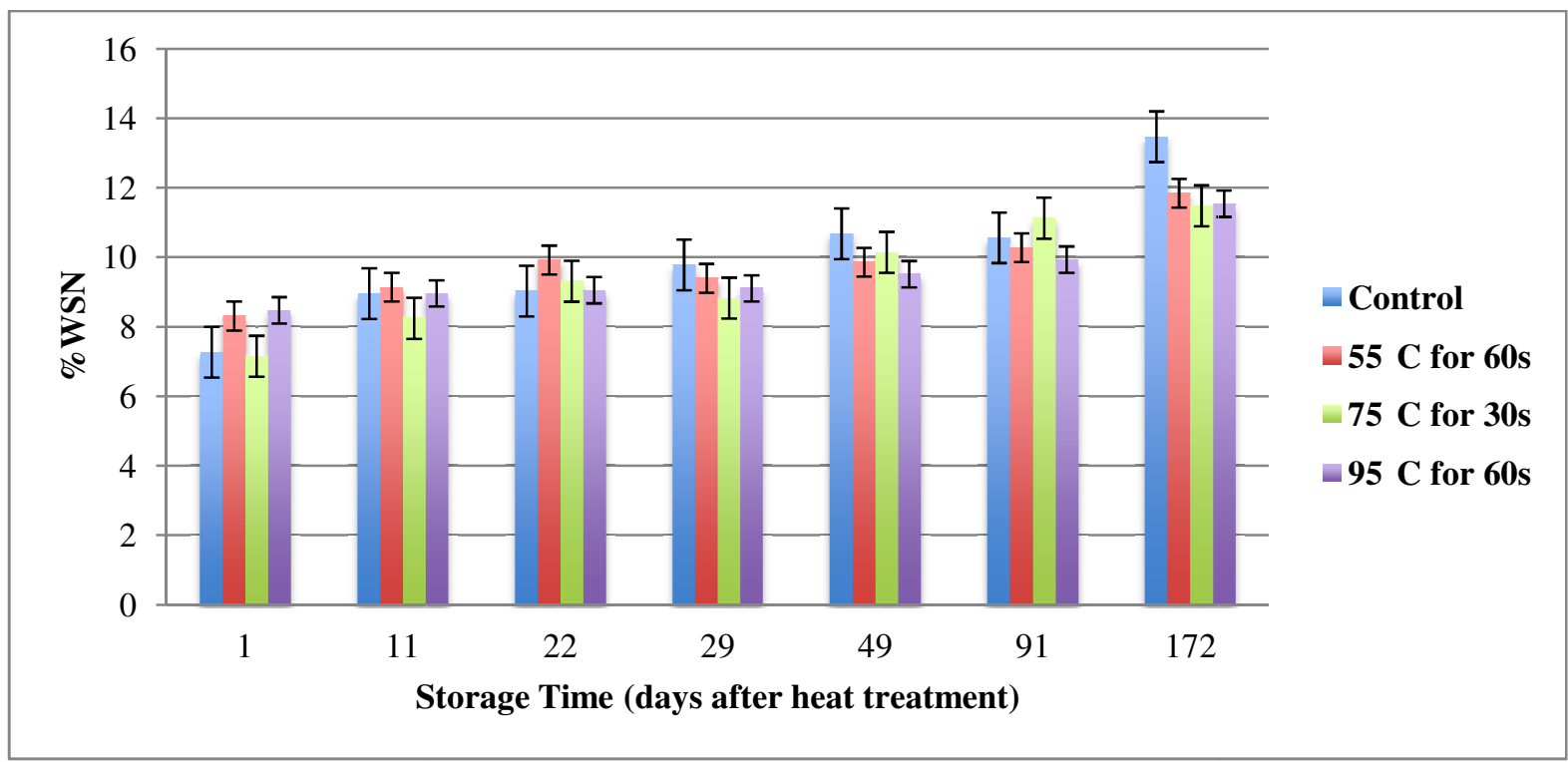

Figure 21: Evolution of water-soluble nitrogen values per total nitrogen (\%WSN) during storage time after treatment at $4^{\circ} \mathrm{C}$ of control, $55^{\circ} \mathrm{C}$ for $60 \mathrm{~s}, 75^{\circ} \mathrm{C}$ for $30 \mathrm{~s}$, and $95^{\circ} \mathrm{C}$ for 60 s treated string cheese for the average both batches. Error bars represent standard error for each sample.

As mentioned earlier, both Figures 20 and 21 illustrate that at the final time point of 172 days after treatment, all treated samples reflected a lower \%WSN value than that of the control. This result suggests that the treatments may have their greatest impact on proteolysis during a longer storage study.

Figure 22 depicts the evolution of water-soluble nitrogen values per total nitrogen during refrigerated storage time for the control and string cheese samples treated at $95^{\circ} \mathrm{C}$ for 60 seconds. Least squares trend lines were applied to both sets of data to predict the rate that \%WSN would increase beyond the storage period used in this study. It was noticed that the slope of the trend line for the control is steeper than slope of the trend line for the string cheese treated at $95^{\circ} \mathrm{C}$ for 60 seconds. Though inconclusive, it is 
possible that at even later times during shelf life, a significant relationship between the treatment and extent of proteolysis may be reached.

It is also possible that treatments at different temperature and time combinations would have resulted in a significant relationship between the treatment and the degree of proteolysis. Prior to this study, a preliminary pilot study was conducted using higher temperature and longer time combinations for treatment levels. The treatment levels were $75^{\circ} \mathrm{C}$ for 45,50 , and 55 minutes, $85^{\circ} \mathrm{C}$ for 55,60 , and 65 minutes, and $95^{\circ} \mathrm{C}$ for 65,70 , and 75 minutes. The longer treatment times were applied to ensure the internal temperature of the cheese was the same as the water bath's temperature. The control consisted of untreated string cheese. The results of the pilot study showed that there was a significant relationship between the interaction of the treatments and storage time and proteolysis $(\mathrm{p}<0.027)$. However, the treatments caused adverse effects on the string cheese's color and texture. The cheese turned from its off-white, creamy color to dark yellow. The texture also became brittle with no stringability. 


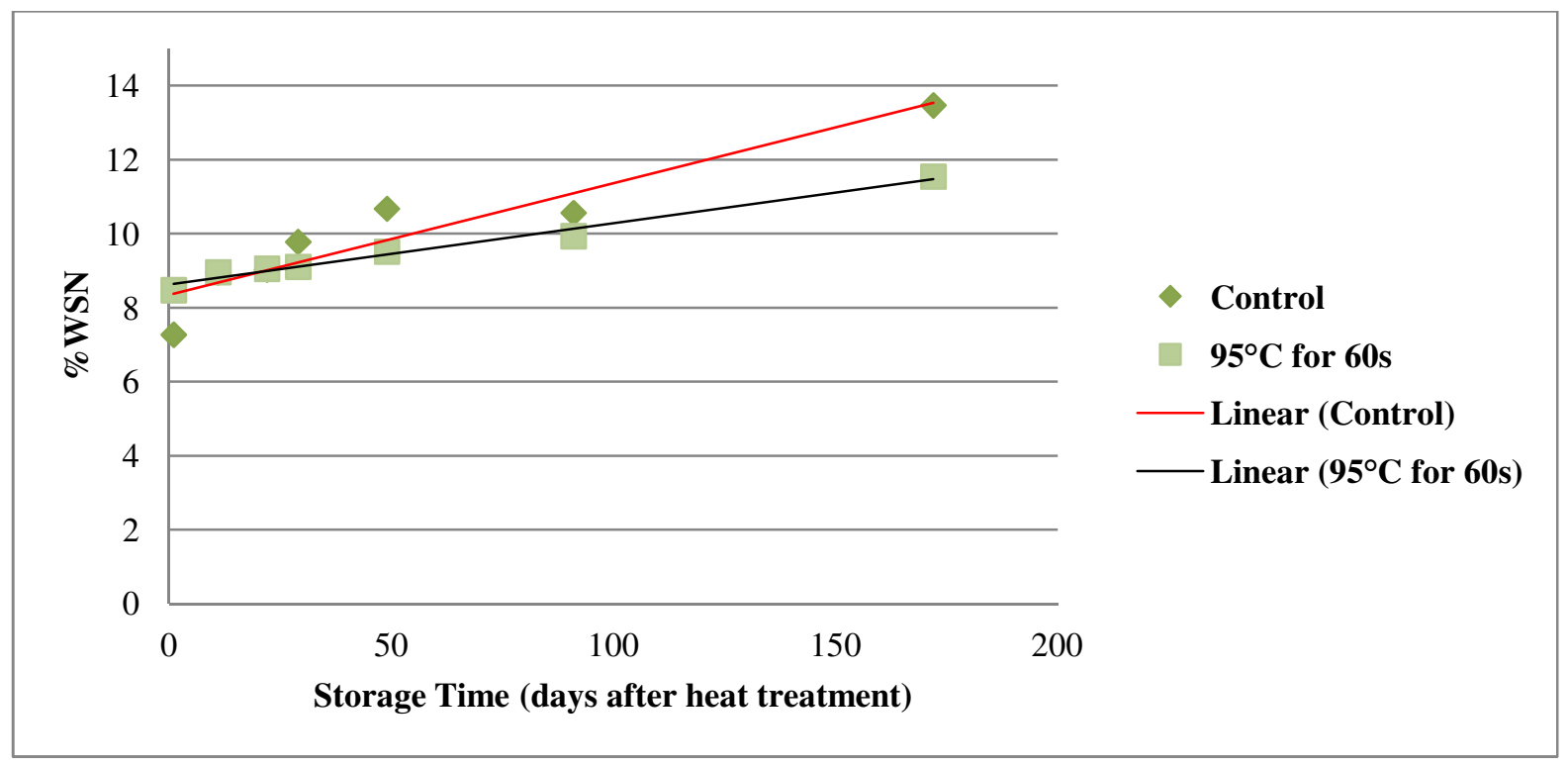

Figure 22: Evolution of water-soluble nitrogen values per total nitrogen (\%WSN) during storage time after treatment at $4^{\circ} \mathrm{C}$ of control and $95^{\circ} \mathrm{C}$ for $60 \mathrm{~s}$ treated string cheese for the average of all replicates of both batches.

\subsection{Texture}

The texture of the string cheese was evaluated over the duration of refrigerated storage as discussed in Section 3.7.1. The data was analyzed using the "Ordinal Logistic Fit” command in JMP Pro 10 (Appendix F).

\subsubsection{Stringability Analysis}

At $\alpha=0.05$, there was no evidence that the post manufacture heat treatments had a significant effect on the amount of stringiness in the string cheese samples during storage time $(\mathrm{p}=0.1738)$. There was also no significant interaction between treatment and storage time $(\mathrm{p}=0.2727)$. Only refrigerated storage time had a significant effect on the string cheeses' stringability $(\mathrm{p}<0.0001)$. Consequently, it is concluded that the differences in stringiness cannot be attributed to the treatments; only storage time had a significant effect. An additional analysis was performed where the control data was eliminated, which allowed for a factorial design. Similarly, these results did not show any 
evidence for differences between heat treatments; only storage time had a significant effect on the stringability rating $(\mathrm{p}<0.0001)$ (Appendix $\mathrm{G})$.

The following bar graph (Figure 23) shows the ratings of stringability given to all of the untreated and treated string cheeses over the duration of the study. As mentioned in Section 2.3.9, the texture of Mozzarella cheese should improve in the first one to three weeks of ripening time. Since the treatment was applied six days after the manufacturing date, it was expected that the optimal stringiness would be captured throughout the shelf life. Section 2.2.7 and 2.3.9 also discussed the softening of cheese during extensive ripening time. This is depicted in the bar graphs since there were lower scores in the later time points of storage than in the beginning. This suggests that there was a positive correlation between softening of cheese and ripening time. This direct relationship was coincidentally observed as the \%WSN values for all string cheese samples increased during storage time (see Section 4.3.1). Though literature has not connected secondary proteolysis with textural changes, it is plausible to speculate that there exists an association since secondary proteolysis is a result of further breakdown of primary proteolysis.

For the average of both batches, there were higher ratings for stringability on days 1 to 49 after heat treatment. This was expected since Mozzarella cheese develops its optimal texture within this time period. This also means that the treatment did not have immediate, negative effect on the texture of the cheese. There was overall very good stringability throughout the study until 91 and 172 days after heat treatment. Most of the scores assigned to the control and treated string cheese samples prior to these days were either three or four. At the last two sampling dates, there were lower scores of one or two 
assigned to some of the string cheese samples. The string cheese treated at $95^{\circ} \mathrm{C}$ for 30 seconds was rated unusually poor on day 22 after heat treatment. This could be due to human error when conducting the study and/or inherent variations in the string cheese samples. Also worth noting is that the heat treatment times of the string cheeses were applied so that just the surface layer of the cheeses achieved the targeted temperatures of $55^{\circ} \mathrm{C}, 75^{\circ} \mathrm{C}$, and $95^{\circ} \mathrm{C}$ (see Section 3.3). Since the stringability analysis was performed using the observation of the interior of the cheese, it is possible that there was no clear association between the heat treatments and texture because the string cheeses' internal temperatures did not reach the targeted temperatures.

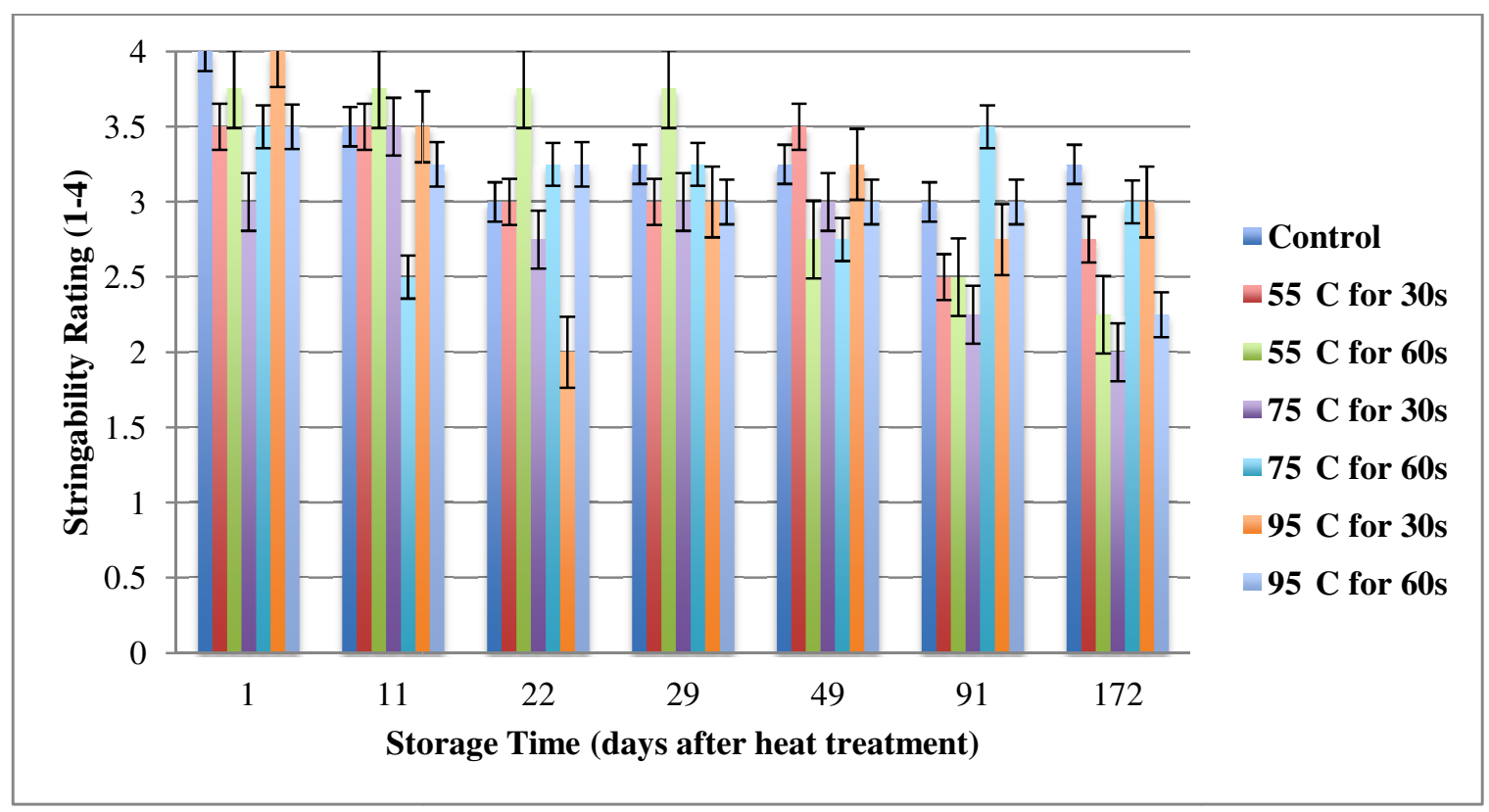

Figure 23: Effect of different levels of post manufacture heat treatment on stringability of string cheese during refrigerated storage at $4^{\circ} \mathrm{C}$ for the average of both batches. Error bars represent standard error for each sample.

There seemed to be no distinct trend of stringability for each of the treatments, as there were consecutively low and then high ratings during storage time. This makes it difficult to assess which treatments may have had noticeably greater effects on 
stringability. However, it is worth mentioning that there were several isolated cases at 11 through 91 days after treatment where at least one of the heat treated string cheeses had a higher stringability rating when compared to the control. This finding shows the potential for post manufacture heat treatments to improve the stringy texture of string cheese over storage time. Perhaps it is also possible that if the storage time of the study were extended, then there may have been significant effects of the heat treatment on the stringability rating.

Although the statistical analysis did not show that batch had a significant effect on stringability as a block, it was noticed that there were discrepancies in the compositional analysis between and within batches of string cheese (see Section 4.1). String cheese from the same batch should technically have a homogenous composition since each cheese stick comes from the same initial curd mass. This was not the case in this study as there were some string cheese samples with high salt and low moisture contents within the second batch; this result could be due to an uneven amount of time that the cheese sticks spent in the brine tank. Similarly, one possible reason that the second batch of cheese had a higher average salt content than the first batch is that the cheese sticks from the second batch spent more time in the brine tank. If the string cheese samples used in this study had less variability in composition, then it is possible that the heat treated cheeses could have shown significant differences in stringability rating when compared to the control. 


\subsection{CONCLUSIONS AND SIGNIFICANCE}

The main objective of this thesis was to examine the effects that a post manufacture thermal dip treatment of commercial string cheese would have on its proteolytic activity. It was originally hypothesized that a decrease in proteolysis with post manufacture heat treatment would allow for the string cheese to maintain optimal stringy texture beyond current shelf-life standards of four months.

It was learned through the study of electrophoretograms that the heat treatments did not have a clear effect on the extent of primary proteolysis. At 172 days after treatment or one month past the expiration date of the string cheese, $\beta$ - $\mathrm{CN}$ did not decrease due to the treatment levels. This was expected to happen since Mozzarella and other types of cheeses that undergo high heat processing tend to have higher plasmin activity. The degree of $\alpha_{\mathrm{s} 1}-\mathrm{CN}$ breakdown was only slightly less intense in the highest heat treatment than in the control and other less severely heat-treated string cheeses in three out of four replicates. Therefore, the heat treatments had just a small effect on lessening the extent of $\alpha_{\mathrm{s} 1}$-CN degradation by qualitative observations.

Analysis of secondary proteolysis revealed that there were no significant differences in \%WSN in the string cheeses due to the thermal treatment levels. There was also no significant interaction between treatment and storage time. Only refrigerated storage time had a significant effect on secondary proteolysis. However, it was observed that at the final time point of 172 days after heat treatment, all treated string cheeses had a lower \%WSN when compared to the control. This suggests that an extension of the storage period may be able to show that the heat treatments could have a significant effect on secondary proteolysis. 
Analysis of the string cheeses' stringability also showed that only storage time had a significant relationship to the amount of stringy texture. There was no evidence that the treatment levels had a significant effect on the texture of string cheese. There was also no significant interaction between treatment and storage time. Nevertheless, this study was successful in reaffirming a positive correlation between time and loss of stringability in string cheese. It was also learned that there were isolated cases at several time points of the study where at least one heat treated cheese had a higher stringability rating than the control. These occurrences lead to the possibility that the heat treatments did have some influence on the texture of string cheese though the differences were not detectable at a significant level.

This study delivers preliminary information for future researchers investigating the effect of a post cheese manufacture thermal treatments on proteolysis. With slight modifications of the experimental design, it is possible that a certain combination of temperature and time for thermal treatment could significantly lessen the degree of proteolysis. It is also plausible to explore an extension of the storage time to see if the treatments would have a significant effect on the amount of proteolysis at a later shelf life. These capabilities have the opportunity to benefit both string cheese manufacturers and consumers. 


\subsection{DIRECTIONS FOR FUTURE RESEARCH}

Further research of the relationship between a post cheese manufacture thermal dip treatment and the extent of proteolysis would improve the understanding that an additional heat treatment could have on the prospect of extending shelf life of string cheese. Potential research directions are as follows:

1. Investigate the effects of extending the storage period of the study to see if thermal treatments have a significant relationship to the degree of proteolysis at a later time in shelf life

2. Explore different temperature and time combinations for post cheese manufacture thermal dip treatments and their effects on the extent of proteolysis

3. Investigate similar study with Mozzarella loaves to prolong shelf life for potential benefit to the pizza industry

4. Investigate post cheese manufacture thermal dip treatment effects on composition of string cheese

5. Quantify residual coagulant, plasmin activity, and intracellular enzymes from starter culture lysis to determine source and amount of contribution to proteolysis in string cheese

6. Investigate similar study with string cheese manufactured by direct acidification so all enzymatic activity from starter culture would be eliminated

7. Investigate other employable post cheese manufacture treatments such as microwave heating and their effects on extent of proteolysis 


\subsection{REFERENCES}

Andrews, A. T. (1983). Proteinases in bovine milk and their action on caseins. Journal of Dairy Research, 50, 45-55.

Anderson, P. (1996, September). Cheese in all the right places. Dairy Foods, 97-99.

Anonymous. (2010, March). Natural and specialty cheeses: The U.S. market and a global perspective. Packaged Facts.

Anonymous. (2012, November). Snapshot: String cheese. Dairy Management Inc.

Anonymous. (2013a). Chy-Max ® M. Retrieved February 5, 2013, from http://www.chrhansen.com/products/product-areas/enzymes/our-products/coagulants/chy-maxr-m.html.

Anonymous. (2013b). Original Armenian string cheese. Retrieved February 8, 2013, from http://www.karlacti.com/Armenian-String-Cheeses.php.

[AOAC] Association of Official Analytical Chemists. 2005. Official Methods of Analysis. $18^{\text {th }}$ ed. AOAC, Gaithersburg, MD.

Barry, J. G. and Donnelly, W. J. (1980). Casein composition studies 1. The composition of casein from Fresian herd milks. Journal of Dairy Research, 47, 71-82.

Blakesley, R. W. and Boezi, J. A. (1977). A new staining technique for proteins in polyacrylamide gels using Coomassie Brilliant Blue G250. Analytical Biochemistry, 82, $580-582$.

Brooks, D. W. (2013). Recombinant Chymosin. Retrieved February 5, 2013, from http://dwb.unl.edu/Teacher/NSF/C08/C08Links/www.fst.rdg.ac.uk/courses/fs560/topic1/t $1 \mathrm{~g} / \mathrm{t} 1 \mathrm{~g} . \mathrm{htm}$.

Brothersen, C. (1986). Application of external pH control in the manufacture of Italian cheese starter, Pages 6-24 in Proc. $23^{\text {rd }}$ Annual Marschall Italian Cheese Sem., Madison, WI.

Buragas, A. (2006). Technology transforms string cheese into a convenient snack. Retrieved January 12, 2013, from http://www.cheesemarketnews.com/articlearch/cheese/31mar06_02.html.

Choisy, C., Desmazeaud, M., Gripon, J. C., Lamberet, G., and Lenoir, J. (2000). The biochemistry of ripening. Pages 82-151 in Cheesemaking from science to quality assurance $2^{\text {nd }}$ ed. Eck, A., Gillis, J. C. (Eds.) Lavoisier Publishing, France.

Cortes-Martinez, E., Schroeder, A., Wolfschoon, A., Schmid, T., and Mehnert, D. Mozzarellatype string cheese product. U.S. Patent Application No. 11/076,349, Publication No. 2005/0208193 (published 22 Sept. 2005). 
Cortez, M. A. S., Furtado, M. M., Gigante, M. L. and Kindstedt, P. S. (2008). Effect of pH on characteristics of low-moisture Mozzarella cheese during refrigerated storage. Journal of Food Science, 73, 443-448.

Costabel, L., Pauletti, M. S., and Hynes, E. (2007). Proteolysis in Mozzarella cheeses manufactured by different industrial processes. Journal of Dairy Science, 90, 2103-2112.

Creamer, L. K. (1976). Casein proteolysis in Mozzarella-type cheese. New Zealand Journal of Dairy Science and Technology, 11, 130-131.

Creamer, L. K., and Olson, N. F. (1982). Rheological evaluation of maturing Cheddar cheese. Journal of Food Science, 47, 631-646.

De Rham, O. and Andrews, A. T. (1982). The role of native milk proteinase and its zymogen during proteolysis in normal bovine milk. New Zealand Journal of Dairy Science and Technology, 15, 99-108.

Delgado, F. J., González-Crespo, J., Cava, R., and Ramirez, R. (2011). Proteolysis, texture and colour of a raw goat milk cheese throughout the maturation. European Food Research and Technology, 233, 483-488.

Eigel, W. N., Butler, J. E., Ernstrom, C. A., Farrell, Jr., H. M., Harwalkar, V. R., Jenness, R., and Whitney, M. R. (1984). Nomenclature of proteins of cow's milk: Fifth revision. Journal of Dairy Science, 67, 1599.

Everett, D. W. and Auty, M. A. E. (2008). Cheese structure and current methods of analysis. International Dairy Journal, 18, 759-773.

Farkye, N. Y. (1995). Contribution of milk-clotting enzymes and plasmin to cheese ripening. Advances in Experimental Medicine and Biology, 367, 195-207.

Farkye, N. Y. and Fox, P. F. (1990a). Objective indices of cheese ripening. Trends in Food Science and Technology, 37-40.

Farkye, N. Y. and Fox, P. F. (1990b). Observations on plasmin activity in cheese. Journal of Dairy Research, 57, 412-418.

Farkye, N. Y., Kiely, L. J., Allhouse, R. D., and Kindstedt, P. S. (1991b). Proteolysis in Mozzarella cheese during refrigerated storage. Journal of Dairy Science, 74, 1433.

Farkye, N. Y. and Landkammer, C. F. (1992). Milk plasmin activity influence on Cheddar cheese quality during ripening. Journal of Food Science, 57, 622-639.

Feeney, E. P., Guinee, T. P. and Fox, P. F. (2002). Effect of pH and calcium concentration on proteolysis in Mozzarella cheese. Journal of Dairy Science, 85, 1646-1654. 
Fox, P. F. (1988). Rennets and their action in cheese manufacture and ripening. Biotechnology and Applied Biochemistry, 10, 522-535.

Fox, P. F. (1989). Proteolysis during cheese manufacture and ripening. Journal of Dairy Science, $72,1379-1400$.

Fox, P. F. (1970). Influence of aggregation on the susceptibility of casein to proteolysis. Journal of Dairy Research, 37, 173-180.

Fox, P. F., Guinee, T. P., Cogan, T. M., McSweeney, P. L. H. (2000). Cheese as a food ingredient. Pages 452-483 in Fundamentals of cheese science. Aspen Publishers, Gaithersburg, MD.

Fox, P. F. and Law, J. (1991). Enzymology of cheese ripening. Food Biotechnology, 5, 239-262.

Ganesan, B., Irish, D. A., Brothersen, C., and McMahon, D. J. (2012). Evaluation of microbial survival post-incidence on fresh Mozzarella cheese. Journal of Dairy Science, 95, 68916896.

Garnot, P. (1985). Heat stability of milk clotting enzymes, technological consequences. Pages 27 in Milk clotting enzymes. Bulletin no. 194. International Dairy Federation, Brussels, Belgium.

Garnot, P. and Mollé, D. (1987). Heat stability of milk clotting enzymes in conditions encountered in Swiss cheese-making. Journal of Food Science, 52, 75-78.

Grufferty, M. B. and Fox, P. F. (1988a). Milk alkaline proteinase. Journal of Dairy Research, 55, 609-630.

Grufferty, M. B. and Fox, P. F. (1988b). Factors affecting the release of plasmin activity from casein micelles. New Zealand Journal of Dairy Science and Technology, 23, 153-163.

Guerrero-Legarreta, I. and Hui, Y. H. (2010). Thermal processing. Pages 435-448 in Handbook of Poultry Science and Technology. Vol. 2. Guerrero-Legarreta, I. (Ed.). John Wiley and Sons, Inc., Hoboken, NJ.

Guinee, T. P. (2004). Salting and the role of salt in cheese. International Journal of Dairy Technology, 57, 99-109.

Guinee, T. P., Feeney, E. P., Auty, M. A., Fox, P. F. (2002). Effect of pH and calcium concentration on some textural and functional properties of Mozzarella cheese. Journal of Dairy Science, 85, 1655-1669. 
Hayes, M. G., Oliveira, J. C., McSweeney, P. L. H., and Kelly, A. L. (2002). Thermal inactivation of chymosin during cheese manufacture. Journal of Dairy Research, 69, 269279.

Holmes, D. G., Duersch, J. W., and Ernstrom, C. A. (1977). Distribution of milk-clotting enzymes between curd and whey, and their survival during Cheddar cheese making. Journal of Dairy Science, 60, 862-869.

Hooi, R., Barbano, D. M., Bradley, R. L., Budde, D., Bulthaus, M., Chettiar, M., Lynch, J., and Reddy, R. (2004). Chemical and physical methods. Pages 363-536 in Standard methods for the examination of dairy products. Victor Graphics, Inc., Baltimore, MD.

Hull, R. R., Roberts, A. V., and Mayes, J. J. (1983). The association of Lactobacillus casei with soft body defect in commercial Mozzarella cheese. Australian Journal of Dairy Technology, 38, 78-80.

Jana, A. H. and Mandal, P. K. (2011). Manufacturing and quality of Mozzarella cheese: A review. International Journal of Dairy Science, 6, 199-226.

Justesen, S. F. L., Lamberth, K., Nielsen, L. B., Schafer-Nielsen, C., and Buus, S. (2009). Recombinant chymosin used for exact and complete removal of a prochymosin derived fusion tag releasing intact native target protein. Protein Science, 18, 1023-1032.

Kaminogawa, S., Mizobuchi, H., and Yamauchi, K. (1972). Comparison of bovine milk protease with plasmin. Agricultural and Biological Chemistry, 36, 2163-2167.

Kaminogawa, S. and Yamauchi, K. (1972). Acid protease of bovine milk. Agricultural and Biological Chemistry, 36, 2351-2356.

Kimura, T., Sagara, Y., Fukushima, M., and Taneya, S. (1992). Effect of pH on the submicroscopic structure of string cheese. Milchwissenschaft, 47, 547-552.

Kindstedt, P. S. (1993). Mozzarella and pizza cheese. Pages 337-362 in Cheese: Chemistry, Physics and Microbiology. Vol. 2: Major Cheese Groups. $2^{\text {nd }}$ Ed. Fox, P. F. (Ed.). Aspen Publishers, New York, NY.

Kindstedt, P. S., Kiely, L. J., and Gilmore, J. A. (1992). Variation in composition and functional properties within brine salted Mozzarella cheese. Journal of Dairy Science, 75, 29132921.

Kindstedt, P. S., Rowney, M., and Roupas, P. (1999). Technology, biochemistry and functionality of pasta filata/pizza cheese. Pages 193-221 in Technology of Cheesemaking. $1^{\text {st }}$ ed. Law, B. A. (Ed.). Taylor and Francis, Inc. 
Kindstedt, P. S., Zielinksi, A., Almena-Aliste, M., Ge, C. (2001). A post-manufacture method to evaluate the effect of $\mathrm{pH}$ on Mozzarella cheese characteristics. Australia Journal of Dairy Technology, 56, 202-207.

Korycka-Dahl, M., Ribadeau Dumas, B., Chene, N., and Martal, J. (1983). Plasmin activity in milk. Journal of Dairy Science, 66, 704-711.

Kosikowski, M. F. and Mistry, V. V. (1997). Cheese with eyes. Pages 108-117 in Cheese and fermented milk foods. Vol. 2: Procedures and analysis. $3^{\text {rd }}$ ed. Kosikowski, M. F., Mistry, V. V. (Eds.). F. V. Kosikowski, LLC, Westport, CT.

Kuchroo, C. N. and Fox, P. F. (1982). Soluble nitrogen in Cheddar cheese: Comparison of extraction procedures. Milchwissenschaft, 37, 331-335.

Law, B. A. and Kolstad, J. (1983). Proteolytic systems in lactic acid bacteria. Antonie van Leeuwenhoek, 49, 225-245.

Lawrence, R. C., Creamer, L. K., and Gilles, J. (1987). Texture development during cheese ripening. Journal of Dairy Science, 70, 1748-1760.

Man, C. M. D. and Jones, A. A. (2000). Shelf-life evaluation of foods. Aspen Publishers, Gaithersburg, MD.

Matheson, A. R. (1981). The immunochemical determination of chymosin activity in cheese. New Zealand Journal of Dairy Science and Technology, 16, 33-41.

Mayer, M. (2011, December). String cheese makers tie up sales increase. Dairy Foods, 20.

McCoy, D. R. (1997). Italian type cheeses. Pages 75-83 in Cultures for the Manufacture of Dairy Products. Chr. Hansen, Inc., Milwaukee, WI.

McGoldrick, M., and Fox, P. F. (1999). Intervarietal comparison of proteolysis in commercial cheese. Zeitschrift für Lebensmittel Untersuchung und-Forchung, 208, 90-99.

McMahon, D. J., Fife, R. L., and Oberg, C. J. (1999). Water partitioning in Mozzarella cheese and its relationship to cheese meltability. Journal of Dairy Science, 82, 1361-1369.

McMeekin, T. L., Hipp, N. J., and Groves, M. L. (1959). The separation of the components of $\alpha-$ casein. I. The preparation of $\alpha_{1}$-casein. Archives of Biochemistry and Biophysics, 83, 3543.

Metzger, L. E., Barbano, D. M., and Kindstedt, P. S. (2001). Effect of milk preacidification on low fat Mozzarella cheese: 2. Chemical and functional properties during storage. Journal of Dairy Science, 84, 1348-1356. 
Mullan, W. M. A. (2005). Role of cheese starters. Retrieved February 26, 2013, from http://www.dairyscience.info/index.php/cheese-starters/225-role-of-starters.html.

Mulvihill, D. M., and Fox, P. F. (1980). Proteolysis of $\alpha_{s 1}$-casein by chymosin in dilute $\mathrm{NaCl}$ solutions and in Cheddar cheese. Irish Journal of Food Science and Technology, 4, 1323.

Nip, W. (2004). Manufacture of fermented products. Pages 51-88 in Handbook of Food and Beverage Fermentation Technology. Hui, Y. H. (Ed.). Marcel Dekker, New York, NY.

Oberg, C. J. and Broadbent, J. R. (1993). Thermophilic starter cultures: another set of problems. Journal of Dairy Science, 76, 2392-2406.

O’Mahoney, J. A., Lucey, J., and McSweeney, P. L. H. (2005). Chymosin-mediated proteolysis, calcium solubilization, and texture development during the ripening of Cheddar Cheese. Journal of Dairy Science, 88, 3101-3114.

Park, Y. W. (2001). Proteolysis and lipolysis of goat milk cheese. Journal of Dairy Science, 84, E84-E92.

Persson, J. (2008). Handbook for Kjeldahl Digestion: A recent review of the classical method with improvements developed by FOSS. FOSS, DK-3400 Hilleroed, Denmark, Malmoe, Sweden.

Rank, T. C., Grappin, R., and Olson, N. F. (1985). Secondary proteolysis of cheese during ripening: A review. Journal of Dairy Science, 68, 801-805.

Rankin, S. A., Chen, C. M., and Sommer, D. (2006). Mozzarella and Scamorza cheese. Pages 150.1-150.12 in Handbook of Science, Technology, and Engineering. Vol. 4. Hui, Y. H. (Ed.). CRC Press, Boca Raton, FL.

Rehman, S. and Farkye, N. Y. (2006). Effect of setting pH on the properties of Mozzarella cheese made by direct acidification of whole milk standardized with dry milk protein concentrate. Australian Journal of Dairy Technology, 61, 8-12.

Richardson, B. C. (1983). The proteinases of bovine milk and the effects of pasteurization on their activity. New Zealand Journal of Dairy Science and Technology, 18, 233-245.

Richardson, B. C. and Elston, P. D. (1984). Plasmin activity in commercial caseins and caseinates. New Zealand Journal of Dairy Science and Technology, 19, 63-67.

Rollema, H. S. and Poll, J. K. (1986). The alkaline milk proteinase system: Kinetics and mechanism of heat-inactivation. Milchwissenschaft, 41, 536-540. 
Rulikowska, A., Kilcawley, K. N., Doolah, I. A., Alonso-Gomez, M., Nongonierma, A. B., Hannon, J. A., and Wilkinson, M. G. (2013). The impact of reduced sodium chloride content on Cheddar cheese quality. International Dairy Journal, 28, 45-55.

Sheehan, J. J., and Guinee, T. P. (2004). Effect of pH and calcium level on the biochemical, textural, and functional properties of reduced-fat Mozzarella cheese. International Dairy Journal, 14, 161-172.

Sheehan, J. J., Oliveira, J. C., Kelly, A. L., and McSweeney, P. L. H. (2007). Effect of cook temperature on primary proteolysis and predicted residual chymosin activity of a semihard cheese manufactured using thermophilic cultures. International Dairy Journal, 17, 826-834.

Snoeren, T. H. M. and van Riel, J. A. M. (1979). Milk proteinase, its isolation and action on $\alpha_{\mathrm{s} 2^{-}}$ and $\beta$-casein. Milchwissenschaft, 34, 528.

Somers, J. M. and Kelly, A. L. (2002). Contribution of plasmin to primary proteolysis during ripening of cheese: Effect of milk heat treatment and cheese cooking temperature. Lait, $82,181-191$.

Stadhouders, J. and Hup, G. (1975). Factors affecting bitter flavour in Gouda cheese. Netherlands Milk and Dairy Journal, 29, 335-353.

Taneya, S., Izutsu, T., Kimura, T., and Shioya, T. (1992). Structure and rheology of string cheese. Food Structure, 11, 61-71.

Thomas, T. D. and Pritchard, G. G. (1987). Proteolytic enzymes of dairy starter cultures. FEMS Microbiology Review, 46, 245-268.

Tunick, M. H., Malin, E. L., Smith, P. W., and Holsinger, V. H. (1995). Effects of skim milk homogenization on proteolysis and rheology of Mozzarella cheese. International Dairy Journal, 5, 483-491.

Van Slyke, L. L. and Price, W. V. (1952). Cheese. Orange Judd Publishing Company, New York, NY.

Veloso, A. C. A., Teixeira, N., Peres, A. M., Mendonça, Á., and Ferreira, I. M. P. L. V. O. (2004). Evaluation of cheese authenticity and proteolysis by HPLC and ureapolyacrylamide gel electrophoresis. Food Chemistry, 87, 289-295.

Villanueva-Carvajal, A., Esteban-Chávez, M., Espinoza-Ortega, A., Arriaga-Jordán, C. M., and Dominguez-Lopez, A. (2012). Oaxaca cheese: flavour, texture and their interaction in a Mexican traditional pasta filata cheese. CyTA Journal of Food, 10, 63-70. 
Viotto Chaves, W. H. and Grosso, C. R. F. (1999). Proteolysis and functional properties of Mozzarella cheese as affected by refrigerated storage. Journal of Food Science, 64, 202205.

Visser, S. (1993). Proteolytic enzymes and their relation to cheese ripening and flavor: An overview. Journal of Dairy Science, 76, 329-350.

Winwood, J. (1989). Rennet and rennet substitutes. Journal of the Society of Dairy Technology, $42,1-2$.

Yun, J. J., Barbano, D. M., Kiely, L. J., and Kindstedt, P. S. (1995). Mozzarella cheese: Impact of rod to coccus ratio on chemical composition, proteolysis and functional characteristics. Journal of Dairy Science, 78, 751-760.

Yun, J. J., Barbano, D. M., and Kindstedt, P. S. (1993a). Mozzarella cheese: Impact of coagulant type on chemical composition and proteolysis. Journal of Dairy Science, 76, 3648-3656.

Yun, J. J., Kiely, L. J., Barbano, D. M., and Kindstedt, P. S. (1993b). Mozzarella cheese: Impact of cooking temperature on chemical composition, proteolysis, and functional properties. Journal of Dairy Science, 76, 3664-3673. 


\section{APPENDIX A: Data for Compositional Analysis of String Cheese}

Table 6: Salt Concentration of Commercial String Cheese

\begin{tabular}{|c|c|}
\hline Batch 1 & Salt (\%) \\
\hline 1 & $1.38 \pm 0.01$ \\
\hline 2 & $1.46 \pm 0.01$ \\
\hline 3 & $1.38 \pm 0.01$ \\
\hline 4 & $1.38 \pm 0.01$ \\
\hline 5 & $1.38 \pm 0.01$ \\
\hline 6 & $1.46 \pm 0.01$ \\
\hline 7 & $1.32 \pm 0.01$ \\
\hline 8 & $1.44 \pm 0.00$ \\
\hline 9 & $1.42 \pm 0.01$ \\
\hline 10 & $1.38 \pm 0.01$ \\
\hline & \\
\hline Batch 2 & Salt (\%) \\
\hline 1 & $1.42 \pm 0.01$ \\
\hline 2 & $2.04 \pm 0.01$ \\
\hline 3 & $1.78 \pm 0.01$ \\
\hline 4 & $1.90 \pm 0.01$ \\
\hline 5 & $1.36 \pm 0.00$ \\
\hline 6 & $1.82 \pm 0.01$ \\
\hline 7 & $1.34 \pm 0.01$ \\
\hline 8 & $1.38 \pm 0.02$ \\
\hline 9 & $1.84 \pm 0.00$ \\
\hline 10 & $1.76 \pm 0.00$ \\
\hline &
\end{tabular}

$\mathrm{n}=2$ 
Table 7: Moisture Content of Commercial String Cheese

\begin{tabular}{|c|c|}
\hline Batch 1 & $\begin{array}{c}\text { Moisture } \\
(\%)\end{array}$ \\
\hline 1 & $49.95 \pm 0.00$ \\
\hline 2 & $49.87 \pm 0.00$ \\
\hline 3 & $49.36 \pm 0.01$ \\
\hline 4 & $49.64 \pm 0.00$ \\
\hline 5 & $49.41 \pm 0.01$ \\
\hline 6 & $49.25 \pm 0.01$ \\
\hline 7 & $50.55 \pm 0.01$ \\
\hline 8 & $49.20 \pm 0.01$ \\
\hline 9 & $49.95 \pm 0.00$ \\
\hline 10 & $50.67 \pm 0.00$ \\
\hline Batch 2 & $\begin{array}{c}\text { Moisture } \\
(\%)\end{array}$ \\
\hline 1 & $50.83 \pm 0.01$ \\
\hline 2 & $48.67 \pm 0.02$ \\
\hline 3 & $51.27 \pm 0.00$ \\
\hline 4 & $51.32 \pm 0.00$ \\
\hline 5 & $49.53 \pm 0.00$ \\
\hline 6 & $50.38 \pm 0.01$ \\
\hline 7 & $50.01 \pm 0.00$ \\
\hline 8 & $49.77 \pm 0.00$ \\
\hline 9 & $49.67 \pm 0.00$ \\
\hline 10 & $50.82 \pm 0.00$ \\
\hline
\end{tabular}

$\mathrm{n}=2$ 
Table 8: Fat-on-dry-matter Content of Commercial String Cheese

\begin{tabular}{|c|c|}
\hline Batch 1 & $\begin{array}{c}\text { Fat-on-dry-matter } \\
(\%)\end{array}$ \\
\hline 1 & 29.17 \\
\hline 2 & 32.94 \\
\hline 3 & 31.38 \\
\hline 4 & 30.76 \\
\hline 5 & 33.25 \\
\hline 6 & 30.94 \\
\hline 7 & 30.18 \\
\hline 8 & 32.00 \\
\hline 9 & 33.81 \\
\hline 10 & 29.13 \\
\hline Batch 2 & $\begin{array}{c}\text { Fat-on-dry-matter } \\
(\%)\end{array}$ \\
\hline 1 & 30.94 \\
\hline 2 & 34.12 \\
\hline 3 & 31.67 \\
\hline 4 & 31.57 \\
\hline 5 & 31.43 \\
\hline 6 & 32.70 \\
\hline 7 & 30.19 \\
\hline 8 & 29.30 \\
\hline 9 & 32.97 \\
\hline 10 & 31.75 \\
\hline
\end{tabular}

$\mathrm{n}=1$ 
Table 9: Total Nitrogen Content of Commercial String Cheese

\begin{tabular}{|c|c|}
\hline Batch 1 & Total Nitrogen (\%) \\
\hline 1 & $3.45 \pm 0.02$ \\
\hline 2 & $3.40 \pm 0.04$ \\
\hline 3 & $3.45 \pm 0.01$ \\
\hline 4 & $3.44 \pm 0.03$ \\
\hline 5 & $3.42 \pm 0.01$ \\
\hline 6 & $3.47 \pm 0.01$ \\
\hline 7 & $3.45 \pm 0.02$ \\
\hline 8 & $3.45 \pm 0.02$ \\
\hline 9 & $3.45 \pm 0.00$ \\
\hline 10 & $3.49 \pm 0.01$ \\
\hline & \\
\hline Batch 2 & Total Nitrogen (\%) \\
\hline 1 & $3.55 \pm 0.01$ \\
\hline 2 & $3.44 \pm 0.02$ \\
\hline 3 & $3.49 \pm 0.03$ \\
\hline 4 & $3.45 \pm 0.01$ \\
\hline 5 & $3.50 \pm 0.02$ \\
\hline 6 & $3.43 \pm 0.02$ \\
\hline 7 & $3.50 \pm 0.02$ \\
\hline 8 & $3.52 \pm 0.02$ \\
\hline 9 & $3.41 \pm 0.01$ \\
\hline 10 & $3.53 \pm 0.04$ \\
\hline
\end{tabular}

$n=2$ 
Table 10: $\mathrm{pH}$ of Commercial String Cheese

\begin{tabular}{|c|c|}
\hline Batch 1 & pH \\
\hline 1 & $5.28 \pm 0.00$ \\
\hline 2 & $5.29 \pm 0.00$ \\
\hline 3 & $5.28 \pm 0.00$ \\
\hline 4 & $5.34 \pm 0.00$ \\
\hline 5 & $5.32 \pm 0.00$ \\
\hline 6 & $5.29 \pm 0.00$ \\
\hline 7 & $5.31 \pm 0.00$ \\
\hline 8 & $5.29 \pm 0.00$ \\
\hline 9 & $5.29 \pm 0.00$ \\
\hline 10 & $5.34 \pm 0.00$ \\
\hline & \\
\hline Batch 2 & pH \\
\hline 1 & $5.15 \pm 0.00$ \\
\hline 2 & $5.06 \pm 0.00$ \\
\hline 3 & $5.08 \pm 0.00$ \\
\hline 4 & $5.10 \pm 0.00$ \\
\hline 5 & $5.19 \pm 0.00$ \\
\hline 6 & $5.01 \pm 0.00$ \\
\hline 7 & $5.09 \pm 0.00$ \\
\hline 8 & $5.08 \pm 0.00$ \\
\hline 9 & $5.04 \pm 0.00$ \\
\hline 10 & $5.03 \pm 0.00$ \\
\hline & \\
\hline
\end{tabular}

$\mathrm{n}=2$ 


\section{APPENDIX B: Urea-PAGE Electrophoretograms of String Cheese}

$\begin{array}{llllllll}1 & 2 & 3 & 4 & 5 & 6 & 7 & 8\end{array}$

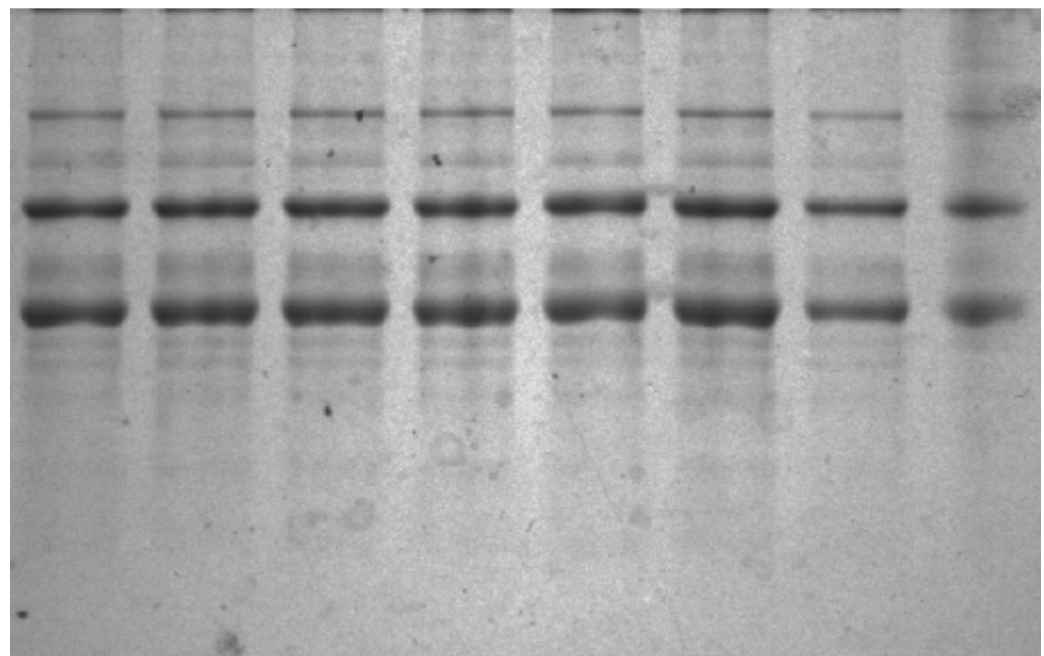

Figure 24: Urea-PAGE electrophoretogram of all treated samples at 1 days after treatment day for the first replicate of the first batch (lane $1=$ control/untreated, lane $2=55^{\circ} \mathrm{C}$ for $30 \mathrm{~s}$, lane $3=55^{\circ} \mathrm{C}$ for $60 \mathrm{~s}$, lane $4=75^{\circ} \mathrm{C}$ for $30 \mathrm{~s}$, lane $5=75^{\circ} \mathrm{C}$ for $60 \mathrm{~s}$, lane $6=95^{\circ} \mathrm{C}$ for $30 \mathrm{~s}$, lane $7=95^{\circ} \mathrm{C}$ for $60 \mathrm{~s}$, lane $8=\mathrm{NaCN}$ standard)

$\begin{array}{lllllllll}1 & 2 & 3 & 4 & 5 & 6 & 7 & 8\end{array}$

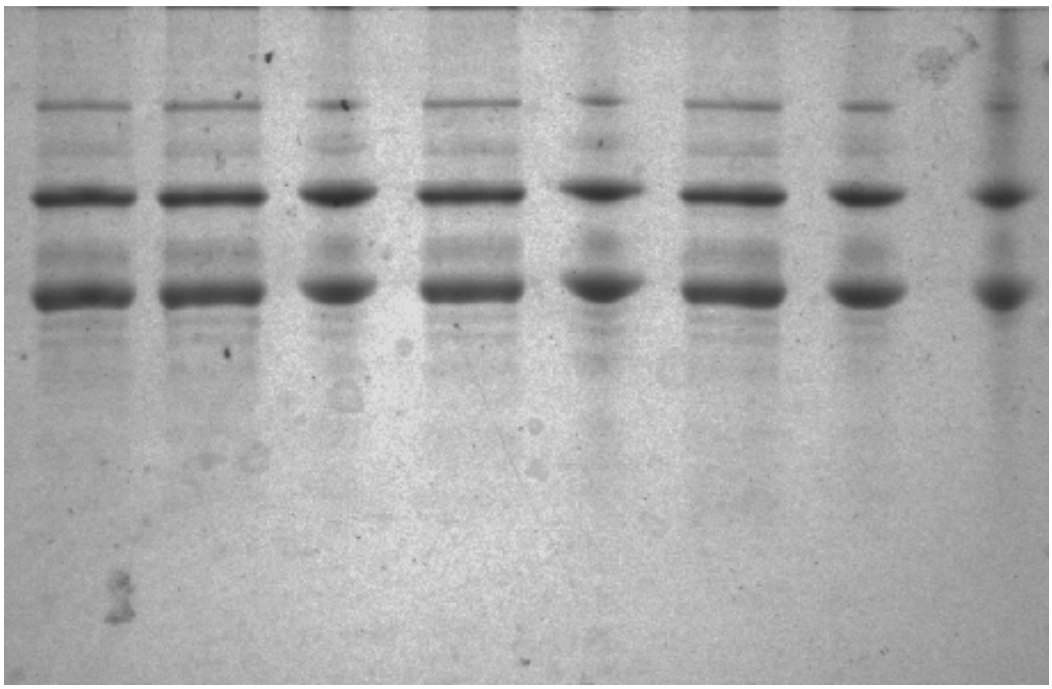

Figure 25: Urea-PAGE electrophoretogram of all treated samples at 1 days after treatment day for the second replicate of the first batch (lane $1=$ control/untreated, lane $2=55^{\circ} \mathrm{C}$ for $30 \mathrm{~s}$, lane $3=55^{\circ} \mathrm{C}$ for $60 \mathrm{~s}$, lane $4=75^{\circ} \mathrm{C}$ for $30 \mathrm{~s}$, lane $5=75^{\circ} \mathrm{C}$ for $60 \mathrm{~s}$, lane $6=95^{\circ} \mathrm{C}$ for $30 \mathrm{~s}$, lane $7=95^{\circ} \mathrm{C}$ for $60 \mathrm{~s}$, lane $8=\mathrm{NaCN}$ standard) 
$\begin{array}{llllllll}1 & 2 & 3 & 4 & 5 & 6 & 7 & 8\end{array}$

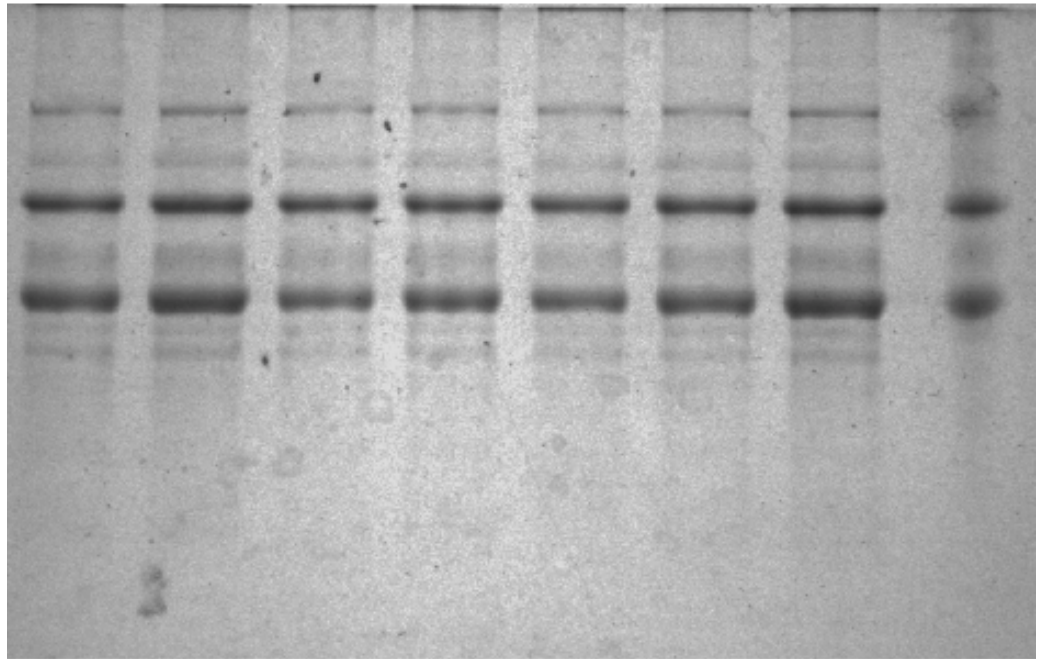

Figure 26: Urea-PAGE electrophoretogram of all treated samples at 1 days after treatment day for the first replicate of the second batch (lane $1=$ control/untreated, lane $2=55^{\circ} \mathrm{C}$ for 30 s, lane $3=55^{\circ} \mathrm{C}$ for $60 \mathrm{~s}$, lane $4=75^{\circ} \mathrm{C}$ for $30 \mathrm{~s}$, lane $5=75^{\circ} \mathrm{C}$ for $60 \mathrm{~s}$, lane $6=95^{\circ} \mathrm{C}$ for $30 \mathrm{~s}$, lane $7=95^{\circ} \mathrm{C}$ for $60 \mathrm{~s}$, lane $8=\mathrm{NaCN}$ standard)

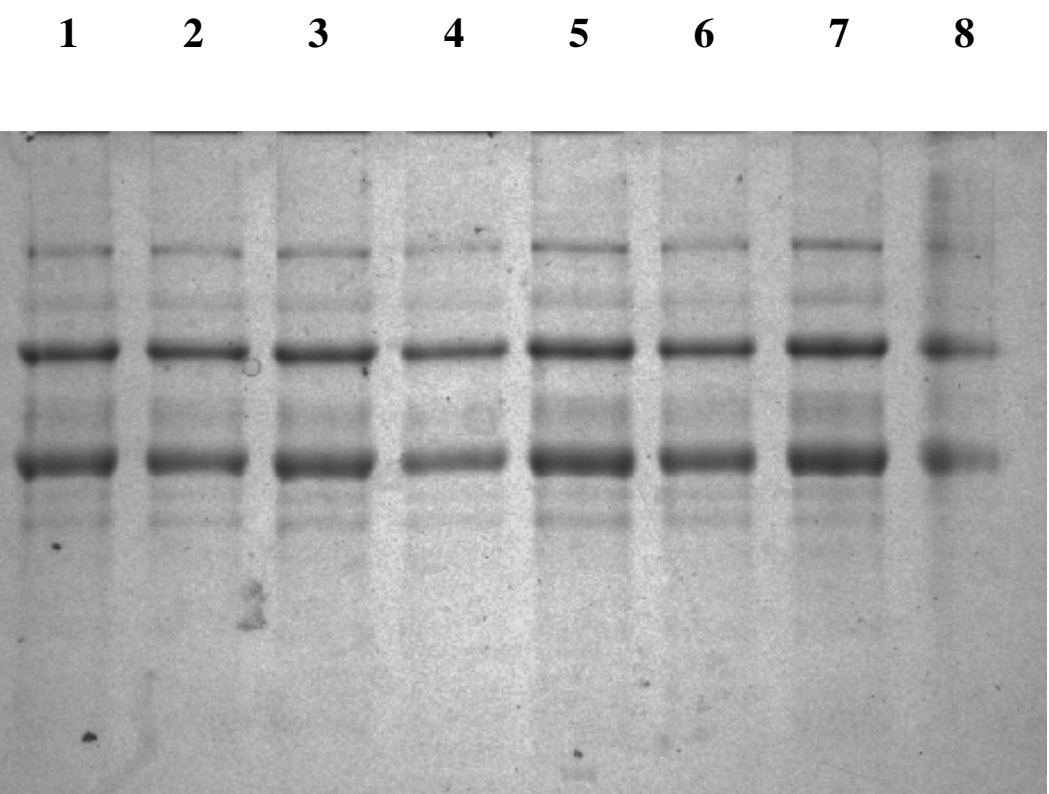

Figure 27: Urea-PAGE electrophoretogram of all treated samples at 1 days after treatment day for the second replicate of the second batch (lane $1=$ control/untreated, lane $2=55^{\circ} \mathrm{C}$ for $30 \mathrm{~s}$, lane $3=55^{\circ} \mathrm{C}$ for $60 \mathrm{~s}$, lane $4=75^{\circ} \mathrm{C}$ for $30 \mathrm{~s}$, lane $5=75^{\circ} \mathrm{C}$ for $60 \mathrm{~s}$, lane $6=95^{\circ} \mathrm{C}$ for $30 \mathrm{~s}$, lane $7=95^{\circ} \mathrm{C}$ for $60 \mathrm{~s}$, lane $8=\mathrm{NaCN}$ standard) 


\section{APPENDIX C: Raw \%WSN Data}

Table 11: Raw \%WSN data for the first replicate of the first batch

\begin{tabular}{|c|c|c|c|c|c|c|c|}
\hline Day & Control & $\begin{array}{c}\mathbf{5 5}^{\circ} \mathbf{C} \text { for } \\
\mathbf{3 0}\end{array}$ & $\begin{array}{c}\mathbf{5 5}^{\circ} \mathbf{C} \text { for } \\
\mathbf{6 0} \mathbf{s}\end{array}$ & $\begin{array}{c}\mathbf{7 5}^{\circ} \mathbf{C} \text { for } \\
\mathbf{3 0} \mathbf{s}\end{array}$ & $\begin{array}{c}\mathbf{7 5}^{\circ} \mathbf{C} \text { for } \\
\mathbf{6 0 s}\end{array}$ & $\begin{array}{c}\mathbf{9 5}^{\circ} \mathbf{C} \text { for } \\
\mathbf{3 0} \mathbf{s}\end{array}$ & $\begin{array}{c}\mathbf{9 5}^{\circ} \mathbf{C} \text { for } \\
\mathbf{6 0 s}\end{array}$ \\
\hline $\mathbf{1}$ & 8.389 & 8.846 & 8.178 & 8.168 & 7.661 & 8.882 & 8.886 \\
\hline $\mathbf{1 1}$ & 8.994 & 9.032 & 8.316 & 8.679 & 7.965 & 9.332 & 8.908 \\
\hline $\mathbf{2 2}$ & 10.305 & 8.854 & 8.826 & 10.410 & 9.454 & 7.457 & 8.313 \\
\hline $\mathbf{2 9}$ & 8.778 & 8.796 & 8.455 & 9.724 & 7.822 & 7.652 & 10.061 \\
\hline $\mathbf{4 9}$ & 8.659 & 10.434 & 10.006 & 10.219 & 8.424 & 8.231 & 9.021 \\
\hline $\mathbf{9 1}$ & 10.199 & 9.556 & 9.858 & 10.762 & 9.928 & 9.694 & 9.539 \\
\hline $\mathbf{1 7 2}$ & 13.516 & 12.553 & 11.918 & 10.038 & 10.931 & 12.263 & 11.141 \\
\hline
\end{tabular}

Table 12: Raw \%WSN data for the second replicate of the first batch

\begin{tabular}{|c|c|c|c|c|c|c|c|}
\hline Day & Control & $\begin{array}{c}\mathbf{5 5}^{\circ} \mathbf{C} \text { for } \\
\mathbf{3 0}\end{array}$ & $\begin{array}{c}\mathbf{5 5}^{\circ} \mathbf{C} \text { for } \\
\mathbf{6 0 s}\end{array}$ & $\begin{array}{c}\mathbf{7 5}^{\circ} \mathbf{C} \text { for } \\
\mathbf{3 0 s}\end{array}$ & $\begin{array}{c}\mathbf{7 5}^{\circ} \mathbf{C} \text { for } \\
\mathbf{6 0 s}\end{array}$ & $\begin{array}{c}\mathbf{9 5}^{\circ} \mathbf{C} \text { for } \\
\mathbf{3 0 s}\end{array}$ & $\begin{array}{c}\mathbf{9 5}^{\circ} \mathbf{C} \text { for } \\
\mathbf{6 0 s}\end{array}$ \\
\hline $\mathbf{1}$ & 8.469 & 7.812 & 10.087 & 7.215 & 9.123 & 8.816 & 8.856 \\
\hline $\mathbf{1 1}$ & 10.069 & 8.915 & 8.787 & 8.823 & 10.382 & 10.317 & 8.649 \\
\hline $\mathbf{2 2}$ & 8.959 & 8.345 & 10.887 & 9.144 & 9.470 & 9.333 & 7.678 \\
\hline $\mathbf{2 9}$ & 9.191 & 8.044 & 10.644 & 9.560 & 10.869 & 10.272 & 9.165 \\
\hline $\mathbf{4 9}$ & 9.514 & 10.164 & 8.513 & 9.635 & 7.907 & 8.414 & 10.195 \\
\hline $\mathbf{9 1}$ & 10.341 & 10.824 & 9.976 & 11.600 & 8.904 & 9.697 & 10.036 \\
\hline $\mathbf{1 7 2}$ & 12.568 & 10.639 & 10.589 & 9.684 & 12.216 & 10.974 & 11.056 \\
\hline
\end{tabular}


Table 13: Raw \%WSN data for the first replicate of the second batch

\begin{tabular}{|c|c|c|c|c|c|c|c|}
\hline Day & Control & $\begin{array}{c}\mathbf{5 5}^{\circ} \mathbf{C} \text { for } \\
\mathbf{3 0 s}\end{array}$ & $\begin{array}{c}\mathbf{5 5}^{\circ} \mathbf{C} \text { for } \\
\mathbf{6 0 s}\end{array}$ & $\begin{array}{c}\mathbf{7 5}^{\circ} \mathbf{C} \text { for } \\
\mathbf{3 0 s}\end{array}$ & $\begin{array}{c}\mathbf{7 5}^{\circ} \mathbf{C} \text { for } \\
\mathbf{6 0 s}\end{array}$ & $\begin{array}{c}\mathbf{9 5}^{\circ} \mathbf{C} \text { for } \\
\mathbf{3 0 s}\end{array}$ & $\begin{array}{c}\mathbf{9 5}^{\circ} \mathbf{C} \text { for } \\
\mathbf{6 0 s}\end{array}$ \\
\hline $\mathbf{1}$ & 6.700 & 6.749 & 6.623 & 6.639 & 6.617 & 7.462 & 7.958 \\
\hline $\mathbf{1 1}$ & 9.176 & 9.486 & 9.472 & 8.392 & 7.426 & 9.381 & 8.690 \\
\hline $\mathbf{2 2}$ & 8.348 & 7.500 & 10.223 & 8.364 & 9.767 & 8.222 & 10.213 \\
\hline $\mathbf{2 9}$ & 10.618 & 9.824 & 9.743 & 8.512 & 9.871 & 9.666 & 8.902 \\
\hline $\mathbf{4 9}$ & 12.706 & 8.723 & 10.988 & 10.090 & 7.769 & 10.004 & 9.606 \\
\hline $\mathbf{9 1}$ & 10.714 & 9.798 & 11.862 & 11.200 & 9.527 & 8.678 & 9.870 \\
\hline $\mathbf{1 7 2}$ & 14.105 & 12.622 & 12.840 & 13.297 & 12.458 & 11.309 & 12.266 \\
\hline
\end{tabular}

Table 14: Raw \%WSN data for the second replicate of the second batch

\begin{tabular}{|c|c|c|c|c|c|c|c|}
\hline $\mathbf{D a y}$ & Control & $\begin{array}{c}\mathbf{5 5}^{\circ} \mathbf{C} \text { for } \\
\mathbf{3 0 s}\end{array}$ & $\begin{array}{c}\mathbf{5 5}^{\circ} \mathbf{C} \text { for } \\
\mathbf{6 0} \mathbf{s}\end{array}$ & $\begin{array}{c}\mathbf{7 5}^{\circ} \mathbf{C} \text { for } \\
\mathbf{3 0 s}\end{array}$ & $\begin{array}{c}\mathbf{7 5}^{\circ} \mathbf{C} \text { for } \\
\mathbf{6 0 s}\end{array}$ & $\begin{array}{c}\mathbf{9 5}^{\circ} \mathbf{C} \text { for } \\
\mathbf{3 0 s}\end{array}$ & $\begin{array}{c}\mathbf{9 5}^{\circ} \mathbf{C} \text { for } \\
\mathbf{6 0 s}\end{array}$ \\
\hline $\mathbf{1}$ & 5.543 & 7.171 & 8.360 & 6.596 & 6.270 & 8.251 & 8.205 \\
\hline $\mathbf{1 1}$ & 7.598 & 10.185 & 9.993 & 7.096 & 9.390 & 10.138 & 9.604 \\
\hline $\mathbf{2 2}$ & 8.509 & 7.818 & 9.761 & 9.339 & 10.342 & 9.372 & 10.026 \\
\hline $\mathbf{2 9}$ & 10.532 & 10.731 & 8.745 & 7.527 & 11.510 & 8.620 & 8.305 \\
\hline $\mathbf{4 9}$ & 11.828 & 11.695 & 9.940 & 10.638 & 10.293 & 10.369 & 9.247 \\
\hline $\mathbf{9 1}$ & 11.006 & 12.010 & 9.421 & 10.956 & 10.431 & 10.273 & 10.299 \\
\hline $\mathbf{1 7 2}$ & 13.698 & 12.068 & 12.029 & 12.915 & 14.040 & 13.067 & 11.716 \\
\hline
\end{tabular}




\section{APPENDIX D: JMP Output for \% WSN Analysis}

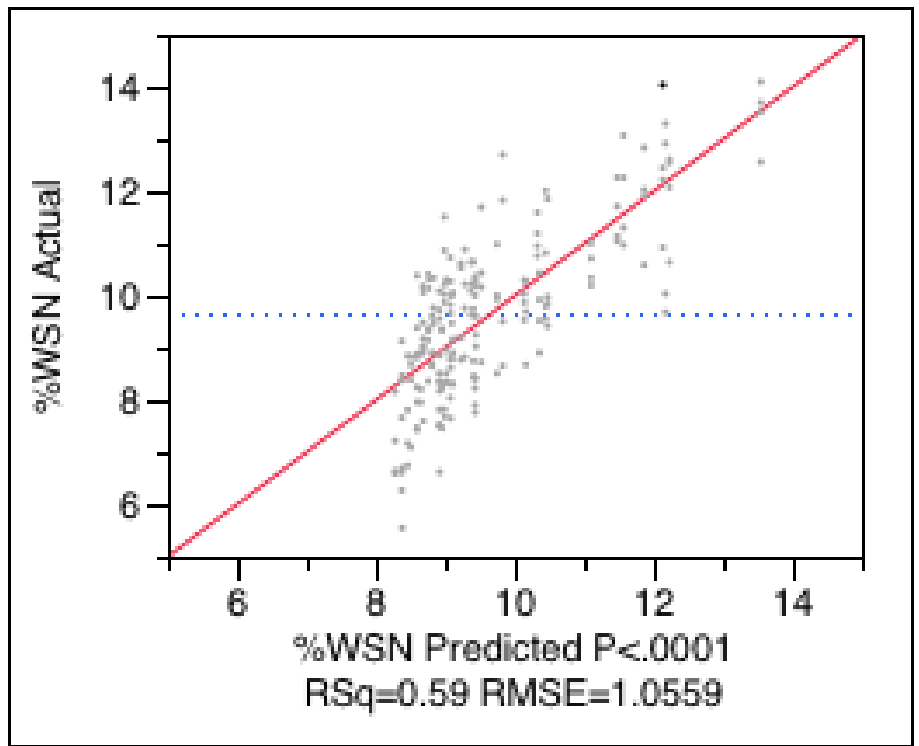

Figure 28: Actual by Predicted Plot for the Whole Model

JMP Output for \%WSN Analysis

\section{Summary of Fit}

RSquare

RSquare Adj

Root Mean Square Error

Mean of Response

Observations (or Sum Wgts)
0.589608

0.560295

1.055914

9.63173

196

\section{Parameter Estimates}

\section{Term}

Intercept

$\operatorname{Trt}[\mathrm{a}]$

$\operatorname{Trt}[\mathrm{b}]$

$\operatorname{Trt}[\mathrm{c}]$

$\operatorname{Trt}[\mathrm{d}]$

$\operatorname{Trt}[\mathrm{e}]$

$\operatorname{Trt}[\mathrm{f}]$

Day after Trt

(Day after Trt-

53.5714)*Trt[a]

(Day after Trt-

53.5714)*Trt[b]
Estimate Std Error DFDen t Ratio Prob $>|t|$

8.4978913

0.129884

2.118

$65.430 .0002 *$

0.3336504

0.184747

181

1.81

0.0726

$-0.017612$

0.184747

181

$-0.10$

0.9242

0.1911873

0.184747

181

1.03

0.3021

$-0.15957$

0.184747

181

$-0.86$

0.3889

$-0.104213$

0.184747

181

$-0.56$

0.5734

$-0.126467$

0.184747

181

$-0.68$

0.4945

0.021165

0.001357

181

15.60

$<.0001 *$

0.009024

0.003324

181

2.71

$0.0073 *$

0.0008902

0.003324

181

0.27

0.7892 


\section{Term}

(Day after Trt53.5714)*Trt[c]

(Day after Trt$53.5714) * \operatorname{Trt}[\mathrm{d}]$

(Day after Trt53.5714)*Trt[e]

(Day after Trt53.5714)*Trt[f]

$\begin{array}{rrrrr}\text { Estimate } & \text { Std Error } & \text { DFDen } & \text { t Ratio } & \text { Prob>|t| } \\ -0.003964 & 0.003324 & 181 & -1.19 & 0.2346 \\ 0.0015836 & 0.003324 & 181 & 0.48 & 0.6344 \\ 0.0008049 & 0.003324 & 181 & 0.24 & 0.8089 \\ -0.003761 & 0.003324 & 181 & -1.13 & 0.2593\end{array}$

REML Variance Component Estimates

Random Var Ratio Var Std Error $\quad 95 \% \quad 95 \%$ Pct of Total

Effect Component

Batch 0.0105769

0.0117928

$-0.0524720 .076058$

1.047

Residual

1.11495540 .117201

$\begin{array}{lll}0.9166893 & 1.3856749\end{array}$

98.953

Total

$0.9233315 \quad 1.4060515$

100.000

-2 LogLikelihood $=$

647.69305716

Note: Total is the sum of the positive variance components.

Total including negative estimates $=$

1.1267482

Fixed Effect Tests

\section{Source}

Trt

Day after Trt

Day after Trt*Trt

$\begin{array}{rrrrr}\text { Nparm } & \text { DF } & \text { DFDen } & \text { F Ratio } & \text { Prob }>\text { F } \\ 6 & 6 & 181 & 0.8965 & 0.4987 \\ 1 & 1 & 181 & 243.2578 & <.0001^{*} \\ 6 & 6 & 181 & 1.7609 & 0.1095\end{array}$




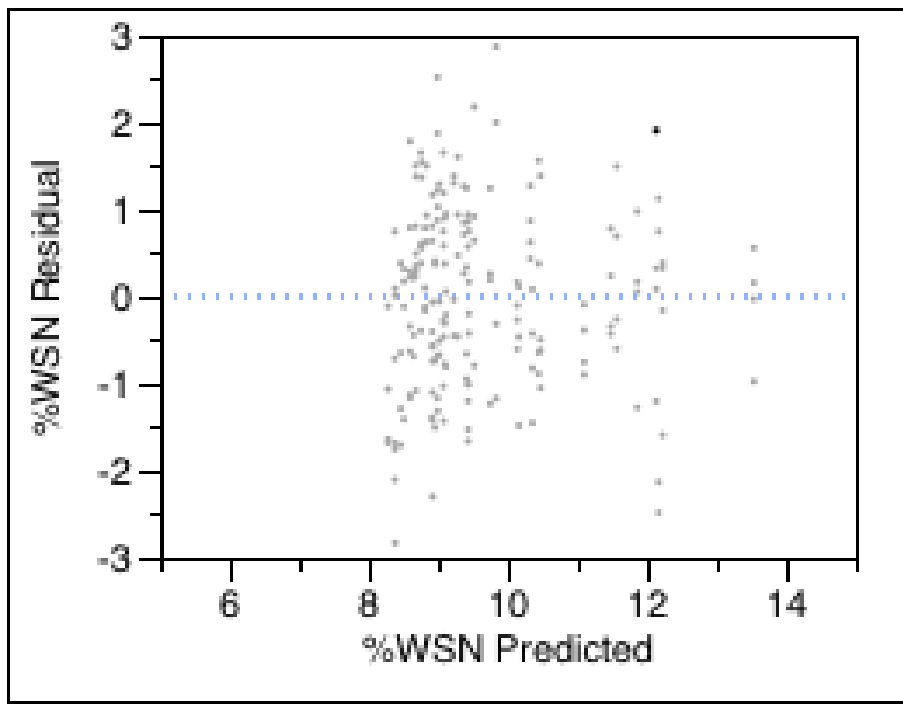

Figure 29: \%WSN Residual by \%WSN Predicted Plot

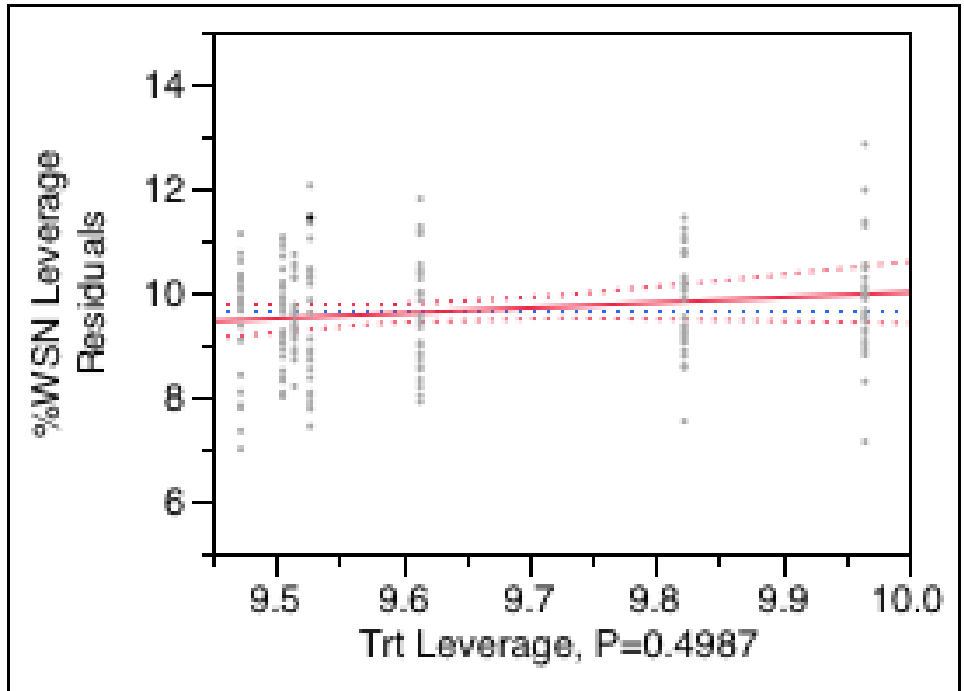

Figure 30: \%WSN Leverage Residuals by Treatment Leverage

$\begin{array}{lcc}\begin{array}{l}\text { Least Squares Means Table } \\ \text { Level }\end{array} & \begin{array}{r}\text { Least Sq } \\ \text { Mean }\end{array} & \text { Std Error } \\ \text { a } & 9.9653801 & 0.21381353 \\ \mathrm{~b} & 9.6141178 & 0.21381353 \\ \mathrm{c} & 9.8229171 & 0.21381353 \\ \mathrm{~d} & 9.4721600 & 0.21381353 \\ \mathrm{e} & 9.5275169 & 0.21381353 \\ \mathrm{f} & 9.5052628 & 0.21381353 \\ \mathrm{~g} & 9.5147535 & 0.21381353\end{array}$




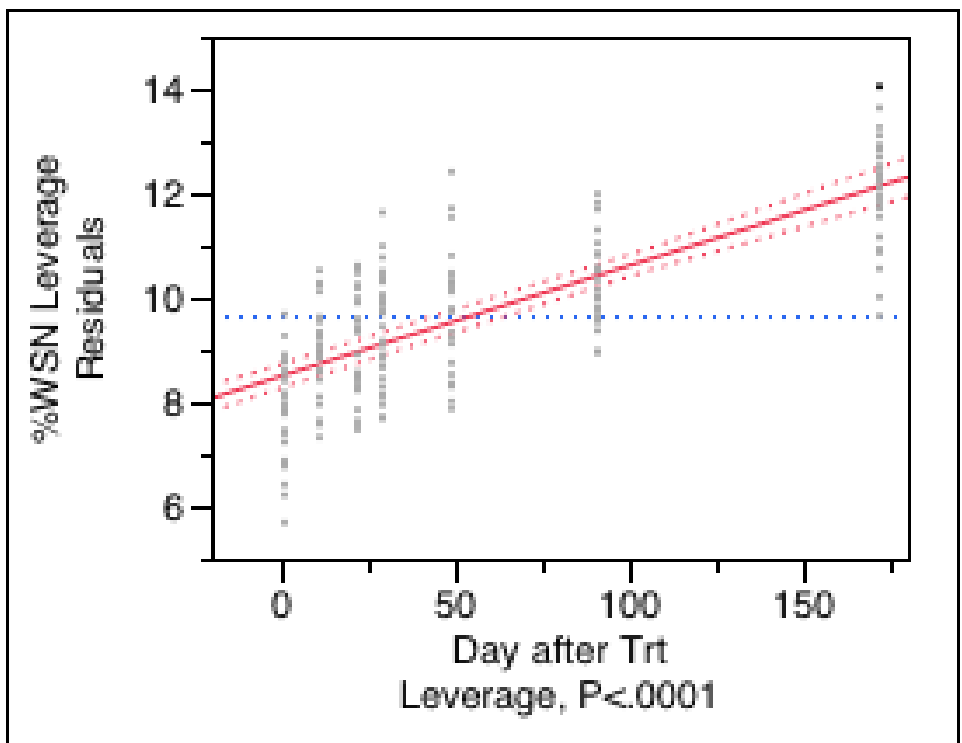

Figure 31: \%WSN Leverage Residuals by Day after Treatment Leverage

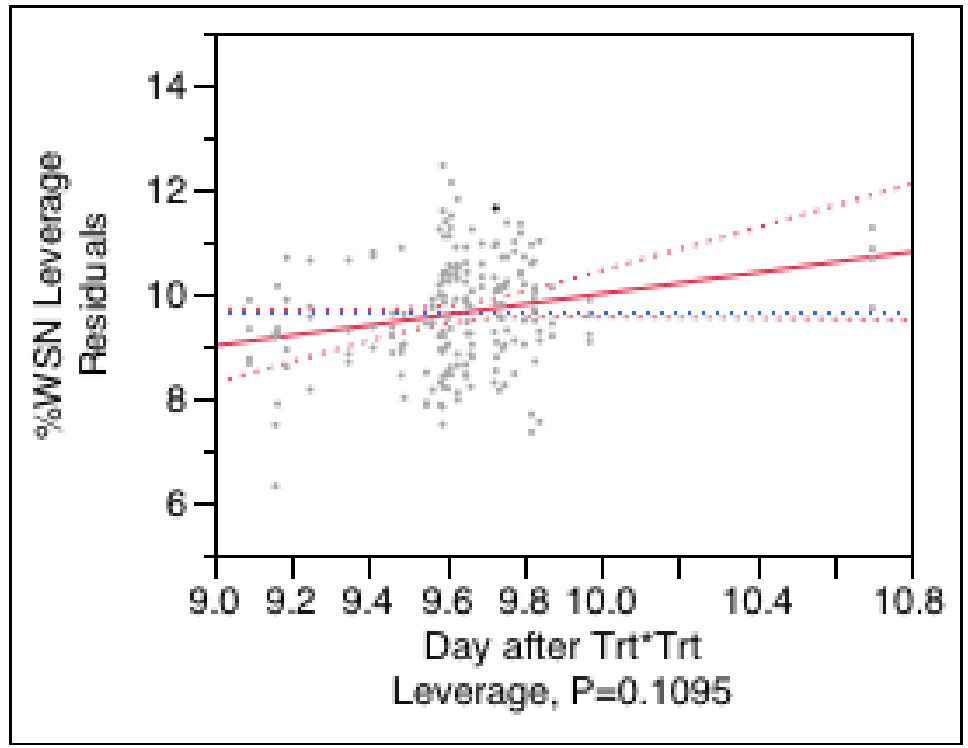

Figure 32: \%WSN Leverage Residuals by Treatment and Day After Treatment Interaction 
APPENDIX E: Alternative JMP Output for \% WSN Analysis (Factorial Design)

Response \%WSN

\section{Summary of Fit}

RSquare

RSquare Adj

Root Mean Square Error

Mean of Response

Observations (or Sum Wgts)

Parameter Estimates

\section{Term}

Intercept

Temp

Time

Day after Trt

(Temp-75)*(Time-45)

(Day after Trt-53.5714)*(Temp-75)

(Day after Trt-53.5714)*(Time-45)
0.548855

0.532043

1.024489

9.576121

168

\section{Random Effect Predictions}

$\begin{array}{lrrrrr}\text { Term } & \text { BLUP } & \text { Std Error } & \text { DFDen } & \text { t Ratio } & \text { Prob }>|\mathbf{t}| \\ \text { Batch[1] } & -0.048526 & 0.089579 & 1 & -0.54 & 0.6839 \\ \text { Batch[2] } & 0.0485263 & 0.089579 & 1 & 0.54 & 0.6839\end{array}$

\section{REML Variance Component Estimates}

$\begin{array}{lrrrrrr}\text { Random } & \text { Var Ratio } & \begin{array}{r}\text { Var } \\ \text { Effect }\end{array} & \text { Std Error } & \text { 95\% Lower } & \text { 95\% Upper } & \text { Pct of Total } \\ \text { Batch } & 0.009889 & 0.0103792 & 0.0323792 & -0.053083 & 0.0738412 & 0.979 \\ \text { Residual } & & 1.0495768 & 0.1173463 & 0.8528155 & 1.3236559 & 99.021 \\ \text { Total } & & 1.059956 & 0.1203773 & 0.8585816 & 1.3419434 & 100.000\end{array}$

Estimate Std Error DFDen t Ratio Prob $>|\mathbf{t}|$ $\begin{array}{llllll}8.7769862 & 0.453047 & 115.2 & 19.37 & <.0001 *\end{array}$ $\begin{array}{lllll}-0.005213 & 0.00484 & 160 & -1.08 & 0.2831\end{array}$ $\begin{array}{lllll}0.0030405 & 0.005269 & 160 & 0.58 & 0.5647\end{array}$ $\begin{array}{lllll}0.019661 & 0.001422 & 160 & 13.83 & <.0001 *\end{array}$ $\begin{array}{lllll}-0.000166 & 0.000323 & 160 & -0.51 & 0.6075\end{array}$

$\begin{array}{lllll}-6.58 \mathrm{e}-5 & 0.000087 & 160 & -0.76 & 0.4510\end{array}$

$\begin{array}{lllll}-7.166 e-5 & 9.481 e-5 & 160 & -0.76 & 0.4509\end{array}$

-2 LogLikelihood $=$ 558.27415736

Note: Total is the sum of the positive variance components.

Total including negative estimates $=$ 1.059956

Covariance Matrix of Variance Component Estimates

Random Batch Residual

Effect

Batch $\quad 0.0010484 \quad-0.000164$

$\begin{array}{lll}\text { Residual } & -0.000164 & 0.0137701\end{array}$ 
Fixed Effect Tests

$\begin{array}{lrrrrr}\text { Source } & \text { Nparm } & \text { DF } & \text { DFDen } & \text { F Ratio } & \text { Prob > F } \\ \text { Temp } & 1 & 1 & 160 & 1.1598 & 0.2831 \\ \text { Time } & 1 & 1 & 160 & 0.3329 & 0.5647 \\ \text { Day after Trt } & 1 & 1 & 160 & 191.1338 & <.0001^{*} \\ \text { Temp*Time } & 1 & 1 & 160 & 0.2649 & 0.6075 \\ \text { Day after Trt*Temp } & 1 & 1 & 160 & 0.5709 & 0.4510 \\ \text { Day after Trt*Time } & 1 & 1 & 160 & 0.5712 & 0.4509\end{array}$

\section{Effect Details}

Temp

\section{Time}

Day after Trt

Temp*Time

Day after Trt*Temp

Day after Trt*Time

\section{Batch}

Least Squares Means Table

Level

1

2
Least Sq

Mean

$9.5275950 \quad 0.09530107$

$9.6246477 \quad 0.09530107$
Std Error 


\section{APPENDIX F: JMP Output for Stringability Analysis}

\section{Ordinal Logistic Fit for String \\ Whole Model Test \\ Model \\ Difference \\ Full \\ Reduced \\ -LogLikelihood \\ 18.58226 \\ 216.72116 \\ 235.30342

$\begin{array}{rrr}\text { DF } & \text { ChiSquare } & \text { Prob }>\text { ChiSq } \\ 14 & 37.16453 & 0.0007^{*}\end{array}$

RSquare (U)

$\mathrm{AICc}$

BIC

Observations (or Sum Wgts)
0.0790

470.881

523.17

196
Measure

Entropy RSquare

Generalized RSquare

Mean -Log $p$

RMSE

Mean Abs Dev

Misclassification Rate

$\mathrm{N}$

\section{Lack Of Fit}

Source

Lack Of Fit

Saturated

Fitted

\section{Parameter Estimates}

Term

Intercept[1]

Intercept[2]

Intercept[3]

Trt[a]

$\operatorname{Trt}[\mathrm{b}]$

$\operatorname{Trt}[\mathrm{c}]$

$\operatorname{Trt}[\mathrm{d}]$

$\operatorname{Trt}[\mathrm{e}]$

$\operatorname{Trt}[\mathrm{f}]$

Day after Trt

Batch[1]

\section{Training Definition}

0.0790 1-Loglike(model)/Loglike(0)

$0.1899\left(1-(\mathrm{L}(0) / \mathrm{L}(\text { model }))^{\wedge}(2 / \mathrm{n})\right) /\left(1-\mathrm{L}(0)^{\wedge}(2 / \mathrm{n})\right)$

$1.1057 \sum-\log (\rho[\mathrm{j}]) / \mathrm{n}$

$0.6326 \sqrt{ } \sum(y[j]-\rho[j])^{2} / n$

$0.6108 \sum|y[j]-\rho[j]| / n$

$0.5000 \sum(\rho[\mathrm{j}] \neq \rho \mathrm{Max}) / \mathrm{n}$

$196 \mathrm{n}$

\section{-LogLikelihood ChiSquare 267.087 \\ 83.17766 Prob $>$ ChiSq \\ $216.72116 \quad 0.6546$}

$\begin{array}{rrr}\text { DF } & \text {-LogLikelihood } & \text { ChiSquare } \\ 277 & 133.54349 & 267.087 \\ 291 & 83.17766 & \text { Prob }>\text { ChiSq } \\ 14 & 216.72116 & 0.6546\end{array}$

$\begin{array}{rrrr}\text { Estimate } & \text { Std Error } & \text { ChiSquare } & \text { Prob }>\text { ChiSq } \\ -3.3699732 & 0.3484255 & 93.55 & <.0001^{*} \\ -2.1775286 & 0.2592089 & 70.57 & <.0001^{*} \\ -0.0545346 & 0.1956815 & 0.08 & 0.7805 \\ -0.6644675 & 0.3449978 & 3.71 & 0.0541 \\ 0.10852117 & 0.3299093 & 0.11 & 0.7422 \\ -0.4508478 & 0.3523235 & 1.64 & 0.2007 \\ 0.68522637 & 0.3299507 & 4.31 & 0.0378^{*} \\ 0.05299595 & 0.3296076 & 0.03 & 0.8723 \\ -0.0207319 & 0.330803 & 0.00 & 0.9500 \\ 0.01081837 & 0.0025159 & 18.49 & <.0001^{*} \\ -0.0891163 & 0.1362295 & 0.43 & 0.5130\end{array}$




\section{Term}

(Day after Trt-53.5714)*Trt[a]

(Day after Trt-53.5714)*Trt[b]

(Day after Trt-53.5714)*Trt[c]

(Day after Trt-53.5714)*Trt[d]

(Day after Trt-53.5714)*Trt[e]

(Day after Trt-53.5714)*Trt[f]

$\begin{array}{rr}\text { Estimate } & \text { Std Error } \\ -0.0026971 & 0.0060251 \\ -0.00036 & 0.0058446 \\ 0.01204455 & 0.0060842 \\ 0.00364674 & 0.0058434 \\ -0.0120525 & 0.0059722 \\ -0.0026766 & 0.0058822\end{array}$

ChiSquare

0.20

0.00

3.92

0.39

4.07

0.21

\section{Prob $>$ ChiSq}

0.6544

0.9509

$0.0477 *$

0.5326

$0.0436 *$

0.6491

\section{Effect Likelihood Ratio Tests}

Source

Trt

Day after Trt

Batch

Day after Trt*Trt
Nparm

6

1

1

6
DF

\section{6}

1

1
L-R
ChiSquare

8.99684711

20.0937446

0.42804279

7.55332765
Prob $>$ ChiSq

0.1738

$<.0001 *$

0.5130

0.2727 
APPENDIX G: Alternative JMP Output for Stringability Analysis (Factorial

Design)

Ordinal Logistic Fit for String

Whole Model Test

$\begin{array}{lr}\text { Model } & \text {-LogLikelihood } \\ \text { Difference } & 11.49105 \\ \text { Full } & 192.46332 \\ \text { Reduced } & 203.95437\end{array}$

$\begin{array}{rrr}\text { DF } & \text { ChiSquare } & \text { Prob }>\text { ChiSq } \\ 6 & 22.98211 & 0.0008 *\end{array}$

RSquare (U)

0.0563

$\mathrm{AICc}$

404.066

BIC

431.042

Observations (or Sum Wgts)

168

Measure

Entropy RSquare

Generalized RSquare

Mean $-\log p$

RMSE

Mean Abs Dev

Misclassification Rate

$\mathrm{N}$

\section{Lack Of Fit}

Source

Lack Of Fit

Saturated

Fitted

DF

117

123

6
Training Definition

0.0563 1-Loglike(model)/Loglike(0)

$0.1402\left(1-(\mathrm{L}(0) / \mathrm{L}(\operatorname{model}))^{\wedge}(2 / \mathrm{n})\right) /\left(1-\mathrm{L}(0)^{\wedge}(2 / \mathrm{n})\right)$

$1.1456 \sum-\log (\rho[\mathrm{j}]) / \mathrm{n}$

$0.6519 \sqrt{ } \sum(\mathrm{y}[\mathrm{j}]-\rho[\mathrm{j}])^{2} / \mathrm{n}$

$0.6367 \sum \mid y[j]-\rho[j] 1 / n$

$0.5714 \sum(\rho[\mathrm{j}] \neq \rho \mathrm{Max}) / \mathrm{n}$

$168 \mathrm{n}$

Parameter Estimates

Term

Intercept[1]

Intercept[2]

Intercept[3]

Temp

Time

Day after Trt

(Temp-75)*(Time-45)

(Day after Trt-53.5714)*(Temp-75)

(Day after Trt-53.5714)*(Time-45)
Estimate Std Error

$\begin{array}{lll}-3.5588255 & 0.8757318\end{array}$

$\begin{array}{lll}-2.2284437 & 0.8401336\end{array}$

$\begin{array}{lll}-0.1718649 & 0.8188015\end{array}$

$\begin{array}{ll}0.00751307 & 0.0089094\end{array}$

$\begin{array}{lll}-0.0078683 & 0.0096848\end{array}$

$\begin{array}{ll}0.01148223 & 0.0027073\end{array}$

$\begin{array}{ll}0.00062865 & 0.0005941\end{array}$

$\begin{array}{ll}-0.0001411 & 0.0001575\end{array}$

$\begin{array}{ll}4.75247 \mathrm{e}-5 & 0.0001711\end{array}$
ChiSquare

16.51

7.04

0.04

0.71

0.66

17.99

1.12

0.80

0.08
Prob $>$ ChiSq $<.0001 *$ $0.0080^{*}$

0.8337

0.3991

0.4165 $<.0001 *$

0.2900

0.3704

0.7813 
Effect Likelihood Ratio Tests

$\begin{array}{lrrrr}\text { Source } & \text { Nparm } & \text { DF } & \begin{array}{r}\text { L-R } \\ \text { ChiSquare }\end{array} & \text { Prob>ChiSq } \\ \text { Temp } & 1 & 1 & 0.71121941 & 0.3990 \\ \text { Time } & 1 & 1 & 0.66117257 & 0.4161 \\ \text { Day after Trt } & 1 & 1 & 19.8827761 & <.0001 * \\ \text { Temp*Time } & 1 & 1 & 1.12912979 & 0.2880 \\ \text { Day after Trt*Temp } & 1 & 1 & 0.90325113 & 0.3419 \\ \text { Day after Trt*Time } & 1 & 1 & 0.0830917 & 0.7732\end{array}$




\section{APPENDIX H: Minitab Output for Power Size and Maximum Detectable \\ Differences Information For WSN Analysis}

General Full Factorial Design

Alpha $=0.05$ Assumed standard deviation $=1.05591$

Factors: 3 Number of levels: 7, 7, 2

Include terms in the model up through order: 3

Include blocks in model.
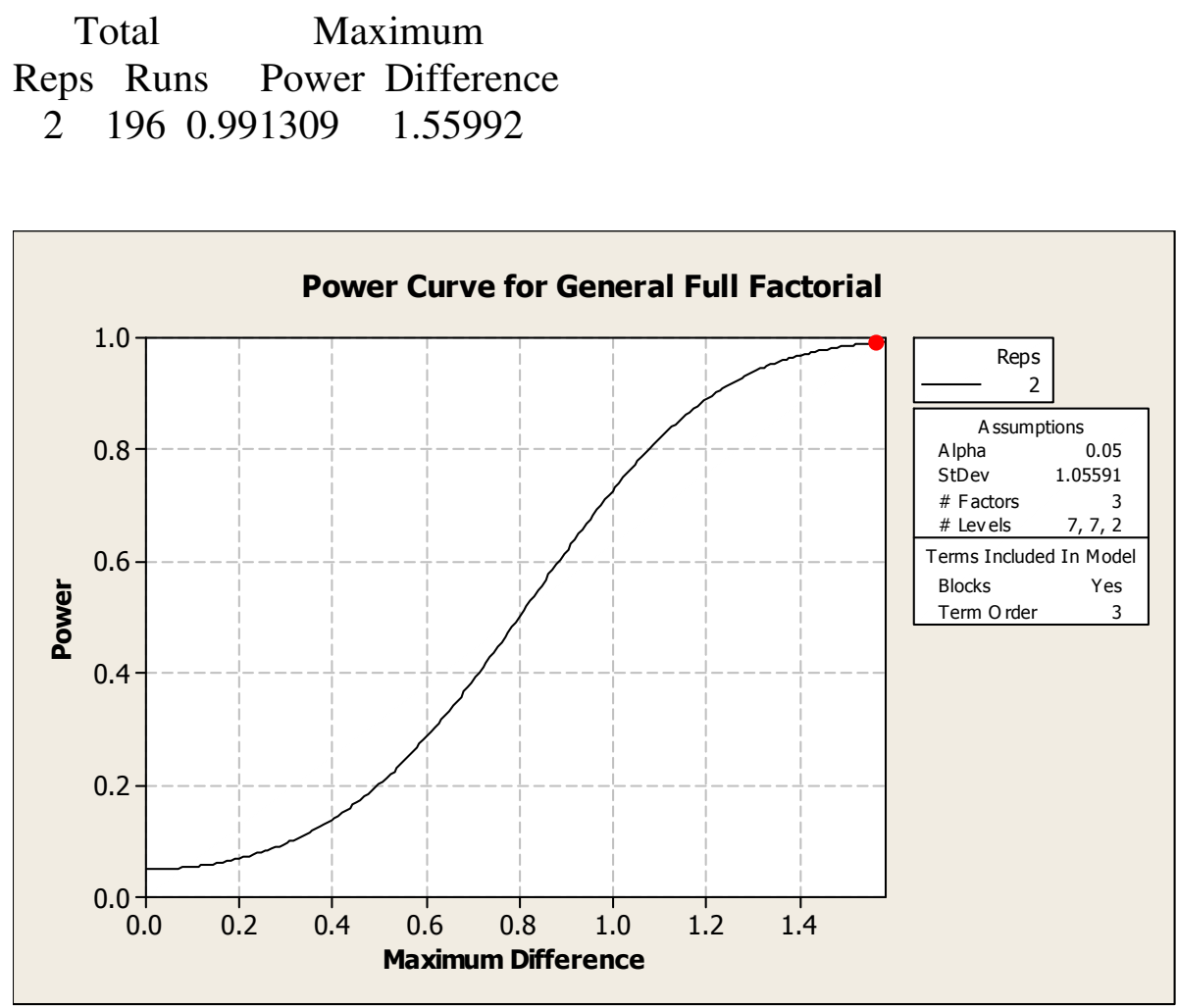

Figure 33: Power Curve for One-Way ANOVA \%WSN Analysis. $\mathrm{x}$-axis is the maximum detectable difference in \%WSN. 


\section{APPENDIX I: Minitab Output for Power Size and Maximum Detectable \\ Differences Information for Alternative WSN Analysis}

General Full Factorial Design

Alpha $=0.05$ Assumed standard deviation $=1.02449$

Factors: 3 Number of levels: 7, 7, 2

Include terms in the model up through order: 3

Include blocks in model.
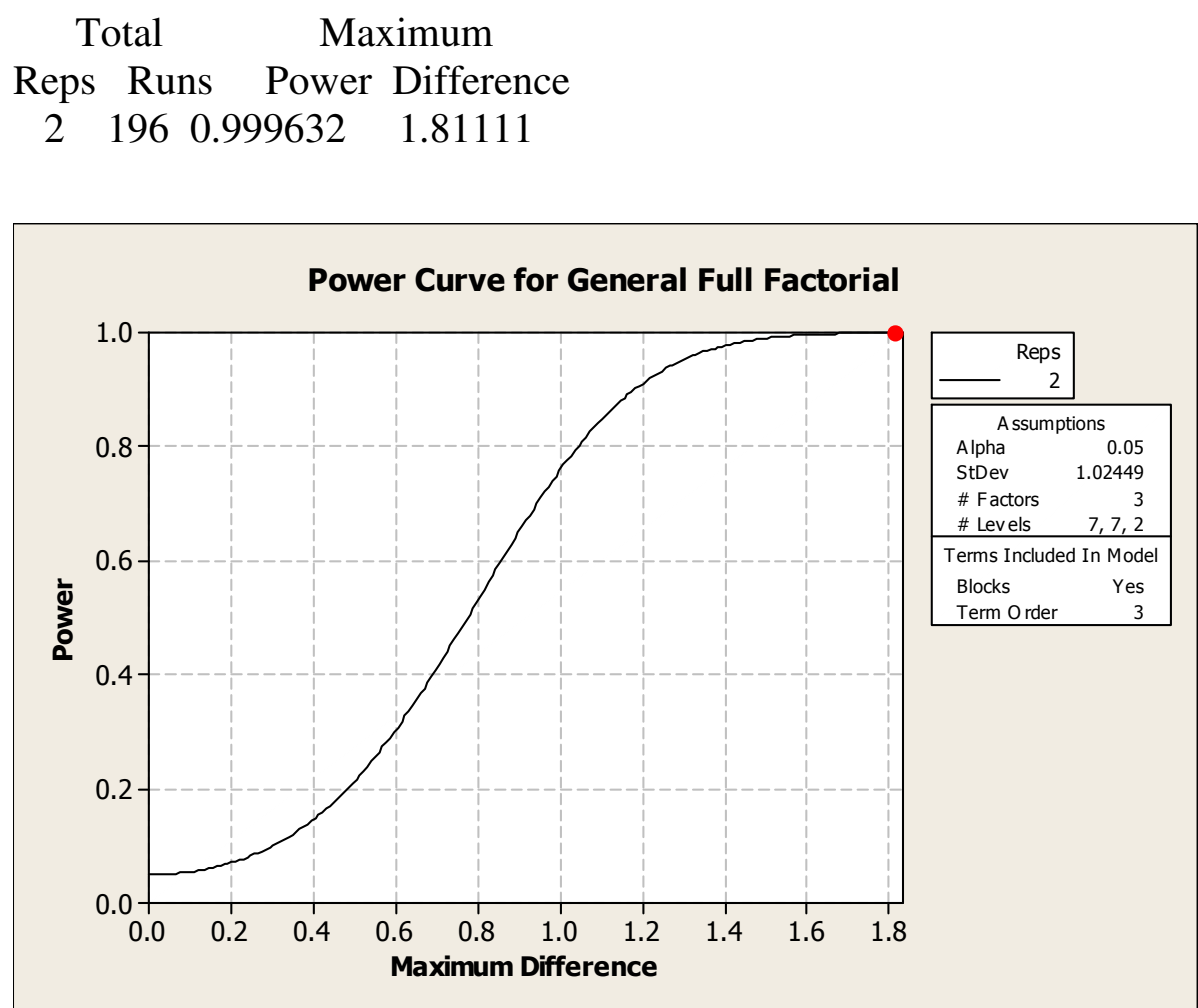

Figure 34: Power Curve for One-Way ANOVA \%WSN Alternative Analysis. X-axis is the maximum detectable difference in \%WSN. 